\title{
Definição de uma nova função critério baseada em distâncias nebulosas com múltiplos protótipos para seleção de características
}

\author{
Jishu Ashimine \\ Dissertação apresentada ao Instituto de Matemática e Estatística \\ da Universidade de São Paulo \\ para obtenção do grau de mestre em Ciência da Computação \\ Área de Concentração : Ciência da Computação \\ Orientador: Prof. Dr. Roberto Marcondes César Júnior
}

São Paulo, 4 de março de 2005 


\section{Definição de uma nova função critério baseada em distâncias nebulosas com múltiplos protótipos para seleção de características}

Este exemplar corresponde à redação da dissertação final defendida por Jishu Ashimine

São Paulo, 4 de março de 2005.

Comissão julgadora:

- Prof. Dr. Roberto Marcondes César Júnior (orientador) - IME/USP

- Prof. Dr. João Eduardo Ferreira - IME/USP

- Profa. Dra. Agma Juci Machado Traina - ICMC/USP 


\section{Agradecimentos}

Inicio os meus agradecimentos ao Prof. Dr. Roberto M. César Jr., pelo incentivo e dedicação em orientar este mestrado. Sempre disposto a ajudar, foi fundamental para o andamento de todo trabalho.

Agradeço também ao Teófilo E. Campos pelas importantes observações e discussões sobre a implementação da principal contribuição deste trabalho, e em especial, pelo fornecimento do código-fonte dos métodos de busca flutuante para seleção de características desenvolvido por ele em [10].

Aos Prof. Dr. Paulo J. S. Silva e Prof. Dr. João E. Ferreira pelas importantes observações e considerações sobre o texto de qualificação.

À Profa. Dra. Agma J. M. Traina e ao Prof. Dr. João E. Ferreira e pelas importantes observações e considerações finais sobre o texto da dissertação.

Ao pessoal do laboratório de processamento de imagens do IME-USP, que me ajudaram na realização de tarefas ligadas a este trabalho.

Aos amigos David da Silva Pires, Jesús Mena-Chaleo, Yossi-Zana e a minha irmã Rika pelas importantes observações e sugestões na revisão da dissertação.

Por último, gostaria de agradecer aos meus pais, Kiyoshi e Kazuko, minha irmã Rika, e a minha namorada, Cristiane Walder, pelo apoio, carinho e paciência, fundamentais para o desenvolvimento desta pesquisa. 


\section{Resumo}

A seleção de características tem um papel importante no processo de reconhecimento de padrões. Métodos de seleção automática de características que gerem bons subconjuntos a partir de um conjunto com grande número de características são de importância fundamental dentro desse contexto. Estes métodos de seleção focam em dois pontos principais: o algoritmo de seleção e a função-critério. No projeto de mestrado, descrito neste texto de dissertação, desenvolvemos uma extensão da abordagem de seleção de características baseada em distâncias nebulosas entre classes, proposto anteriormente em [10], com a introdução de uma nova função critério. Nesta extensão, cada classe do conjunto de treinamento será subdividida em $k$ grupos, utilizando o algoritmo fuzzy $k$-means. Isto permitirá a generalização para que a função critério utilize $k$ protótipos por classe, no lugar de um único protótipo, como em [10]. Além disso, a função de pertinência associada a cada amostra do conjunto de treinamento será estendida apropriadamente de maneira a incorporar a informação proveniente dos $k$ protótipos por classe. Foi avaliado o desempenho de seleção dessas duas funções critério realizando-se testes em dados sintéticos (utilizando-se distribuições Gaussianas) e em dados reais (a base de dados Ionosphere obtidas de UCI [6]). 


\section{Abstract}

Feature selection plays an important role in the pattern recognition process. Automatic feature selection methods, which select good subsets from the large feature set, are very important in pattern recognition. These sort of feature selection methods are based on two main points: a search algorithm and a criterion function.

In our work, we developed an extension of a feature selection method based on fuzzy distances between classes, proposed before in [10], by introducing a new criterion function. In this extension, each training set class is divided in $k$ parts by using fuzzy $k$-means algorithm. Each part is represented by one prototype, and the new criterion function uses $k$ prototypes per class, extending the unique prototype approach proposed in [10]. Also, the $k$ means found by the clustering algorithm have been used as the set of prototypes of each class, leading to a new fuzzification function. Both criterion functions (unique prototype and multiple prototypes) were tested with artificial datasets (Gaussian distribuitions) and real dataset (Ionosphere dataset from UCI Database [6]). 


\section{Lista de símbolos e abreviatu- ras utilizados}

$x, y, f \quad$ Características

$\mathbf{x}, \mathbf{y}$ Vetores de observação ou padrões. Geralmente $\mathbf{x}$ e y são usados para representar padrões em espaços de características diferentes.

KNN Regra de classificação por $K$ vizinhos mais próximos

$\mathcal{Y}, \mathcal{X} \quad$ Conjuntos ou tuplas de características (feature sets)

F Espaço de características após fusão de características

$N$ Dimensionalidade total do espaço de características $F$

$\mid \mathcal{X} \quad \quad$ Número de elementos do conjunto $\mathcal{X}$

$M \quad$ Dimensionalidade de um sub-espaço de $F(M \leq N)$

$\omega \quad$ Uma classe de padrões

$\Omega \quad$ Conjunto de todas as classes de padrões

$C$ Conjunto de todos os conjuntos nebulosos definidos em $F$

c Número de classes

$\mathrm{S} \quad$ Número de suportes disponíves por classe

$z \quad$ expoente nebuloso

$A_{i} \quad$ sub-divisão de uma classe A (fuzzy $k$-means)

$T \quad$ Conjunto de padrões de treinamento

$R \quad$ Conjunto de padrões de testes

$t,|T| \quad$ Número de exemplos no conjunto de treinamento; 
cardinalidade de $T$

$X \quad$ Conjunto de todos os exemplos de treinamento e de testes

$D \quad$ Fronteira de decisão

$\mathcal{S}_{k}\left(x_{j}\right) \quad$ Significância da característica $x_{j}$

$\mathcal{B}(\mathbf{x}, \tau) \quad$ Uma bola no espaço de características centrado no padrão $\mathbf{x}$ e com distância $\tau$

$\Upsilon($.$) \quad Classificador$

$\sigma \quad$ Desvio padrão

$f($.$) \quad Função$

$d($.$) \quad Função de distância$

$d_{\mathcal{E}}($.$) \quad Distância Euclidiana$

$\mathcal{N}(\mu, \Sigma) \quad$ Distribuição normal

$\xi($.$) \quad Função de erro$

$J($.$) \quad Função critério$

$\|\mathbf{x}\| \quad$ Norma euclidiana de $\mathbf{x}$

$\nu_{\omega_{i}}(\mathbf{x}) \quad$ Função de pertinência de $\mathbf{x}$ à classe $\omega_{i}$

$p_{i}^{\omega_{j}} \quad \mathrm{O} i$-ésimo suporte do conjunto nebuloso $\omega_{j}$

SFSM Métodos de busca sequencial flutuante

(Sequential Floating Search Methods)

SFFS Busca sequencial flutuante para frente

(Sequential Floating Forward Search)

SFBS Busca sequencial flutuante para trás

(Sequential Floating Backward Search)

ASFSM Métodos de busca sequencial flutuante adaptitativa

(Adaptive Sequential Floating Search Methods)

ASFFS Busca sequencial flutuante adaptativa para frente

(Adaptive Sequential Floating Forward Search)

ASFBS Busca sequencial flutuante adaptativa para trás

(Adaptive Sequential Floating Backward Search)

FPI Índice de performance de nebulosidade

(Fuzziness performance index)

MPE Entropia de partição modificada

(Modified Partition Entropy) 


\section{Lista de Figuras}

2.1 Esquema de um sistema genérico de reconhecimento de padrões . . . . . . 8

3.1 Efeito do problema de dimensionalidade . . . . . . . . . . . . . . . 10

3.2 Taxonomia dos métodos de seleção de características . . . . . . . . . . . . 13

3.3 Fluxograma simplificado SFFS . . . . . . . . . . . . . . . . . . . . . 21

4.1 Fluxo de execução de seleção de características. . . . . . . . . . . . . . . . 28

4.2 Exemplo de uma classe não compacta. . . . . . . . . . . . . . . . . . 31

4.3 Exemplos de distribuições . . . . . . . . . . . . . . . . . . . . 47

5.1 Espaços de características de dimensão 2 do conjunto sintético 1 . . . 52

5.2 Espaços de características de dimensão 2 do conjunto sintético 2 . . . 55

5.3 Resultados obtidos pelas melhores taxas de acerto do classificador $\mathrm{KNN}(\mathrm{K}=3)$ no intervalo de tamanho da bola selecionado (para $M=7$ ). . . . . . . . 61

5.4 Resultados obtidos pelas melhores taxas de acerto do classificador $\operatorname{KNN}(\mathrm{K}=3)$ no conjunto de características selecionado. . . . . . . . . . . . . . . . 62 


\section{Lista de Tabelas}

3.1 Métodos de seleção de características . . . . . . . . . . . . . . . . . 15

5.1 Comparativo entre protótipo único e múltiplos protótipos em relação aos valores da função critério e das características selecionadas (conjunto sintético 1). . 53

5.2 Comparativo entre protótipo único e múltiplos protótipos em relação à taxa de acerto dos classificadores (conjunto sintético 1) (em porcentagem). . . . . . . 54

5.3 Comparativo entre protótipo único e múltiplos protótipos em relação à taxa de acerto dos classificadores (conjunto sintético 2) (em porcentagem). . . . . . 56

5.4 Comparativo entre protótipo único e múltiplos protótipos em relação aos valores da função critério e das características selecionadas (conjunto sintético 2). $\quad$. 57

5.5 Melhores taxas de acerto do classificador $\mathrm{KNN}(\mathrm{K}=3)$ para $M=7$ para as funções critério de protótipo único e de múltiplos protótipos. . . . . . . . . . . . 60 


\section{Sumário}

1 Introdução 1

1.1 Considerações preliminares . . . . . . . . . . . . . . . . . . . . 1

1.2 Objetivos . . . . . . . . . . . . . . . . . . . . . . . . . 3

1.3 Contribuições . . . . . . . . . . . . . . . . . . . . . . . . 3

1.4 Organização do trabalho . . . . . . . . . . . . . . . . . . . 4

2 Revisão e conceitos básicos de reconhecimento de padrões 5

2.1 Reconhecimento de padrões . . . . . . . . . . . . . . . . 6

2.2 Abordagem estatística para o reconhecimento de padrões . . . . . . . . . . 7

3 Métodos de seleção de características 9

3.1 Visão geral . . . . . . . . . . . . . . . . . . . . . . . . . . . . 9 9

3.2 Fusão de características . . . . . . . . . . . . . . . . . . . . . . . . . . 11

3.3 Seleção de características . . . . . . . . . . . . . . . . . . . . . . . . . . 11

3.3.1 Algoritmos de seleção de características . . . . . . . . . . . . . . . . 12

3.3.2 Métodos determinísticos com solução única . . . . . . . . . . . . . . . 15

3.3.2.1 Busca Seqüencial para Frente . . . . . . . . . . . . . . . . 17

3.3.2.2 Busca Seqüencial para Trás . . . . . . . . . . . . . . . . . 17

3.3.2.3 Mais $l$ menos $r \ldots \ldots . \ldots . \ldots 18$

3.3.2.4 Algoritmos de busca seqüêncial generalizada . . . . . . . . 20 
3.3.2.5 Métodos de busca seqüencial flutuante para frente e para trás . . . . . . . . . . . . . . . 20

3.3.2.6 Métodos adaptativos de busca seqüêncial flutuante para frente e para trás . . . . . . . . . . . . . . . . 23

3.3 .3 Função critério . . . . . . . . . . . . . . . . . . . . . . 23

3.4 Classificação de padrões . . . . . . . . . . . . . . . . . . . . . 24

3.4 .1 Mínima distância ao protótipo . . . . . . . . . . . . 26

3.4 .2 Regra dos $K$ vizinhos mais próximos . . . . . . . . . . . . 26

4 Função critério baseada em múltiplos protótipos $\quad 27$

4.1 Panorama do método de seleção de características baseada em distâncias nebulosas . . . . . . . . . . . . . . . . . . . 27

4.2 Seleção de características: Função critério . . . . . . . . . . . . . . . . . 29

4.2 .1 Conjuntos Nebulosos . . . . . . . . . . . . . . . . . . . . . . . . 29

4.2.2 Processo de obtenção de múltiplos protótipos . . . . . . . . . . . . 30

4.2.2.1 Algoritmo fuzzy $k$-means . . . . . . . . . . . . . . . . 31

4.2.2.2 Descrição do algoritmo e complexidade . . . . . . . . . . 33

4.2.2.3 Eficiência e validação de agrupamento . . . . . . . . . . 34

4.2.2.4 Descrição do algoritmo e complexidade . . . . . . . . . . . 36

4.2.3 Processo de obtenção de conjuntos nebulosos . . . . . . . . . . . . . . 40

4.2 .4 Distância Nebulosa . . . . . . . . . . . . . . . . . . . . . . . . . . . 41

4.2 .5 Algoritmo e complexidade . . . . . . . . . . . . . . . . 42

4.2.6 Considerações sobre o comportamento da função critério . . . . . . . 44

5 Experimentos e resultados $\quad 49$

5.1 Considerações preliminares . . . . . . . . . . . . . . . . . . . . 49

5.2 Dados sintéticos . . . . . . . . . . . . . . . . . . . 50

5.2 .1 Descrição dos experimentos . . . . . . . . . . . . . . . . . . . . 50

5.2.2 Classes compactas $\times$ distância entre classes diferentes . . . . . . . . 51

5.2.2.1 Descrição dos dados sintéticos . . . . . . . . . . . . 51

5.2 .2 .2 Discussão . . . . . . . . . . . . . . . . . . . . . 51

5.2 .3 Classes esparsas geradas por união de subclasses . . . . . . . . . . . 54

5.2.3.1 Descrição dos dados sintéticos . . . . . . . . . . . . . . . 54

5.2 .3 .2 Discussão . . . . . . . . . . . . . . . 56

5.3 Dados reais . . . . . . . . . . . . . . . . . . . 57 
5.3 .1 Base de dados Ionosphere . . . . . . . . . . . . . . . . . . . 58

5.3.1.1 Informações da base de dados . . . . . . . . . . . . . . 58

5.3.1.2 Descrição do experimento . . . . . . . . . . . . . . . . . . 59

5.3 .1 .3 Discussão . . . . . . . . . . . . . . . . . 60

6 Conclusões $\quad 63$

$\begin{array}{ll}\text { Referências Bibliográficas } & 65\end{array}$ 


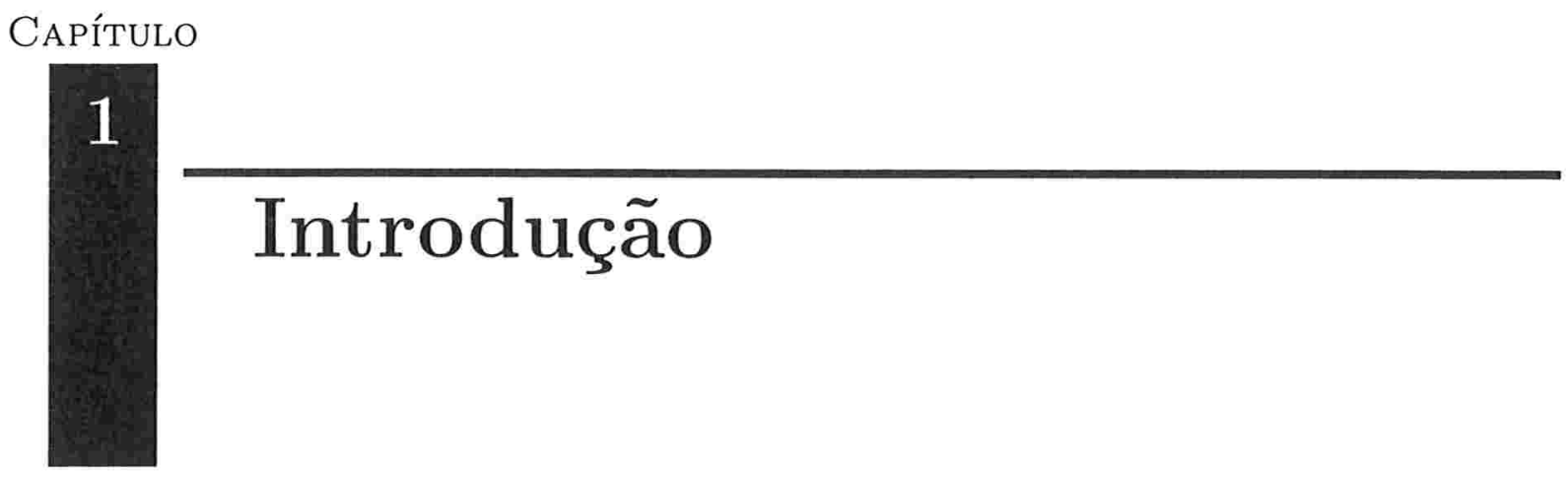

\subsection{Considerações preliminares}

Apesar das diversas abordagens de reconhecimento de padrões, este trabalho de mestrado concentra-se em métodos estatísticos, pois trata-se de uma extensão do trabalho iniciado por Teófilo E. Campos em [10].

Um ponto importante em um sistema de reconhecimento de padrões é que a maioria dos métodos baseia-se na extração de um vetor de características seguida de classificação [18, 22]. Em geral, há um grande número de possíveis características para compor os vetores, sendo desejável que se escolha um subconjunto mínimo entre elas. Embora a abordagem de quanto mais características possíveis possa parecer intuitivamente a melhor para reconhecimento de padrões, sabe-se que tal abordagem conduz a resultados ruins, porque o tamanho do conjunto de treinamento deveria aumentar muito rapidamente em relação ao tamanho do vetor de características [13, 22]. Isso está relacionado com à dimensionalidade, ou seja, a quantidade de características utilizada para reconhecimento de padrões.

O problema da dimensionalidade, também conhecido como comportamento de curva em $U$, torna-se um fator relevante na decisão sobre a dimensionalidade ideal a ser adotada em um problema de reconhecimento de padrões. No caso de sistemas estatísticos, quando o problema abordado for complexo, como normalmente ocorre com dados reais, torna-se essencial o uso de redução de dimensionalidade. 
Assim, para se obter um melhor desempenho de um classificador, é necessário investigar qual é a dimensionalidade para um determinado problema de reconhecimento de padrões e quais as melhores características associadas. Para isso, pode ser aplicada uma estratégia simples de tentativa e erro em relação a dimensionalidade, usando um método de redução de dimensionalidade (incluindo extração e seleção de características) até que o ponto de máximo desempenho de um classificador seja atingido. Nessa estratégia, são realizados testes de redução de dimensionalidade para a obtenção de sub-espaços de características de vários tamanhos diferentes, até que seja obtida a dimensionalidade que minimiza o erro de classificação.

Para o processo de redução da dimensionalidade do espaço de características, muitos algoritmos de seleção automática de características têm sido propostos [23]. Entre muitas diferentes abordagens, há uma grande classe de algoritmos baseados em dois pontos principais: função critério e algoritmo de busca por subconjunto de características que melhor satisfaz essa função critério

Existem duas abordagens básicas para função critério: aquela bașeada nos resultados da classificação, e aquela baseada na distância entre as classes. Na primeira, cada possível subconjunto de características é usado para treinar e para testar um classificador, e as taxas de reconhecimento são usadas como uma função critério; quanto maior a taxa de reconhecimento, melhor é o subconjunto de características. A principal desvantagem disso é que a escolha de um classificador é um problema crítico por si só, e que o último subconjunto selecionado depende diretamente do classificador [22]. Além disso, treinar um classificador pode ser muito caro computacionalmente, inviabilizando essa abordagem na prática. A segunda, por outro lado, depende da definição da distâncias entre classes (conjuntos), e algumas possibilidades são Mahalanobis, Bhattacharyya, distância de separação de classes $[13,36]$. A desvantagem desta abordagem é que grande parte das distâncias entre classes é adequada para conjuntos de padrões convexos, que tendem a privilegiar conjuntos separados linearmente. Desta forma, tais distâncias falham para detectar classes com protótipos próximos uns dos outros.

$\mathrm{Na}$ tentativa de solucionar este problema, uma nova abordagem para medir a separação entre classes baseadas em conjuntos nebulosos (fuzzy sets) e distâncias nebulosas ( $f u z z y$ distances) foi proposta em [10,11]. A idéia por trás desta abordagem é considerar as classes como conjuntos nebulosos (obtidos das classes originais) e aplicar as distâncias nebulosas entre eles como função critério [7].

$\mathrm{Na}$ abordagem em $[10,11]$, utiliza-se um único protótipo por classe no processo de ob- 
tenção de conjuntos nebulosos (processo de "fuzzificação"). Na extensão proposta neste trabalho, vamos explorar múltiplos protótipos por classe. Tais protótipos são estabelecidos através de um algoritmo de análise de agrupamento (clustering algorithm) para cada classe do conjunto de treinamento, cuja idéia central é dividir tais classes em $k$ grupos, determinando um protótipo por grupo, resultando em $k$ protótipos por classe. Desta forma, definimos uma nova função de obtenção do conjunto nebuloso baseada nestes $k$ protótipos, estabelecendo assim, uma nova função critério baseada em múltiplos protótipos. Com a melhora da representatividade dos protótipos, é esperado que haja uma melhora em relação à função critério anteriormente proposta em [10].

\subsection{Objetivos}

O objetivo principal deste trabalho é o estudo de métodos estatísticos de seleção de características e de classificação, estendendo a abordagem de protótipo único por classe proposto em [11] por múltiplos protótipos por classe.

Neste trabalho, a abordagem por múltiplos protótipos resulta em uma nova função critério que utiliza os mesmos algoritmos de busca para seleção de características como a do protótipo único. Com esta extensão de múltiplos protótipos por classe como função critério, visamos melhorar as taxas de acerto com relação ao de protótipo único. Comparações qualitativas e quantitativas entre as duas abordagens foram estabelecidas.

\subsection{Contribuições}

Destacamos as seguintes contribições desta dissertação:

- Generalização da função critério proposta em [10, 11],

- Caracterização dos dados em que a abordagem por múltiplos protótipos é melhor que a de único protótipo,

- Estudo do algoritmo de agrupamento utilizado na escolha dos protótipos e dos critérios para o melhor valor de $k$,

- Estudo de critérios para validação do melhor valor de $k$ em fuzzy $k$-means. 


\subsection{Organização do trabalho}

Uma breve revisão bibliográfica e introdutória aos conceitos e definições necessárias será apresentada no capítulo 2. O capítulo 3 apresenta os conceitos básicos necessários de extração e de seleção de características. O capítulo 4 irá tratar especificamente da seleção de características baseada em distância nebulosa com múltiplos protótipos, que é a principal contribuição deste trabalho. Em seguida, no capítulo 5, experimentos e resultados iniciais obtidos nesta nova abordagem são apresentados. Por fim, no capítulo 6, as conclusões dos experimentos realizados no capítulo anterior são discutidas. 


\section{Capítulo}

\section{2 \\ Revisão e conceitos básicos de reconhecimento de padrões}

Segundo [22], apesar de aproximadamente meio século de pesquisa e desenvolvimento na área, o problema genérico de reconhecimento de padrões complexos permanece ainda sem solução. Recentemente, devido a aplicações tais como mineração de dados e biometria, que requerem técnicas de reconhecimento de padrões robustas e eficientes, tem crescido ainda mais o interesse para esta área de pesquisa. Segundo os autores de [22], as técnicas de reconhecimento de padrões podem ser aplicadas em vários domínios, dentre os quais se destacam:

- bioinformática, em análise de seqüência de proteínas, DNA e dados de expressão gênica;

- mineração de dados (data mining), procurando por padrões significativos em espaços multi-dimensionais;

- classificação de documentos, em pesquisa pela Internet;

- análise de imagens de documentos, para reconhecimento de caracteres (por exemplo, Optical Character Recognition - OCR);

- busca e classificação em base de dados multimídia;

- biometria, utilizando reconhecimento biométrico, incluindo faces, íris ou impressões digitais; 
A seguir, serão abordados os conceitos básicos de reconhecimento de padrões.

\subsection{Reconhecimento de padrões}

Segundo [38], um padrão é "uma entidade, vagamente definida, ao qual pode ser dado um rótulo". Quando um conjunto de padrões possui alguma relação entre si, este conjunto é chamado de classe. Assim, o reconhecimento de padrões é a área de pesquisa que tem por objetivo a classificação de padrões (objetos) em um número de classes [37]. Dado um padrão, sua classificação ou reconhecimento consiste de uma das duas tarefas a seguir [38]: a classificação supervisionada, em que o padrão de entrada é identificado como um membro de uma classe pré-definida; e a classificação não-supervisionada, em que o padrão é atribuído a uma classe desconhecida até então, obtida pelo aprendizado baseado na similaridade de padrões.

Um problema de reconhecimento de padrões bem definido e restrito permite uma representação compacta dos padrões e uma estratégia de decisão simples. Seja $d_{\omega}\left(\omega_{i}\right)$ uma medida de separabilidade global entre os padrões pertencentes a uma classe $\omega_{i}$ (por exemplo, a média das variâncias em todas as características dos padrões de $\omega_{i}$ ). Seja $d_{b}(\Omega)$ uma medida de separabilidade global entre as classes do conjunto de classes $\Omega$ (por exemplo, a média das distâncias entre as médias de todas as classes de $\Omega$ e a média global). Um problema de reconhecimento de padrões bem definido e restrito é aquele que, em seu espaço de características, possui distribuições de padrões com pequena variação intra-classes e grandes variações inter-classes, ou seja, valores pequenos de $d_{\omega}\left(\omega_{i}\right)$ e valores grandes de $d_{b}(\Omega)[37]$.

$\mathrm{Na}$ prática, os padrões obtidos de dados reais a serem reconhecidos geralmente não possuem tais pecularidades. Uma forma de melhorar a representação dos dados é utilizar os algoritmos de fusão e seleção de características, pois eles reduzem a dimensionalidade do espaço de características sem perder o poder de discriminação dos padrões.

Apesar de existirem outras abordagens de reconhecimento de padrões, este trabalho irá focar na abordagem estatística, pois trata-se de uma continuação do trabalho iniciado por [11]. Assim, serão apresentadas os tópicos relevantes dessa abordagem nas próximas seções. 


\subsection{Abordagem estatística para o reconhecimento de padrões}

$\mathrm{Na}$ abordagem estatística, cada padrão é representado em termos de $N$ características, sendo visto como um ponto em um espaço $N$-dimensional. Um padrão é representado por um vetor de características $\mathbf{x}=\left[x_{1}, x_{2}, \ldots, x_{N}\right]^{t}$, modelado como um vetor aleatório, em que cada $x_{i}(1 \leq i \leq N)$ é uma característica [37]. O objetivo da seleção de características é escolher aquelas que permitem vetores de padrões pertencentes a diferentes classes ocuparem regiões compactas e disjuntas em um espaço $N$-dimensional de características. A eficácia da representação espacial (do conjunto de características) é determinada pelo grau de separabilidade dos padrões de diferentes classes. Dado um conjunto de treinamento de cada classe, o objetivo é estabelecer fronteiras de decisões no espaço de características que separam padrões pertencentes a classes diferentes [22]. Na abordagem de decisão estatística, as fronteiras de decisão são determinadas pelas distribuições de probabilidade dos padrões pertencentes a cada classe, que deve estar especificado (rotulado previamente) ou aprendido $[16,18]$.

Em um sistema de reconhecimento estatístico de padrões, conceitos bem conhecidos da teoria de decisão estatística são utilizados para estabelecer fronteiras de decisão entre classes de padrões [22]. Basicamente, um sistema de reconhecimento estatístico de padrões pode ser composto pelas seguintes partes $[18,22]$ (vide figura 2.1):

1. um sistema de aquisição de dados, através de sensores ou câmeras;

2. um sistema de pré-processamento, para eliminar ruídos ou distorções;

3. um extrator de características, que cria um vetor de características com dados extraídos dos objetos adquiridos, reduzindo os dados a atributos, propriedades ou características;

4. um seletor de características, que analisa o conjunto de características e elimina as mais redundantes; e

5. um classificador, que analisa um padrão obtido e toma uma certa decisão.

O classificador toma decisões baseando-se no aprendizado realizado a partir de um conjunto de treinamento, o qual contém exemplos de padrões de todas as classes existentes no sistema. 
O sistema de reconhecimento é operado em dois modos: treinamento e classificação. No modo de treinamento, o módulo de extração/seleção de características encontra as características apropriadas para representar os padrões de entrada e o classificador é treinado para particionar o espaço de características. A retro-alimentação existente entre os módulos de extração/seleção de características e de classificação permite otimizar o pré-processamento e estratégias de extração/seleção de características. No modo de classificação, o classificador treinado atribui o padrão de entrada para uma das classes baseado nas características medidas.

O processo de tomada de decisão em reconhecimento estatístico de padrões pode ser resumido da seguinte forma: Um dado padrão $\mathbf{x}$ deve ser atribuído a uma das $c$ classes $\omega_{1}, \omega_{2}, \ldots, \omega_{c}$, com base em um vetor de $N$ características com valores $\mathbf{x}=$ $\left(x_{1}, x_{2}, \ldots, x_{N}\right)$. Assume-se que as características tenham uma função densidade de probabilidade condicionada à classe de padrões. Então, um vetor $\mathbf{x}$ pertencente a classe $\omega_{i}$ é visto como um evento aleatório com uma função de probabilidade condicional à classe, $p\left(\mathbf{x} \mid \omega_{i}\right)$. Assim, dado um conjunto de $c$ classes, $\omega_{1}, \omega_{2}, \ldots, \omega_{c}$, e um padrão desconhecido $\mathbf{x}$, um classificador de padrões é um sistema que, auxiliado por pré-processamentos, extração e seleção de características, associa $\mathbf{x}$ ao rótulo $i$ da classe $\omega_{i}$.

Para mais detalhes sobre a teoria estatística envolvida, vide $[4,16,22]$.

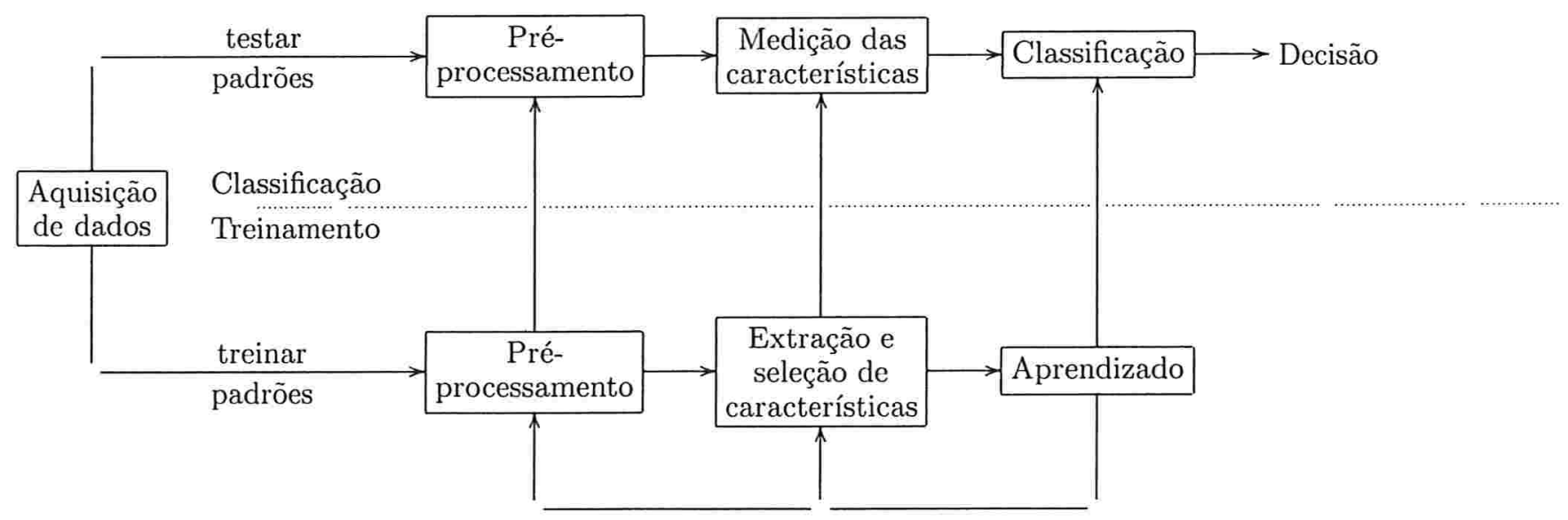

Figura 2.1: Um sistema genérico de reconhecimento de padrões (baseado em [18] e [22]) 


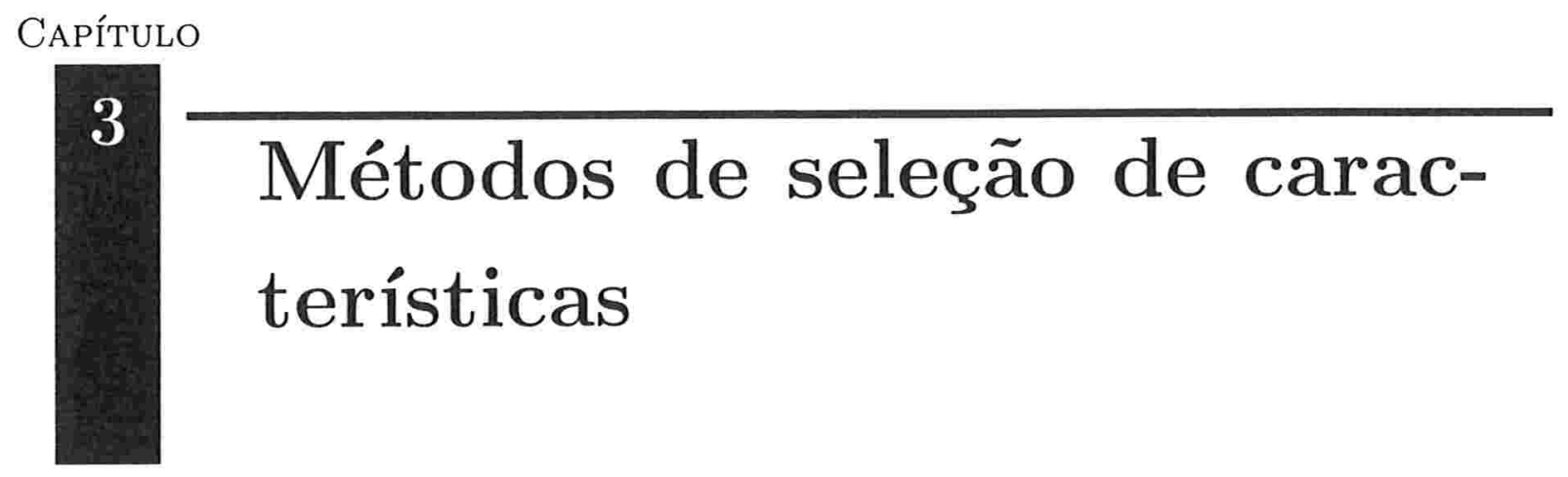

\subsection{Visão geral}

O termo dimensionalidade é atribuído ao número de características de uma representação de padrões, ou seja, a dimensão do espaço de características. Tanto a fusão quanto a seleção de características têm como objetivo a redução da dimensionalidade, visando diminuir o custo de medição, sem perder a precisão do classificador.

De uma maneira geral, os algoritmos de fusão de características criam novas características a partir de transformações ou combinações do conjunto original de características, enquanto os algoritmos de seleção selecionam o melhor subconjunto de características segundo um determinado critério.

Eventualmente, a fusão das características precede a seleção, sendo feita a partir dos dados de entrada para, em seguida, um algoritmo de seleção eliminar os atributos menos relevantes segundo um determinado critério, reduzindo assim, a dimensionalidade.

É importante lembrar que, se a redução da dimensionalidade for excessiva, o classificador pode ter o seu poder de discriminação reduzido, devido ao problema da dimensionalidade. O problema da dimensionalidade, também conhecido como comportamento de curva em $U$, torna-se um fator relevante na decisão sobre a dimensionalidade ideal a ser adotada em um problema de reconhecimento de padrões. A curva apresentada na figura 3.1 ilustra o problema da dimensionalidade, apresentando três regiões no eixo da dimensionalidade com significados diferentes: 
1. Na primeira região, compreendida entre 0 e $m_{1}$, ocorre o comportamento mais esperado intuitivamente, pois a adição de características promove redução na taxa de erro. Isso deve-se ao fato de espaço de características com dimensões muito pequenas não possuir informações suficientes para distinguir-se as classes de padrões. Com isso, a adição de novas características melhora os resultados de classificação;

2. A segunda região é aquela em que se atinge uma estabilidade na taxa de acerto. Nessa região, a adição ou eliminação de características não altera (ou altera muito sutilmente) essa taxa. Para um problema de classificação, a melhor solução está na adoção da dimensionalidade $m_{1}$, pois esse é o menor valor em que a taxa de acerto é máxima. A estabilização na taxa de acerto se deve ao fato de que as características importantes para se distinguir os padrões já foram inseridas na região anterior, e as características extras não são nem ruidosas, nem relevantes para a classificação;

3. A terceira e última região é aquela em que de fato ocorre o problema da dimensionalidade. Uma explicação para este fato é que a maioria dos classificadores estimam os pararâmetros desconhecidos e os utilizam como parâmetros válidos nas funções de densidade condicional à classe. Para um número fixo de padrões de treinamento, na medida que aumenta o número de características, aumenta o número de parâmetros desconhecidos, diminuindo a confiabilidade do parâmetro estimado [21, 30, 31].

Assim, para se obter um melhor desempenho de um classificador, é necessário investigar qual é a dimensionalidade para um determinado problema de reconhecimento de padrões e quais as melhores características associadas. Para isso, pode ser aplicada uma estratégia

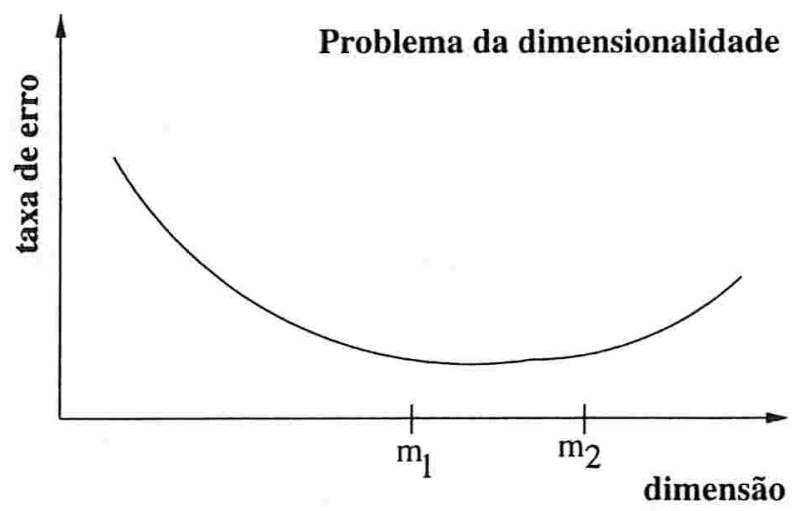

Figura 3.1: Efeito do problema de dimensionalidade. 
simples de tentativa e erro em relação à dimensionalidade, usando um método de redução de dimensionalidade (incluindo fusão e seleção de características) até que o ponto de máximo desempenho de um classificador seja atingido. Nessa estratégia, são realizados testes de redução de dimensionalidade para a obtenção de sub-espaços de características de vários tamanhos diferentes, até que seja obtida a dimensionalidade que minimiza o erro de classificação. Se, por um lado, é difícil de se estabelecer uma exata relação entre a probabilidade de erro na classificação, no número de padrões de treinamento, no número de características e nos parâmetros válidos das funções de densidade condicional à classe, algumas diretrizes podem ser sugeridas. Uma delas, muito aceita, é que a quantidade de padrões de treinamento deve ser pelo menos 10 vezes a quantidade de características selecionadas [21].

A seguir, somente a definição da fusão de características será dada, pois o foco deste trabalho é a seleção de características. Em seguida, os conceitos básicos sobre a seleção de características serão apresentados em mais detalhes.

\subsection{Fusão de características}

Um método de fusão de características cria um novo espaço a partir de transformações ou combinações das características do espaço original. Formalmente, dado um espaço de características $\mathcal{I}$ de dimensão $N$, um método de fusão de características $\mathcal{H}$ é uma função $\mathcal{H}: \mathcal{I} \rightarrow F$, em que $F$ possui dimensão $M$, tipicamente $M<N$. Assim, dado um padrão $\mathrm{x}$ em um espaço de características $\mathcal{I}$, temos:

$$
\mathcal{H}(\mathrm{x})=\mathrm{y}
$$

tal que y $\in F$ é a nova representação do padrão no espaço $F$. Exemplos importantes de transformações para a fusão são transformada de Fourier e Análise de componenentes principais (PCA). Para mais detalhes de extração de características, vide [18, 22, 37].

\subsection{Seleção de características}

A seleção de características consiste na técnica de otimização que, dado um vetor $\mathbf{Y}$ com $N$ características, tenta selecionar um subvetor $\mathrm{X}$ de $\mathrm{Y}$ tal que $|\mathrm{X}|=M$, com 
$M<N$, que maximiza alguma função critério $J$, ou seja:

$$
J(\mathbf{X})=\max _{\mathbf{Z} \subseteq \mathbf{Y},|\mathbf{Z}|=M}(J(\mathbf{Z}))
$$

É desejável que a função critério $J($.$) assuma valor máximo quanto menor for a re-$ dundância entre as características, e de forma semelhante, assuma valor máximo quanto maior for a facilidade de discriminar padrões de classes diferentes. Desta forma, o algoritmo de seleção de características poderá reduzir a dimensionalidade sem que um classificador perca o poder de distinguir classes no espaço de características. Uma conseqüência da aplicação com um bom algoritmo de seleção de características é a redução do número necessário de padrões (amostras) de treinamento para se obter bons resultados com um classificador.

Dentre as diversas abordagens de seleção automática de características [22, 23], existe uma classe de algoritmos baseados em dois pontos principais: uma função critério e um algoritmo de busca de subconjunto de características que maxima essa função critério. A essa classe de algoritmos será dada uma atenção maior, devido à utilização desta abordagem no nosso trabalho.

Para melhor entendimento sobre esses algoritmos de seleção de características, uma breve introdução será apresentada a seguir.

\subsubsection{Algoritmos de seleção de características}

Em várias aplicações recentes, particularmente as de mineração de dados e classificação de documentos que envolvem milhares de características, os requisitos computacionais de um algoritmo de seleção de características são muito importantes [22]. Como o número de subconjuntos de características avaliados pode facilmente tornar proibitivo para quantidades muito grandes de características, diversas técnicas de seleções sub-ótimas têm sido propostas visando conciliar maior eficiência computacional com maior taxa de acerto para o subconjunto de características selecionado.

Há vários métodos diferentes de seleção de características, e de acordo com os autores de [23], tais métodos podem ser agrupados em categorias segundo a taxonomia exibida na figura 3.2. Nesta taxonomia, os métodos são divididos em técnicas de classificação de reconhecimento estatísticos de padrões, e os que usam redes neurais artificiais. O reconhecimento estatístico de padrões é então dividido em aqueles que encontram soluções ótimas 
e em sub-ótimas. Os métodos sub-ótimos são divididos em aqueles que apenas manipularam um subconjunto de características por vez ou aqueles que mantêm uma população de subconjuntos. Uma outra distinção é feita entre algoritmos que são determinísticos, produzindo o mesmo subconjunto sobre um dado problema toda vez, e aquele que tem um elemento aleatório que pode produzir diferentes subconjuntos a cada execução. Alguns dos mais representativos algoritmos estão listados na figura 3.2.

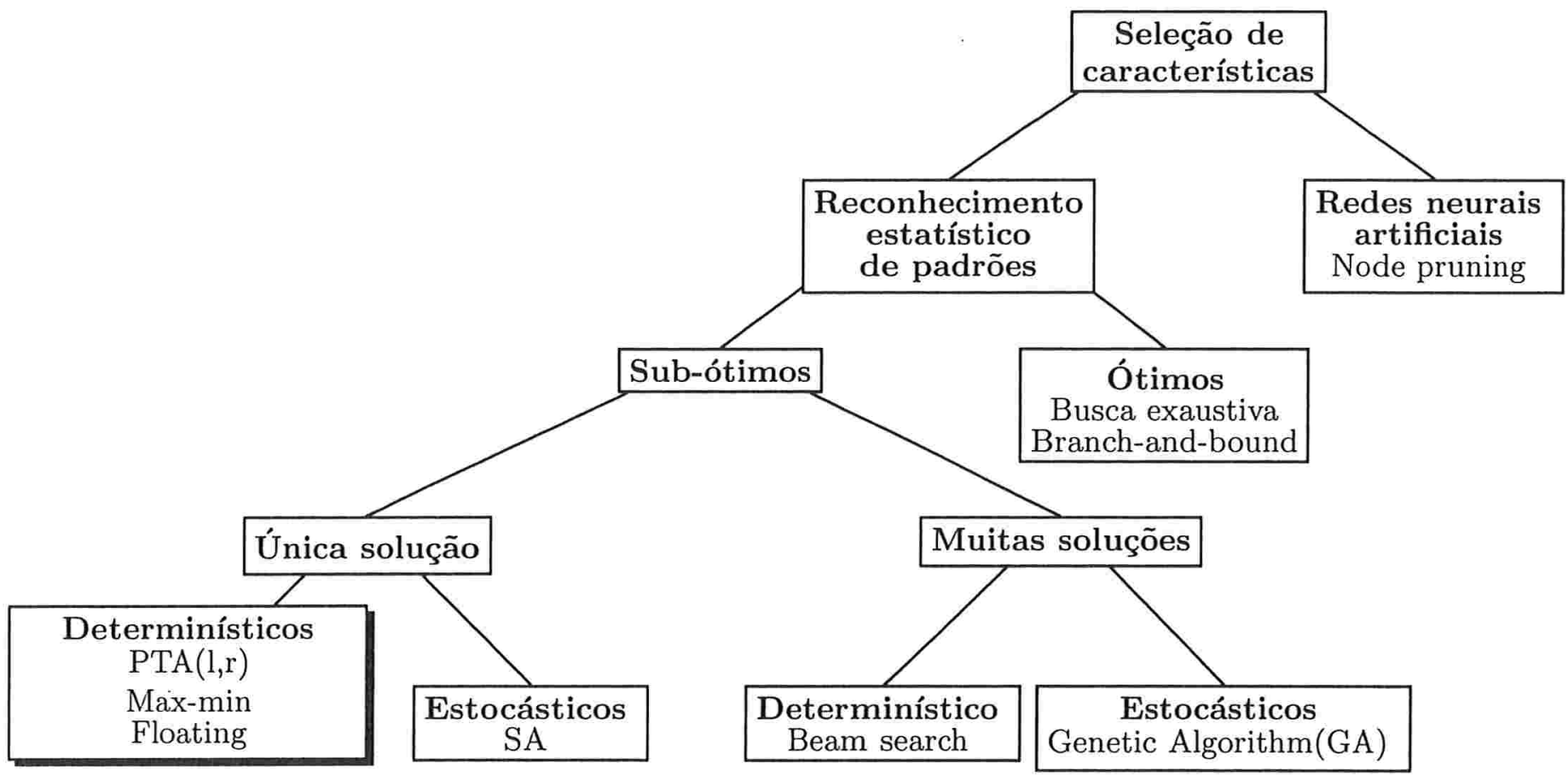

Figura 3.2: Taxonomia dos métodos de seleção de características. Adaptada da figura 1 contida em [23]

Em nosso trabalho, foran utilizados métodos determinísticos de solução única, mais especificamente os métodos flutuantes. Por isso, uma descrição mais detalhada será apresentada na seção 3.3.2. As outras abordagens estarão listadas com uma breve caracterização na tabela 3.1. Para mais detalhes sobre métodos de seleção de características baseadas em algoritmos de busca e função critério, vide $[9,23]$. Para mais detalhes sobre node pruning, vide [26]. Para mais detalhes sobre métodos de reconhecimento estatísticos ótimos, ver [28]. Para mais detalhes sobre métodos estocásticos de múltiplas soluções [35]. Para mais detalhes sobre métodos determinísticos de múltiplas soluções [34]. A seguir, uma descrição mais detalhada sobre esses métodos de buscas seqüênciais será apresentada, e em seguida, os conceitos básicos de função critério. 


\begin{tabular}{|c|c|c|}
\hline Método & Propriedade & Comentários \\
\hline Node pruning & $\begin{array}{l}\text { Funciona através de uma rede neural multi- } \\
\text { camadas com retro-alimentação, utilizando um } \\
\text { algoritmo de aprendizado baseado em retro- } \\
\text { propagação (backpropagation). A seleção de ca- } \\
\text { racterísticas é feita por eliminação dos nós de en- } \\
\text { trada, através de um algoritmo que elimina os nós } \\
\text { menos salientes, definida através de uma medida } \\
\text { de "saliência de nós", que é a soma do erro so- } \\
\text { bre todos os padrões de treinamento resultante da } \\
\text { remoção do nó removido. }\end{array}$ & $\begin{array}{l}\text { Inicialmente, a rede neural é trei- } \\
\text { nada, sendo posteriormente reali- } \\
\text { zada a eliminação de nós, seguida } \\
\text { de um re-treinamento da rede. } \\
\text { Repete-se o processo até que seja } \\
\text { alcançada a dimensão desejada. } \\
\text { A vantagem disso é que deter- } \\
\text { mina, simultaneamente, o melhor } \\
\text { subconjunto de características e o } \\
\text { classificador ótimo. }\end{array}$ \\
\hline Busca exaustiva & Calcula todos os $\left(\begin{array}{l}N \\
M\end{array}\right)$ possíveis subconjuntos & $\begin{array}{l}\text { Garante-se encontrar o subcon- } \\
\text { junto ótimo; não é viável mesmo } \\
\text { para valores explosivos de } M \text { e } N \text {. }\end{array}$ \\
\hline $\begin{array}{l}\text { Busca Branch- } \\
\text { and-bound }\end{array}$ & $\begin{array}{l}\text { Somente uma fração de todos os possíveis subcon- } \\
\text { juntos de características que precisam ser enume- } \\
\text { radas para encontrar o subconjunto ótimo }\end{array}$ & $\begin{array}{l}\text { Garante-se encontrar o subcon- } \\
\text { junto ótimo contanto que a } \\
\text { função critério que satisfaça a } \\
\text { propriedade de monotocidade. } \\
\text { Uma função é monotônica se } \\
J(\mathcal{X} \cup \mathcal{Z}) \geq J(\mathcal{X}), \forall \mathcal{X}, \mathcal{Z} \subseteq \mathcal{Y} \\
\text {; a complexidade no pior caso é } \\
\text { exponencial. }\end{array}$ \\
\hline $\begin{array}{l}\text { Algoritmo } \\
\text { genético (GA) }\end{array}$ & $\begin{array}{l}\text { Os subconjuntos são representados por cadeias } \\
\text { binárias de tamanho } n \text { (características). Cada ca- } \\
\text { deia representa um cromossomo. Cada cromos- } \\
\text { somo é avaliado, através da função critério, para } \\
\text { determinar sua aptidão (fitness), que informa se } \\
\text { o cromossomo irá "sobreviver" ou "morrer". No- } \\
\text { vos cromossomos são criados a partir de mutações } \\
\text { (a cadeia binária de um dos cromossomos é per- } \\
\text { turbada para criar uma nova seqüência) e cruza- } \\
\text { mentos (mecanismo pelo qual dois cromossomos } \\
\text { trocam partes, gerando uma nova combinação). }\end{array}$ & $\begin{array}{l}\text { O principal desafio desta aborda- } \\
\text { gem é o ajuste dos parâmetros } \\
\text { do algoritmo, em especial o ta- } \\
\text { manho da população e a taxa de } \\
\text { mutação. }\end{array}$ \\
\hline
\end{tabular}




\begin{tabular}{|c|c|c|}
\hline $\begin{array}{l}\text { Simulated Anne- } \\
\text { aling (SA) [33] }\end{array}$ & $\begin{array}{l}\text { É um método de otimização global que distingue } \\
\text { entre diferentes mínimos locais no espaço do pro- } \\
\text { blema, com o objetivo de minimizar uma função } \\
\text { objetivo. A funçao objetivo é o tamanho total do } \\
\text { caminho dado pelo conjunto dos pontos que o al- } \\
\text { goritmo selecionar. A distância entre cada par de } \\
\text { pontos é equivalente à energia de uma molécula. } \\
\text { A temperatura, então, é a média desses tamanhos. } \\
\text { Começando de um ponto inicial escolhido aleato- } \\
\text { riamente, o algoritmo troca um par de pontos e a } \\
\text { energia total do caminho é calculada. Se o valor } \\
\text { da funçao objetivo é menor, então a troca é aceita } \\
\text { e o processo se repete. Senão, esta troca pode ser } \\
\text { aceita através do critério de Metropolis, que pos- } \\
\text { sibilita ao algoritmo sair dos pontos de mínimos } \\
\text { locais. À medida em que o processo de otimização } \\
\text { ocorre, o algoritmo aproxima-se do mínimo global. }\end{array}$ & $\begin{array}{l}\text { Este algoritmo tem apresentado } \\
\text { uma boa aproximação para o ca- } \\
\text { minho mais curto para o pro- } \\
\text { blema do caixeiro viajante: en- } \\
\text { contrar o caminho mais curto } \\
\text { dentre os } N \text { ! caminhos que conec- } \\
\text { tam as } N \text { cidades. }\end{array}$ \\
\hline Beam Search & $\begin{array}{l}\text { Os melhores } N \text { estados são salvos em um "beam" } \\
\text { e o melhor estado no "beam" é testado para ex- } \\
\text { pansão futura. Estados testados recentemente são } \\
\text { colocados em locais apropriados de acordo com os } \\
\text { valores computados. }\end{array}$ & $\begin{array}{l}\text { Ao contrário dos métodos es- } \\
\text { tocásticos de múltiplas soluções } \\
\text { como o } G A \text {, os métodos deter- } \\
\text { mínisticos de múltiplas soluções } \\
\text { apresentam sempre os mesmos } \\
\text { conjuntos de características. }\end{array}$ \\
\hline
\end{tabular}

Tabela 3.1: Alguns métodos de seleção de características.

Adaptada da tabela 5 contida em [22]

\subsubsection{Métodos determinísticos com solução única}

A maioria dos métodos de solução única baseia-se em técnicas de busca. Dentre eles, os métodos seqüenciais são os mais comuns para realizar a seleção de características. Os métodos seqüenciais iniciam com uma solução única (um subconjunto de características) e, a cada iteração, adiciona ou remove características até algum critério de parada ser satisfeito. Eles estão divididos em duas categorias: aquelas que iniciam com conjunto vazio e adicionam características (método "bottom-up" ou "para frente"), e aquelas que iniciam com todo conjunto e removem características (método "top-down" ou "para trás"). Note que por esses algoritmos não examinarem todos os possíveis subconjuntos, eles não 
garantem produzir um resultado ótimo [23].

Para a descrição dos algoritmos de buscas seqüenciais em métodos determinísticos com solução única, seguem abaixo as definições utilizadas em [29].

Seja $\mathcal{X}_{k}=\left\{x_{i}: 1 \leq i \leq k, x_{i} \in \mathcal{Y}\right\}$ um subconjunto de $k$ características do conjunto $\mathcal{Y}=\left\{y_{i}: 1 \leq i \leq N\right\}$ das $N$ características disponíveis. $\mathrm{O}$ valor $J\left(y_{i}\right)$ da função critério de seleção de características, quando somente a $i$-ésima característica $y_{i}, i=1,2, \ldots, N$ for utilizada, é chamado de significância individual $\mathcal{S}_{0}\left(y_{i}\right)$ da característica.

A significância $\mathcal{S}_{k-1}\left(x_{j}\right)$ da característica $x_{j}, j=1,2, \ldots, k$ no conjunto $\mathcal{X}_{k}$ é definida por

$$
\mathcal{S}_{k-1}\left(x_{j}\right)=J\left(\mathcal{X}_{k}\right)-J\left(\mathcal{X}_{k}-x_{j}\right)
$$

A significância $\mathcal{S}_{k+1}\left(f_{j}\right)$ da característica $f_{j}$ do conjunto $\mathcal{Y}-\mathcal{X}_{k}$, tal que $\mathcal{Y}-\mathcal{X}_{k}=$ $\left\{f_{i}: i=1,2, \ldots, N-k, f_{i} \in \mathcal{Y}, f_{i} \neq x_{l}, \forall x_{l} \in \mathcal{X}_{k}\right\}$ em relação ao conjunto $\mathcal{X}_{k}$ é definida por:

$$
\mathcal{S}_{k+1}\left(f_{j}\right)=J\left(\mathcal{X}_{k}+f_{j}\right)-J\left(\mathcal{X}_{k}\right)
$$

Nota: para $k=1$, o termo significância de uma característica no conjunto coincide com o termo significância individual.

Dizemos que a característica $x_{j}$ do conjunto $\mathcal{X}_{k}$ é:

1. a característica mais significante (melhor) do conjunto $\mathcal{X}_{k}$ se

$$
\mathcal{S}_{k-1}\left(x_{j}\right)=\max _{1 \leq i \leq k} \mathcal{S}_{k-1}\left(x_{i}\right) \Rightarrow J\left(\mathcal{X}_{k}-x_{j}\right)=\min _{1 \leq i \leq k} J\left(\mathcal{X}_{k}-x_{i}\right)
$$

2. a característica menos significante (pior) do conjunto $\mathcal{X}_{k}$ se

$$
\mathcal{S}_{k-1}\left(x_{j}\right)=\min _{1 \leq i \leq k} \mathcal{S}_{k-1}\left(x_{i}\right) \Rightarrow J\left(\mathcal{X}_{k}-x_{j}\right)=\max _{1 \leq i \leq k} J\left(\mathcal{X}_{k}-x_{i}\right)
$$

Dizemos que a característica $f_{j}$ do conjunto $\mathcal{Y}-\mathcal{X}_{k}$ é:

1. a característica mais significante (melhor) em relação ao conjunto $\mathcal{X}_{k}$ se

$$
\mathcal{S}_{k+1}\left(f_{j}\right)=\max _{1 \leq i \leq N-k} \mathcal{S}_{k+1}\left(f_{i}\right) \Rightarrow J\left(\mathcal{X}_{k}+f_{j}\right)=\max _{1 \leq i \leq N-k} J\left(\mathcal{X}_{k}+f_{i}\right),
$$


2. a característica menos significante (pior) em relação ao conjunto $\mathcal{X}_{k}$ se

$$
\mathcal{S}_{k+1}\left(f_{j}\right)=\min _{1 \leq i \leq N-k} \mathcal{S}_{k+1}\left(f_{i}\right) \Rightarrow J\left(\mathcal{X}_{k}+f_{j}\right)=\min _{1 \leq i \leq N-k} J\left(\mathcal{X}_{k}+f_{i}\right)
$$

Segue abaixo os algoritmos envolvidos dos métodos de seleção de características.

\subsubsection{Busca Seqüencial para Frente}

A busca seqüencial para frente (Sequencial Forward Search - SFS) é um método bottomup que inicia com um conjunto de características vazio e dado um conjunto de características já selecionadas, a cada iteração seleciona a característica que, acrescida ao conjunto determinado pela iteração anterior, produz o melhor resultado da função critério. Assim, essa característica é adicionada ao conjunto de características anterior e uma nova iteração é, então, realizada. A desvantagem desse método é que, uma vez que uma característica tenha sido selecionada, ela não pode ser descartada do subconjunto final. Isto proporciona o chamado efeito nesting que pode ocorrer quando o subconjunto ótimo não contém elementos do conjunto já selecionado. A vantagem é o custo computacional quando se deseja obter conjuntos pequenos em relação ao total de características.

A seguir, a descrição do algoritmo SFS, com $m$ indicando o número de iterações e $\mathcal{X} \leftarrow \emptyset$.

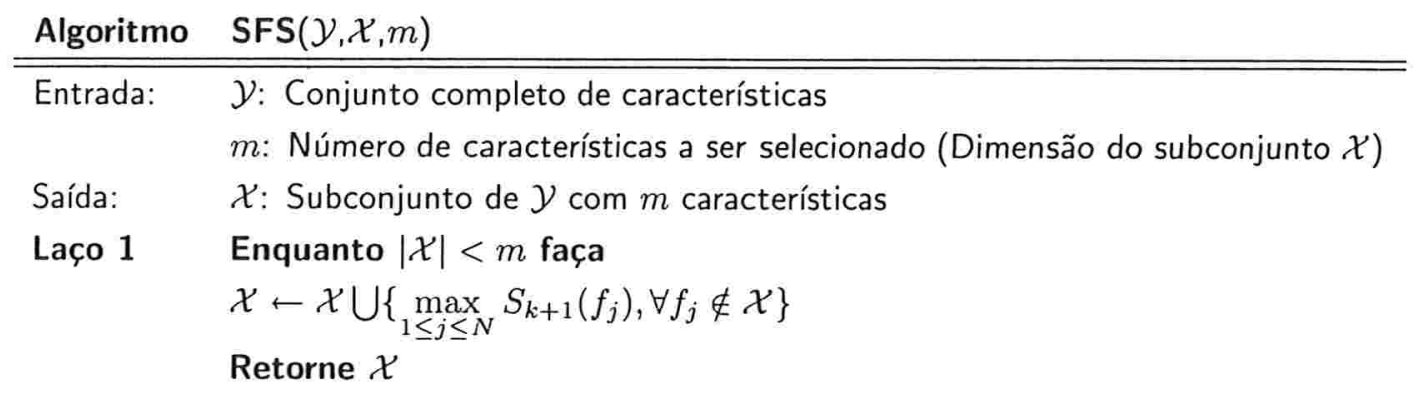

A instrução $\mathcal{X} \leftarrow \emptyset$ não foi incluída no algoritmo dessa função pois ela será utilizada posteriormente para conjuntos não vazios.

\subsubsection{Busca Seqüencial para Trás}

A busca seqüencial para trás (Sequencial Backward Search - SBS) é uma versão top- 
down do algoritmo anterior. A diferença entre $S B S$ e $S F S$ é que $S B S$ inicia-se com um conjunto de características completo, contendo todas as $N$ características. A cada iteração $i$, retira-se uma característica do subconjunto corrente (de dimensão $N-i$ ) e escolhe-se um subconjunto dentre todas as possíveis com dimensão $N-i$ que apresenta o maior valor da função critério. Assim como o SFS, a desvantagem deste é que, uma vez eliminada uma característica, ela não mais retornará ao subconjunto final. Como conseqüência disso, o efeito nesting também ocorre caso o melhor subconjunto contenha alguma das características que foram eliminadas. A vantagem é o método computacional quando se deseja obter conjuntos grandes em relação ao total de características.

A seguir, a descrição do algoritmo SBS, que assume como valor inicial $\mathcal{X} \leftarrow \mathcal{Y}$.

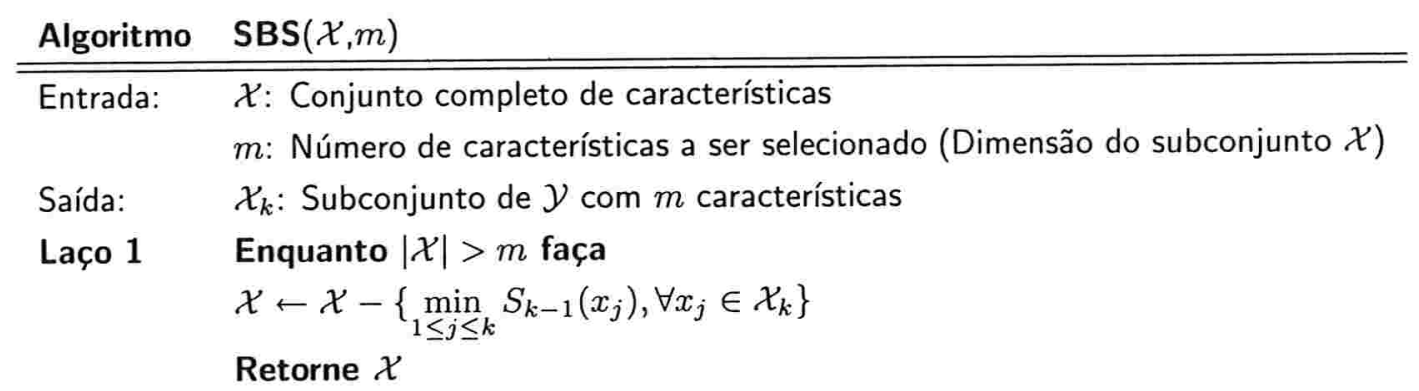

A instrução $\mathcal{X} \leftarrow \mathcal{Y}$ não foi incluída no algoritmo dessa função pois ela será utilizada posteriormente para conjuntos não vazios.

\subsubsection{Mais $l$ menos $r$}

Este método, cujo nome original é "Plus l - Take Away r" (PTA), foi criado visando evitar o efeito nesting. O fluxo do algoritmo consiste, primeiramente, aumentar o conjunto de características em $l$ elementos usando o método de seleção para frente ( $S F S$ ), e depois eliminar as $r$ características utilizando a busca seqüêncial para trás. Os valores de $l$ e $r$ devem ser determinados pelo usuário, o que torna a escolha destes parâmetros um novo problema. Se os valores forem muito pequenos, é possível que o problema de nesting não seja evitado. Por outro lado, para valores grandes de $l$ e $r$, o algoritmo torna-se muito lento. Na versão bottom-up, $l$ deve ser maior que $r$. Já na versão top-down, $l$ deve ser menor que $r$. Para mais detalhes, vide [36, 37].

A seguir, a descrição do algoritmo PTA: 


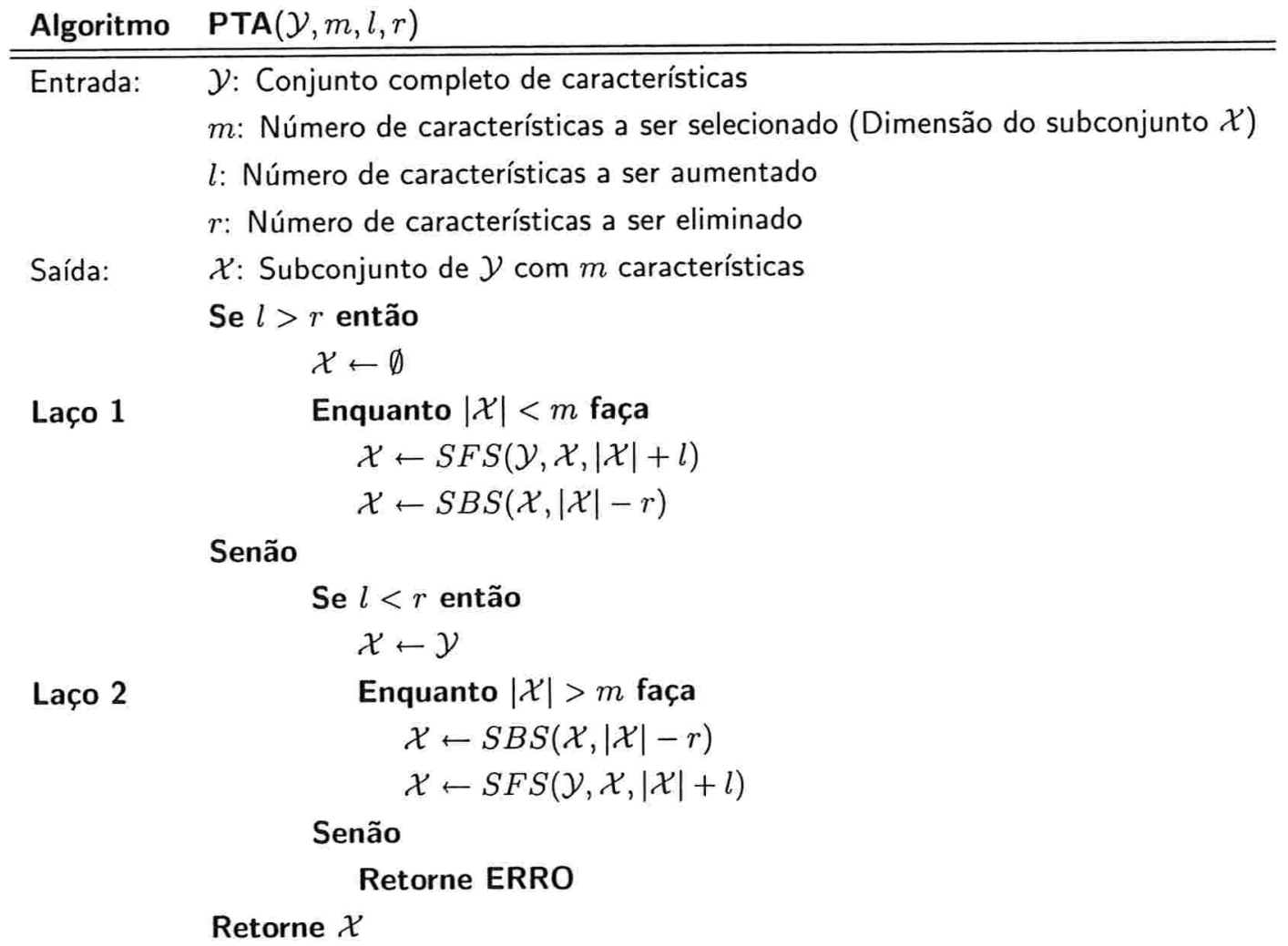

\subsubsection{Algoritmos de busca seqüêncial generalizada}

Trata-se de algoritmos de seleção que inserem (para Generalized Sequential Forward Search - GSFS) ou removem (para Generalized Sequential Backward Search - GSBS) subconjuntos de características em vez de manipular apenas uma característica por vez. O motivo que possibilita o funcionamento dos algoritmos generalizados é a utilização de funções que determinam a "significância" dos subconjuntos. Para mais detalhes, vide [36, $37]$.

\subsubsection{Métodos de busca seqüencial flutuante para frente e para trás}

Os métodos de busca seqüencial flutuante para frente (Sequential Floating Forward Search - SFFS) e para trás (Sequential Floating Backward Search - SFBS), propostos por [29] podem ser vistos como generalizações do método Plus $l$ - take away r(PTA), em que os valores de $l$ e $r$ são determinados e atualizados dinamicamente. Esses métodos frequentemente provêm soluções muito boas com um pequeno custo computacional. $\mathrm{O}$ método de busca para frente é a versão bottom-up, e o de busca para trás, top-down. 
Segundo os autores de $[22,36]$, esses são os métodos que melhor combinam tempo de execução com qualidade de resultados.

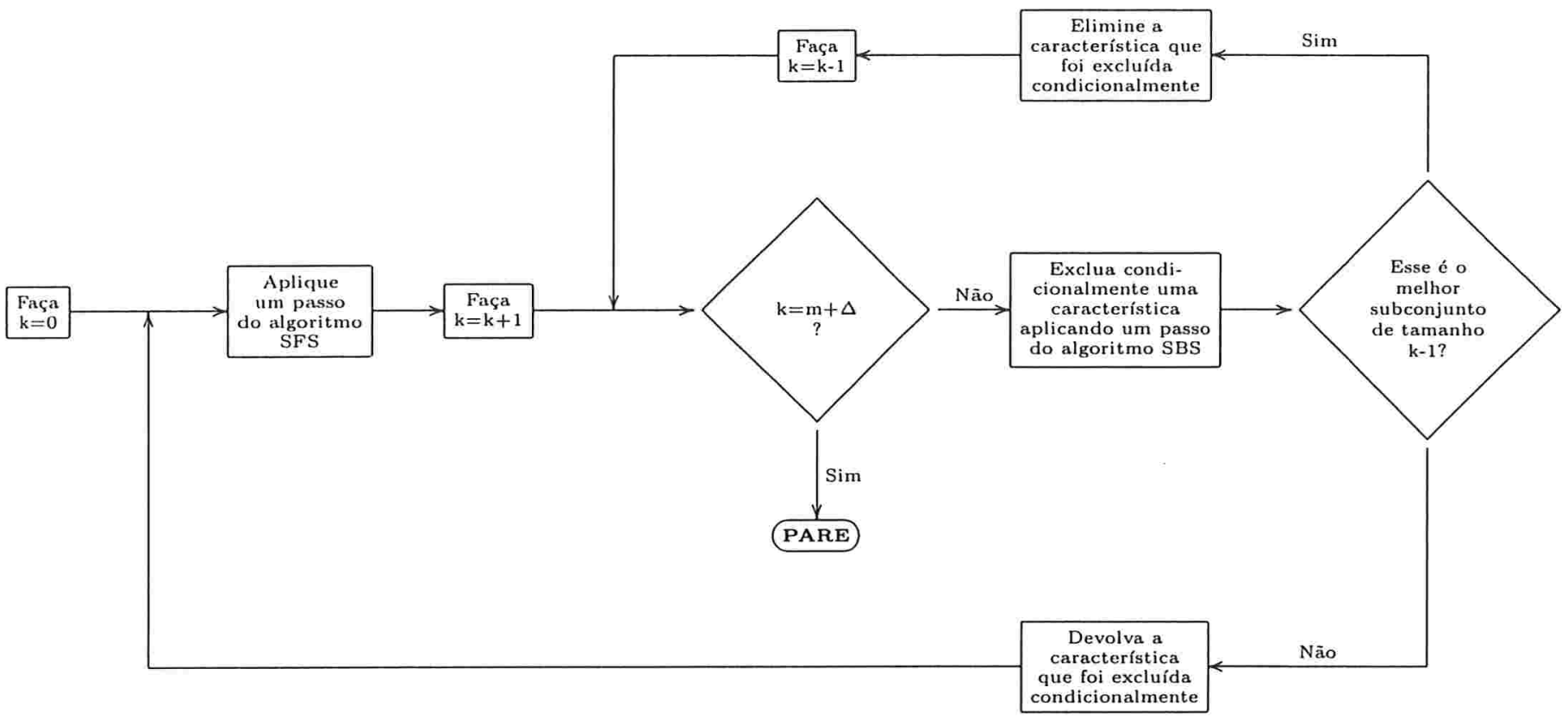

Figura 3.3: Fluxograma simplificado do algoritmo SFFS. Adaptada de [23]

O fluxograma da figura 3.3 resume o funcionamento da versão para frente desse algoritmo. A seguir, apresentamos o algoritmo em sua forma completa.

Para tornar mais clara a exposição, é suposto que $k$ características já foram selecionadas do conjunto completo de características $\mathcal{Y}=\left\{y_{j} \mid j=1,2, \ldots, N\right\}$ para formar o conjunto $\mathcal{X}_{k}$ com a correspondente função critério $J\left(\mathcal{X}_{k}\right)$. Porém, deve-se iniciar esse algoritmo com $k=0$ e $\mathcal{X}=\emptyset$. Além disso, os valores de $J\left(\mathcal{X}_{i}\right)$ de todos os subconjuntos precedentes de tamanho $i=1, \ldots, k-1$ são conhecidos e foram armazenados.

\begin{tabular}{ll} 
Algoritmo & $\operatorname{SFFS}(\mathcal{Y}, \mathcal{X}, m)$ \\
\hline \hline Entrada: & $\mathcal{Y}:$ Conjunto completo de características \\
& $\mathcal{X}:$ Subconjunto de $\mathcal{Y}$ com $m$ características \\
& $m$ : Número de características a ser selecionado (Dimensão do subconjunto $\mathcal{X}$ ) \\
Passo 1 & $/^{*}$ Inclusão $* /$ \\
& $\mathcal{X}_{k+1} \leftarrow \operatorname{SFS}\left(\mathcal{Y}, \mathcal{X}_{k}, k+1\right)$
\end{tabular}


Se $k=m+\Delta$ então

Retorne $\mathcal{X}_{m}$

Passo $2 \quad / *$ Exclusão condicional - Achar a característica menos significativa */

$/ *$ no conjunto $\mathcal{X}_{k+1}$. Seja $\mathrm{x}_{k+1}$ a característica menos $* /$

$/ *$ significativa em $\mathcal{X}_{k+1}:^{*} /$

Se $J\left(\mathcal{X}_{k+1}-\mathbf{x}_{k+1}\right) \geq J\left(\mathcal{X}_{k+1}-x_{j}\right),: \forall j=1,2, \ldots, k$ então

$k \leftarrow k+1$

Vá ao passo 1

Se $\exists x_{r}, 1 \leq r \leq k: J\left(\mathcal{X}_{k+1}-x_{r}\right)>J\left(\mathcal{X}_{k}\right)$ então

$\mathcal{X}_{k}^{\prime} \leftarrow \mathcal{X}_{k+1}-x_{r}$ (observando que neste ponto $J\left(\mathcal{X}_{k}^{\prime}\right)>J\left(\mathcal{X}_{k}\right)$ )

Se $k=2$ então

$$
\begin{aligned}
& \mathcal{X}_{k} \leftarrow \mathcal{X}_{k}^{\prime} \\
& J\left(\mathcal{X}_{k}\right) \leftarrow J\left(\mathcal{X}_{k}^{\prime}\right)
\end{aligned}
$$

Retorne ao passo 1

Senão

$\mathcal{X}_{k}^{\prime} \leftarrow \mathcal{X}_{k}$

Vá ao passo 3

Passo 3 (Continuação da exclusão condicional)

/* Achar a característica menos significativa $\mathrm{x}_{k-1}^{\prime}$ no conjunto $\mathcal{X}_{k}^{\prime *}$ /

$\mathcal{X}_{k-1}^{\prime} \leftarrow S B S\left(\mathcal{X}_{k}^{\prime}, k-1\right)$

Se $J\left(\mathcal{X}_{k-1}^{\prime}\right) \leq J\left(\mathcal{X}_{k-1}\right)$ então

$\mathcal{X}_{k} \leftarrow \mathcal{X}_{k}^{\prime}$

$J\left(\mathcal{X}_{k}\right) \leftarrow J\left(\mathcal{X}_{k}^{\prime}\right)$

Vá ao passo 1

Se $J\left(\mathcal{X}_{k-1}^{\prime}\right)>J\left(\mathcal{X}_{k-1}\right)$ então

$k \leftarrow k-1$

Se $k=2$ então

$\mathcal{X}_{k} \leftarrow \mathcal{X}_{k}^{\prime}$

$J\left(\mathcal{X}_{k}\right) \leftarrow J\left(\mathcal{X}_{k}^{\prime}\right)$

Vá ao passo 1

Senão

Repita o passo 3

Pode-se notar que a condição de parada é que $\left|\mathcal{X}_{k}\right|=m+\Delta$, em que $\Delta$ é um valor de tolerância que é utilizada para que o algoritmo não pare na primeira vez em que o conjunto $\mathcal{X}_{k}$ tenha tamanho $m$, pois o problema de nesting só pode ser evitado se forem realizados cálculos com $\mathcal{X}_{k+1}$. Normalmente, utiliza-se um valor pequeno para $\Delta$ (por exemplo, $\Delta \leq 3)$. A versão para trás desse algoritmo(SFBS) é análoga a esse, diferindose apenas na ordem em que os algoritmos SFS e SBS são executados e em alguns critérios 
de avaliação de conjuntos. Além disso, inicia-se com $k=N$. Para mais detalhes, vide [29].

\subsubsection{Métodos adaptativos de busca seqüêncial flutuante para frente e para trás}

Tanto a busca seqüencial flutuante para frente (Adaptive Sequential Floating Forward Search - ASFFS), quanto a busca seqüêncial flutuante para trás (Adaptive Sequential Floating Backward Search - ASFBS) são generalizações dos métodos de busca sequiêncial flutuante, ou seja, podem ser inseridos e eliminados não somente características, mas também conjuntos de características por vez, sendo que estes conjuntos têm seu tamanho e seu conteúdo determinados dinamicamente.

A vantagem desses métodos é que, em termos da função critério, os resultados obtidos estão mais próximos dos resultados ótimos. A desvantagem, entretanto, é quando o conjunto de dados que são inseridos e retirados por iteração for grande, o algoritmo tornase lento e complexo quando comparados aos métodos de busca seqüêncial flutuante [12]. Para mais detalhes sobre esse método, vide [36].

\subsubsection{Função critério}

Na seleção automática de características, uma das partes mais importantes na redução da dimensionalidade é a escolha de uma função critério. O objetivo da função critério é minimizar o erro dos classificadores, sendo desejável que apresente as seguintes características:

- a função critério seja maior quanto menor for a redundância entre as classes,

- a função critério seja maior quanto maior a facilidade de discriminar padrões de classes diferentes.

Embora a performance do classficador possa ser usada como uma função critério natural, ela apresenta algumas desvantagens, como:

- o tempo gasto para treinar um classificador pode ser muito grande dependendo do classificador,

- a escolha do classificador é um problema crítico por si só, 
- o subconjunto final selecionado nitidamente depende do classificador utilizado como critério, significando que o subconjunto de características resultante pode provavelmente prover bons resultados de classificação somente quando o classificador utilizado para definir a função critério for adotado [22].

Por essas razões, alguma medida da distância entre classes é normalmente utilizada como função critério, levando a subconjuntos de características que podem prover bons resultados de classificação para diferentes tipos de classificadores. O objetivo é minimizar a probabilidade do erro do classificador, maximizando a distância entre padrões de classes diferentes no espaço de características. Dentre algumas possibilidades de medidas de separabilidade entre classes podemos citar a distância de Mahalanobis, a distância de Bhattacharyya e a distância de separação de classes $[13,29,36]$.

A maioria destas distâncias entre classes é mais apropriada para conjuntos convexos, tendendo a privilegiar conjuntos ou classes linearmente separados. $\mathrm{Na}$ tentativa de poder tratar casos não-lineares separáveis, uma função critério baseada em distâncias nebulosas foi proposta em [11]. Essa função critério combina três fatores:

1. a distância entre o centróide das classes,

2. a compacidade de cada classe,

3. a quantidade de regiões sobrepostas de duas classes no espaço de características.

A função aumenta com relação aos dois primeiros fatores e diminui com relação ao terceiro. Neste trabalho, utilizou-se a função critério baseada em distâncias nebulosas em algoritmos de seleção de características. Detalhes sobre esse assunto estão na seção 4.2.

\subsection{Classificação de padrões}

Apesar da utilização de métodos de classificação estatísticos no presente trabalho, o foco deste trabalho é a seleção de características. Desta forma, nesta subseção apenas serão citadas informações gerais sobre alguns métodos mais conhecidos de classificação, tendo um destaque maior aos classificadores de mínima distância ao protótipo e de $k$ vizinhos mais próximos, que são utilizados nos testes realizados.

Dado um padrão desconhecido x pertencente ao conjunto de padrões de teste $R$ em um espaço de características, e o conjunto $\Omega$ de todas as classes existentes, um classificador é 
uma função $\Upsilon: R \rightarrow \Omega$, tal que $\Upsilon(\mathbf{x})=\omega_{i}$, em que $\omega_{i}$ é a $i$-ésima classe de $\Omega$. Assim, um classificador é uma função que possui como entrada padrões desconhecidos e, como saída, rótulos que identificam a que classes tais padrões provavelmente pertencem. Portanto, classificadores são os elementos que efetivamente realizam o reconhecimento de padrões.

Com exceção de alguns classificadores sintáticos e baseados em lógica nebulosa, os classificadores necessitam ser treinados utilizando-se de um conjunto de padrões de treinamento. Esse treinamento é utilizado pelo algoritmo do classificador para determinar as fronteiras de decisão do espaço de características. Fronteiras de decisão são superfícies multidimensionais no espaço de características $F$ que particionam $F$ em $c$ regiões para um problema com $c$ classes, e cada região correspondendo a uma classe. Se as regiões $S_{i}$ e $S_{j}$ são contíguas, são separadas por uma superfície de decisão. Assim, tem-se que $F=\bigcup_{i=1}^{c} S_{i}$. A regra de decisão faz com que um padrão desconhecido que se encontra na região $S_{i}$ do espaço de características seja rotulado como um padrão da classe $\omega_{i}$, ou seja, $\Upsilon(\mathrm{x})=\omega_{i}$.

Assim, o que realmente difere um classificador de um outro é a forma como esse cria as fronteiras de decisão a partir dos padrões do conjunto de treinamento. Os padrões do conjunto de treinamento de cada classe podem ser pré-rotulados (aprendizado supervisionado) ou aprendidos com base nos exemplos (aprendizado não-supervisionado). Neste trabalho de mestrado, foram utilizados padrões previamente rotulados. No caso de métodos não-supervisionados, somente o algoritmo fuzzy $k$-means será detalhado, pois esse algoritmo será utilizado para determinar os protótipos de cada classe. Para mais detalhes, vide [22].

Apesar da existência de vários algoritmos diferentes para determinar fronteiras de decisão, todos têm em comum os seguintes objetivos:

1. minimizar o erro de classificação,

2. a necessidade da classificação ser eficiente computacionalmente.

Entretanto, a importância de cada um desses objetivos varia entre os classificadores. Detalhes sobre outros métodos de classificação se encontram em [18, 37, 38].

A seguir, é apresentada uma breve descrição sobre os dois classificadores utilizados neste trabalho. 


\subsubsection{Mínima distância ao protótipo}

O classificador de mínima distância ao protótipo é o mais simples em termos de esforço computacional, tanto na fase de treinamento quanto na de teste. A fase de treinamento consiste em determinar um protótipo para cada classe, sendo que o protótipo utilizado neste trabalho é o baricentro da classe. Na fase de teste, cada padrão é classificado de acordo com o protótipo mais próximo.

Assim, para cada padrão de teste, é necessário realizar apenas $c$ - 1 comparações caso o número de classes existentes seja $c$. A desvantagem desse classificador é a qualidade dos resultados, visto que os protótipos não contêm informações suficientes sobre a forma da distribuição das classes.

\subsubsection{Regra dos $K$ vizinhos mais próximos}

Este classificador tem como particularidade o fato de não possuir processamento na fase de treinamento. No entanto, é necessário um grande número de padrões de treinamento (padrões cuja classe é conhecida a priori) devido as tarefas de estimativa e de classificação serem fundidas em uma única tarefa. O algoritmo KNN classifica da seguinte maneira um padrão desconhecido de teste $\mathbf{x}$ :

1. Calcula-se a distância entre $\mathbf{x}$ e todos os padrões de treinamento,

2. Verifica-se a quais classes pertencem os $K$ padrões mais próximos a $\mathbf{x}$,

3. Ao padrão $\mathrm{x}$ é associado o rótulo da classe que for mais freqüente entre os $K$ padrões mais próximos de $\mathrm{x}$.

A maior vantagem desse método é a criação de uma superfície de decisão que se adapta à forma de distribuição dos dados de treinamento de forma detalhada. Isto possibilita a obtenção de boas taxas de acerto quando o conjunto de treinamento é grande ou quando representa todas as variações possíveis dos dados, principalmente no caso de $k=1$. A principal desvantagem está na complexidade do teste, pois para cada padrão de teste, é necessário realizar todas as medições de distância aos padrões de treinamento, além da necessidade de ordenar os resultados das medições obtidas. Em nosso trabalho, a distância utilizada foi a distância Euclidiana. Para mais detalhes sobre o algoritmo KNN, vide $[14,37]$. 


\section{Capítulo \\ 4 \\ Função critério baseada em múltiplos protótipos}

Este capítulo apresenta a principal contribuição desta dissertação de mestrado. Tratase da continuidade do trabalho desenvolvido por Teófilo E. Campos descrito em [10]. Inicialmente, será dado um panorama do método de seleção de características proposto em [10], esquematizando o algoritmo de busca e a(s) função(ões) critério adotado(s). Depois, os conceitos necessários da função critério baseada em distância nebulosa serão apresentados. Nesse ponto, serão apresentados os conceitos específicos sobre a nova função critério com múltiplos protótipos. Por fim, as considerações sobre a nova função critério serão descritas.

\subsection{Panorama do método de seleção de características baseada em distâncias nebulosas}

A abordagem de seleção de características proposta em [10] baseia-se no uso dos métodos de busca seqüencial flutuante (Sequential Floating Search Methods - SFSM) proposto em [29], utilizando como função critério a distância nebulosa baseada em tolerância, proposta em [25].

A figura 4.1 mostra como o fluxo de execução é conduzido na etapa de seleção de características, localizando a etapa de execução do algoritmo de busca, bem como a etapa que envolve o processo de obtenção dos conjuntos nebulosos ("fuzzificação") das classes. 
Os dados do conjunto de padrões de treinamento são normalizados, transformados para apresentar média 0 e desvio padrão 1 . Este processo é feito uma única vez e é anterior ao processo de seleção de características. Na região delimitada como search algorithm, ocorre a escolha da $i$-ésima característica a ser acrescentada ao conjunto de características corrente. Esta escolha do subconjunto de características é necessária para calcular o(s) protótipo(s) das classes dos padrões do conjunto de treinamento. É neste ponto que está implementado o SFSM. Em seguida, com o(s) protótipo(s) computados, ocorre o processo de "fuzzificação" onde os valores da função de pertinência são calculados. Com esses valores, aplica-se a função critério para que o algoritmo de busca encontre a característica que maximiza essa função para esta dimensão do espaço de características. Ao atingir a dimensão desejada, o algoritmo retorna um conjunto com as melhores características que representam os padrões de treinamento de entrada.

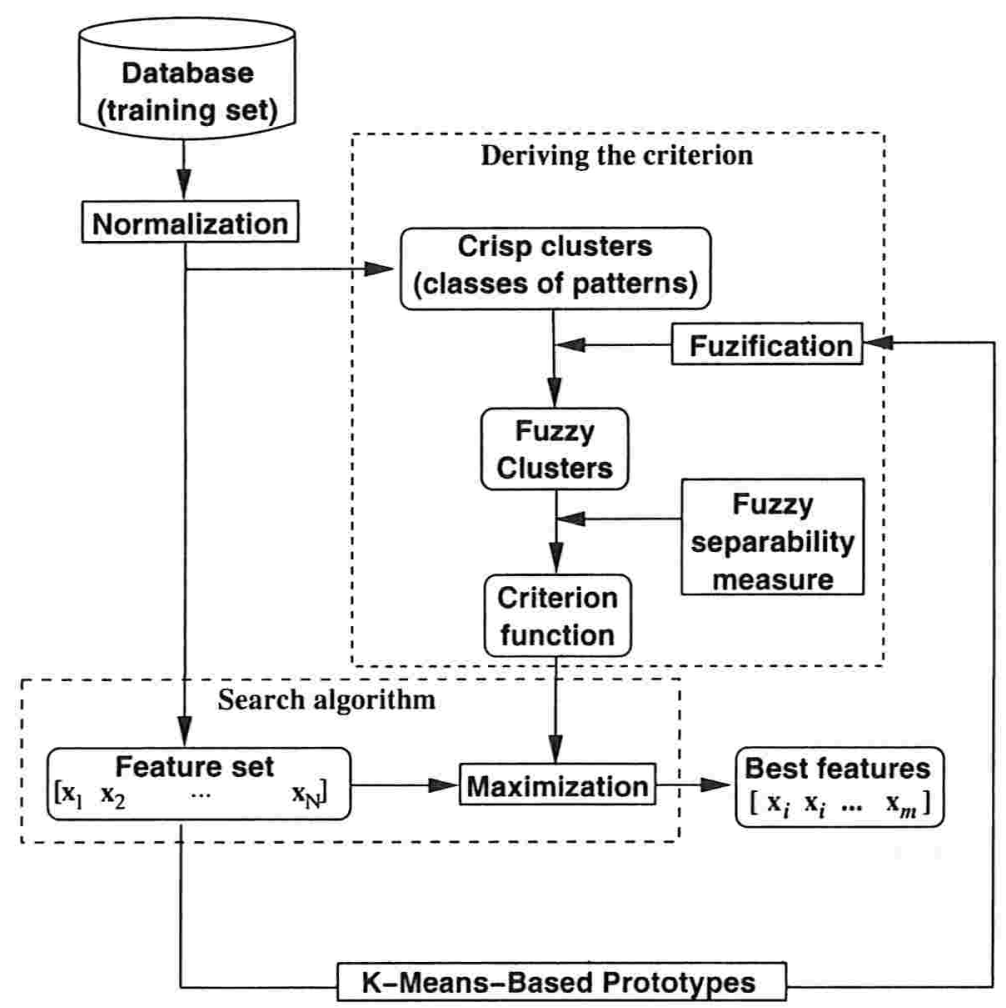

Figura 4.1: Fluxo de execução de seleção de características, indicando também a possibilidade de múltiplos protótipos obtidos através de agrupamento. Baseada na figura 1 do artigo em [2] 
Na próxima seção será descrita com detalhes a nova função critério.

\subsection{Seleção de características: Função critério}

A função critério é uma das partes fundamentais na etapa de seleção de características em reconhecimento de padrões. Ela tem como objetivo minimizar o erro da classificação.

Em nosso trabalho, a função critério está baseada em distância entre classes, onde se tenta maximizar a distância entre classes diferentes no espaço de características para minimizar a taxa de erro do classificador.

De acordo com os estudos realizados por Teófilo E. Campos em métricas entre conjuntos nebulosos [7, 10], constatou-se que uma medida de distância que, juntamente com o algoritmo de busca, maximiza a distância entre padrões que pertencem a classes diferentes e minimiza a distância entre padrões que pertencem à mesma classe é a distância nebulosa baseada em tolerância, proposta em [25]. Nessa medida, a distância é determinada através de uma vizinhança em torno de cada padrão de treinamento. A seguir, serão apresentados os conceitos básicos de conjuntos nebulosos, do processo de "fuzzificação" e da distância nebulosa.

\subsubsection{Conjuntos Nebulosos}

$\mathrm{Na}$ lógica nebulosa, a relação de pertinência entre elementos e um conjunto nebuloso não é binária (pertence ou não-pertence), mas assume um valor real. A função de pertinência é aquela que caracteriza um elemento (padrão) nebuloso. Formalmente, seja $F$ um espaço cartesiano representando um espaço de características, e $\mathbf{x}_{1}, \mathbf{x}_{2}, \ldots, \mathbf{x}_{t}$ variavéis ou padrões no espaço $F$. Um objeto nebuloso é definido biunivocamente pela função de pertinência de um objeto não-nebuloso ( "crisp"), denotada por $\nu, \nu: F \rightarrow[0,1]$. Seja $C$ o conjunto de todos os conjuntos nebulosos definidos em $F$. Para cada $\mathrm{x}$ em $F, \nu_{\omega_{i}}(\mathrm{x})$, com $\omega_{i} \in C$, é um valor em $[0,1]$ que representa o grau de pertinência de $\mathbf{x}$ ao conjunto nebuloso $\omega_{i}[7]$.

As funções de pertinência podem ser criadas com base na relação entre cada elemento e o(s) protótipo(s) dos conjuntos. Um protótipo ou suporte $p^{\omega}$ da classe $\omega$ é um ponto em $F$ tal que $\nu_{\omega}\left(p^{\omega}\right)=1$. Desta forma, os protótipos de uma classe definem regiões que são mais representativas de uma classe, sendo então, os pontos mais típicos dela. Logo, as funções de pertinência apresentam valores maiores quanto maior a proximidade entre 
os padrões e os suportes de uma classe. Como exemplo de protótipo temos o baricentro da classe, conhecido também como centróide.

Para mais detalhes sobre lógica nebulosa e conjuntos nebulosos, vide $[5,17,39]$.

\subsubsection{Processo de obtenção de múltiplos protótipos}

Um protótipo ou suporte de uma classe tem como objetivo ser o ponto mais representativo de uma classe. No entanto, nem sempre as regiões representadas pelas classes no espaço de características são regiões disjuntas e compactas. Como regiões compactas entende-se regiões com alta densidade local de padrões no espaço de características. Logo, classes compactas são classes que apresentam regiões compactas.

Nesses casos, como representado pela figura 4.2, a existência de apenas um protótipo por classe é insuficiente para representar a distribuição dos padrões dentro da classe. Assim, uma abordagem de análise de agrupamento em cada classe pode fornecer uma melhor representatividade. A abordagem adotada é aplicar um algoritmo de agrupamento para dividir cada classe em $k$ grupos, com um protótipo associado a cada grupo. Assim, cada classe fica representada por $k$ protótipos, e a pertinência dos padrões pode ser verificada em todos os $k$ protótipos que identificam cada classe.

Basicamente, existem duas técnicas de agrupamento: "hard", em que cada padrão pertence somente a um grupo; e a "fuzzy", em que cada padrão pode pertencer a mais de um grupo, sendo que a cada padrão é atribuído um valor de pertinência $\nu$, que varia entre 0 e 1 .

Neste trabalho foi utilizada a abordagem nebulosa também para a análise de agrupamento, pois nem sempre as regiões representadas pelas classes no espaço de características são compactas, como na figura 4.2. O algoritmo escolhido para obter os protótipos em cada classe foi o fuzzy k-means. Desta forma, neste trabalho somente o algoritmo fuzzy $k$-means será detalhado. Existem várias formas de implementação disponíveis na Internet para fuzzy k-means, dentre os quais podemos destacar $[1,15,19,24,27]$. Para mais referências de outros algoritmos de agrupamento, vide $[18,37]$.

Apesar do algoritmo fuzzy k-means ser eficiente computacionalmente, a falta de critérios disponíveis para a escolha dos valores dos parâmetos $k$ (número de agrupamentos) e do $\epsilon$ (critério de parada), torna a escolha desses valores um novo problema [3]. Existem, porém, indicadores para a eficiência na partição em agrupamentos. Na página 34 , seção 4.2.2.3, algumas das medidas de validação de agrupamentos existentes serão abor- 
dadas. Na subseção 4.2.6, será estudada a relação entre o valor de $k$ e o desempenho da função critério. Para mais detalhes sobre medidas de validação de agrupamentos, vide $[19,20,27,32]$.

O algoritmo fuzzy $k$-means apresenta um problema em determinar os protótipos quando existem regiões dentro da classe cuja distribuição dos padrões apresenta densidades diferentes. Por exemplo, uma classe apresenta duas regiões distintas (duas subclasses), sendo que uma delas contém $80 \%$ dos padrões desta classe. Neste caso, ao aplicar o algoritmo, o cálculo das coordenadas dos protótipos sofre a influência desta região mais densa, aproximando as coordenadas dos protótipos para essa região [20, 24]. Apesar disso, considerando que fuzzy $k$-means aumenta a representatividade dos protótipos e, consequentemente, os valores de pertinência associados aos padrões, é de se esperar que esta abordagem apresente melhores valores para a nova função critério quando comparada com a função critério com protótipo único.

\subsubsection{Algoritmo fuzzy $k$-means}

Seguem abaixo, os conceitos necessários para o detalhamento do algoritmo fuzzy $k$ means.

O conjunto de padrões de entrada tem $t$ elementos, representado por $\mathcal{X}=\left\{\mathrm{x}_{1}, \mathrm{x}_{2}, \ldots, \mathrm{x}_{t}\right\}$ e cada padrão é representado como um vetor de $N$ características, $\mathbf{x}_{i}=\left(x_{i 1}, x_{i 2}, \ldots, x_{i N}\right)$.

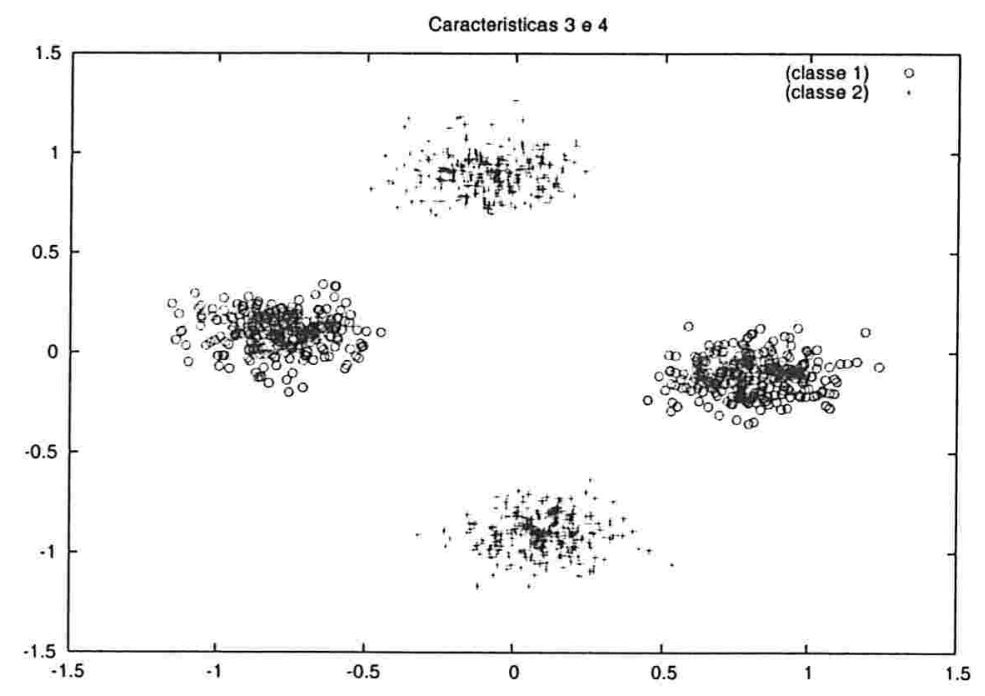

Figura 4.2: Exemplo de duas classes não compactas. 
Cada classe será dividida em $k$ grupos, com $A=A_{1}, A_{2}, \ldots, A_{k}$ e cada grupo representado por um protótipo. O protótipo ou suporte de um grupo $i$ é representado como um vetor de $N$ características, $V_{i}=\left(v_{i 1}, v_{i 2}, \ldots, v_{i N}\right)$.

A distância entre um padrão $\mathrm{x}_{e}$ e $V_{i}$, o protótipo do grupo $i$, é definido como:

$$
d_{i e}=d\left(\mathbf{x}_{e}-V_{i}\right)=\left\|\mathbf{x}_{e}-V_{i}\right\|
$$

em que $d_{i e}$ adotada neste trabalho foi a distância Euclidiana. Esse algoritmo apresenta como propriedade a inexistência de grupos vazios ou grupos contendo o conjunto todo:

$$
\emptyset \subset A_{i} \subset \mathcal{X}, \forall i
$$

Por se tratar de uma abordagem nebulosa, define-se uma função de pertinência $\nu: \mathcal{X} \rightarrow$ $[0,1]$ tal que, para cada padrão $\mathrm{x} \in \mathcal{X}$ e para cada grupo $A_{i}$, essa função $\nu_{A_{i}}\left(\mathrm{x}_{e}\right)=\nu_{i e}$ apresenta um valor de pertinência entre $[0,1]$. Como propriedades dessa função temos:

$$
\begin{aligned}
& \sum_{i=1}^{k} \nu_{i e}=1, \forall e \\
& 0<\sum_{e=1}^{t} \nu_{i e}<t
\end{aligned}
$$

Além dessas propriedades, necessitamos de mais dois conceitos: a matriz de pertinência $U$ e o expoente nebuloso $z$.

A matriz de pertinência $U$ é uma matriz de $k \times t$, representando $k$ grupos com $t$ padrões, contendo os valores de pertinência de cada padrão para cada grupo, cujo valor está entre $[0,1]$. O valor de $\nu_{i j}$ representa o quanto $\mathbf{x}_{j}$ é influenciado pelo protótipo $A_{i}$. Assim, a matriz de pertinência $U$ é representada como:

$$
U=\left[\begin{array}{cccc}
\nu_{11} & \nu_{12} & \cdots & \nu_{1 t} \\
\nu_{21} & \nu_{22} & \cdots & \nu_{2 t} \\
\vdots & \vdots & \ddots & \vdots \\
\nu_{k 1} & \nu_{k 2} & \cdots & \nu_{k t}
\end{array}\right]
$$

sendo que as propriedades 4.3 e 4.4 são satisfeitas. 
O expoente nebuloso $z$, também conhecido como fator de nebulisação ou grau de nebulosidade determina o quanto os grupos podem se sobrepor, indicando o grau de sobreposição entre os grupos. Este fator tem o intervalo de $[1, \infty)$, sendo $z=1$ quando o conjunto é não-nebuloso( "crisp"). Os valores de uso mais comuns para $z$ estão entre 1.25 e 2.0 [15]. Quando este valor tende a $\infty$, todos os valores de pertinência tenderão a $\frac{1}{k}$ [15]. Em nosso trabalho foi utilizado $z=2$. Mais detalhes sobre o expoente nebuloso, vide [24].

\subsubsection{Descrição do algoritmo e complexidade}

A idéia central do algoritmo é tentar minimizar a função $J$ :

$$
J(U, V)=\sum_{e=1}^{t} \sum_{i=1}^{k}\left(\nu_{i e}\right)^{z}\left(d_{i e}\right)^{2}
$$

Segue, então, uma descrição detalhada do algoritmo baseado em [15]:

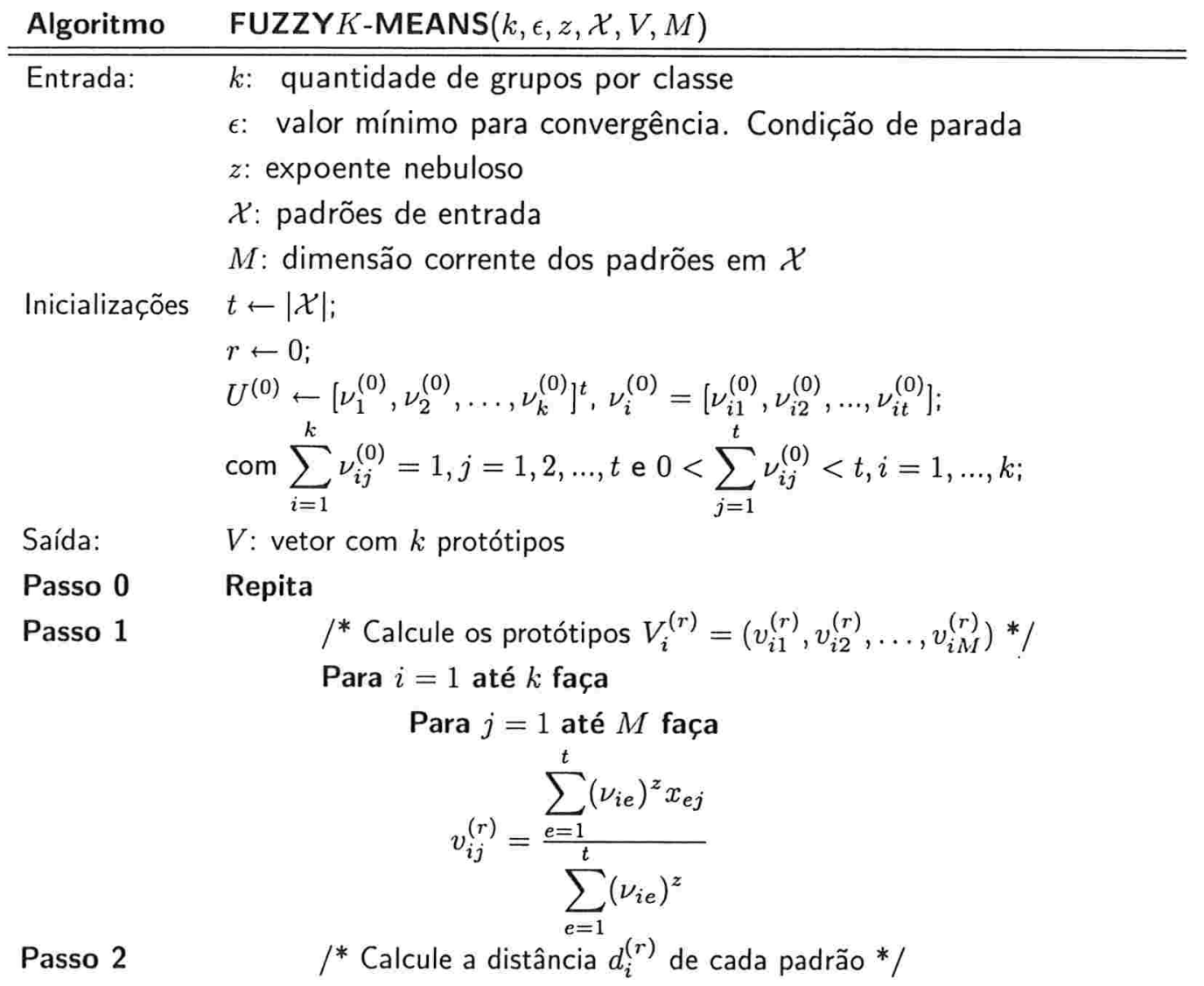


Passo 3:

Passo 3.1:

Passo 3.2:

Passo 4:

$$
\begin{aligned}
& r \leftarrow r+1 \\
& r e s u l t \leftarrow\left\|U^{(r)}-U^{(r-1)}\right\| \\
& U^{(r)} \leftarrow U^{(r-1)}
\end{aligned}
$$

Até que result $<\epsilon$ ou $\left(r>M A X_{-} L O O P\right)$.

Retorne $V$

Se $d_{i j}=0$ então

$\nu_{i j}=1$

$\nu_{e j}=0, \forall e \in[1, \ldots, k], e \neq i$

\section{Vá para o passo 2}

/* protótipos */

Senão

$$
\nu_{i j}=\left[\sum_{l=1}^{k}\left(\frac{d_{i j}}{d_{l j}}\right)^{\frac{2}{z-1}}\right]^{-1}
$$

Para $j=1$ até $t$ faça

$$
d_{i j}^{(r)}=\left\|\mathbf{x}_{j}-V_{i}^{(r)}\right\|=\left[\sum_{e=1}^{t}\left(x_{j e}-v_{i e}^{(r)}\right)^{2}\right]^{\frac{1}{2}}
$$

/* Computar $U^{(r+1)}$, como se segue: */

/* Se existir alguma distância $d_{i j}$ igual a zero, então*/

/* o padrão pertence somente a este grupo. */

/* Senão, a matriz de pertinência é a média */

/* ponderada das distâncias para todos os */ 


\subsubsection{Eficiência e validação de agrupamento}

Nas aplicações práticas, necessita-se medir a qualidade do resultado do agrupamento, verificando se a quantidade de agrupamentos (subclasses de uma classe no nosso caso) foi escolhida adequadamente. Para determinar se essa quantidade é boa, algumas funções de validação foram estudadas. Em nosso trabalho, somente os índices FPI e MPE serão detalhados, devido a utilização destes índices como medida de performance do fuzzy $k$-means em um estudo feito por Boydell e McBratney [8] com o software FuzME ${ }^{1}$ utilizando o algoritmo fuzzy k-means.

Seja $t$ o número de padrões, $k$ o número de agrupamentos e $\nu$ a função de pertinência.

O índice de performance de "nebulosidade" (FPI Fuzziness performance index) é definido como [32]:

$$
F P I(k)=1-\frac{k F-1}{k-1}
$$

em que $F$ é o coeficiente de partição:

$$
F=\frac{1}{t} \sum_{i=1}^{t} \sum_{j=1}^{k} \nu_{i j}^{2}
$$

A entropia de partição modificada(MPE Modified Partition Entropy), também conhecida como entropia de classificação normalizada(NCE Normalised Classification Entropy), é definida como [32]:

$$
M P E(k)=\frac{H}{\log k}
$$

em que $H$ é a função de entropia:

$$
H=-\frac{1}{t} \sum_{i=1}^{t} \sum_{j=1}^{k} \nu_{i j} \log \left(\nu_{i j}\right)
$$

O FPI é uma medida do grau em que classes diferentes compartilham pertinência e está restrito a valores entre 0 e 1 . À medida que FPI aproxima de 1 , aumenta pertinência compartilhada. À medida que aproxima de 0, classes tornam-se mais distintas com menos pertinência compartilhada. Quando o valor é 0, classes não são mais nebulosas, mas são

\footnotetext{
${ }^{1} \mathrm{O}$ programa FuzME foi desenvolvido pelo Centro para precisão agrícola da Austrália. $\mathrm{URL}=$ http://www.usyd.edu.au/su/agric/acpa
} 
consideradas "crisp".

O MPE é uma estimação do tamanho da desorganização criada por um número específico de classes. Da mesma forma que FPI, os valores variam entre 0 e 1 . À medida em que MPE aproxima de 1, desorganização é predominante enquanto valores próximos de 0 indicam uma excelente organização. Tanto o FPI, quanto o MPE, somente modelam a variação nos atributos usados para avaliar a classificação $[8,20]$. De acordo com os estudos realizados em [20], o FPI e o MPE podem ser utilizados para avaliar a eficiência do agrupamento, sendo utilizado para determinar um bom valor para $k$.

A partir de um método de análise do $\operatorname{par}(F P I, M P E)$ apresentado de forma gráfica em [20] para a escolha de $k$, apresentamos um algoritmo para se obter um bom valor de $k$, expresso pela função CALCULA_MELHOR_K $\left(\epsilon, z, \omega_{1}, \ldots, \omega_{c}\right)$ que retorna o maior valor de $k$ tal que:

$$
C A L C U L A \_M E L H O R_{-} K()=\max _{k}\left(H_{k}\left(\omega_{i}\right)\right), \omega_{i} \in \Omega, i=1, \ldots, c
$$

em que a função $H_{k}(\cdot)$ obedece as seguintes condições:

$$
H_{k}\left(\omega_{i}, F P I(k), M P E(k)\right)= \begin{cases}0<F P I(k)<F P I(k+1)<1 & k<k_{\text {lim }} \\ 0<M P E(k)<M P E(k+1)<1 & k<k_{\text {lim }}\end{cases}
$$

onde $k_{\text {lim }}=\max \left(\left\lceil\frac{\left|\omega_{i}\right|}{10}\right\rceil,\left|\omega_{i}\right|\right)$ e $\left|\omega_{i}\right|$ representa o número de padrões existentes na classe $\omega_{i}$.

Esta função poderá ser utilizada após a execução do SFFS ou SFBS, para que uma nova execução do programa de seleção de características seja feita com este valor de $k$. Isto evita que se calcule $H_{k}()$ toda vez que for determinar os protótipos, o que poderia tornar muito lenta a execução do programa de seleção. Para mais detalhes sobre FPI e MPE, vide [20, 27, 32].

\subsubsection{Descrição do algoritmo e complexidade}

Para calcular o valor que melhor representa a quantidade de subclasses por classe, propusemos o seguinte algoritmo: 


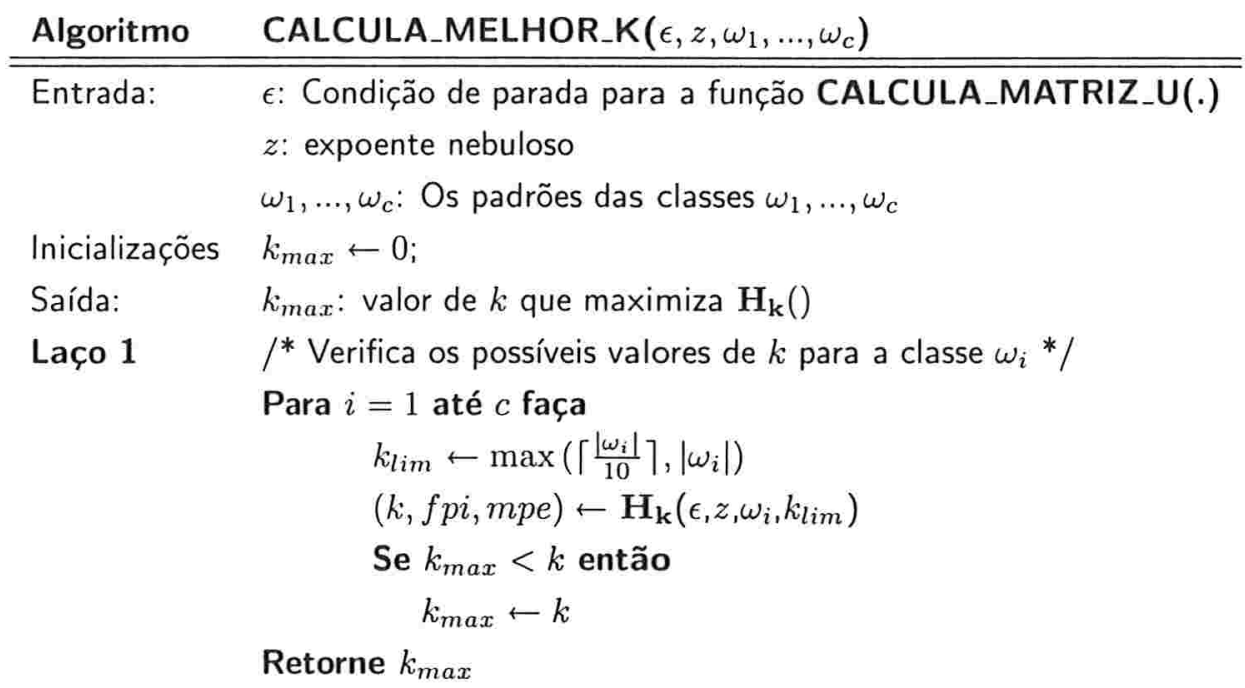

Sendo que a função $\mathbf{H}_{\mathbf{k}}($.$) é calculada através do seguinte algoritmo:$

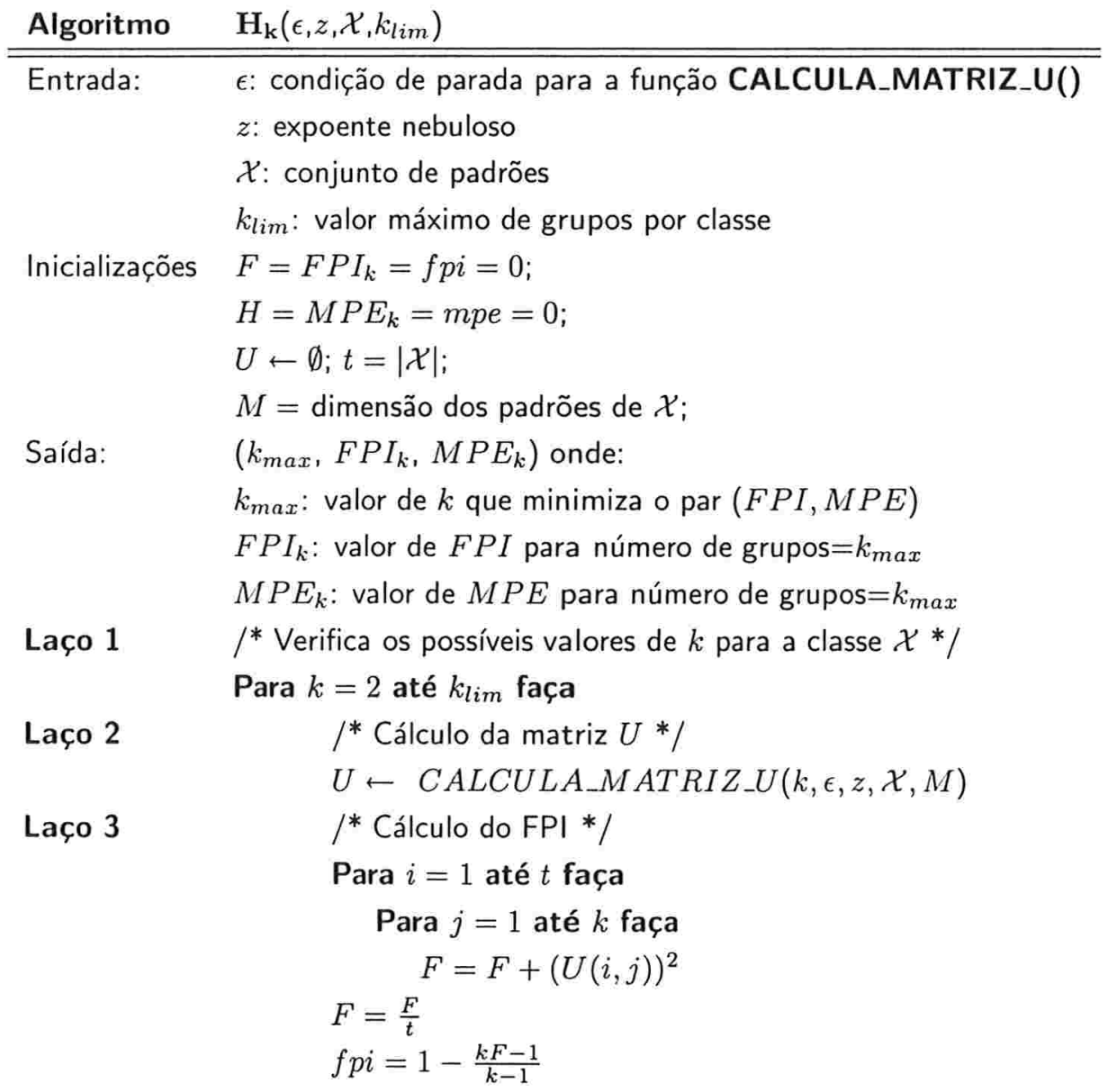




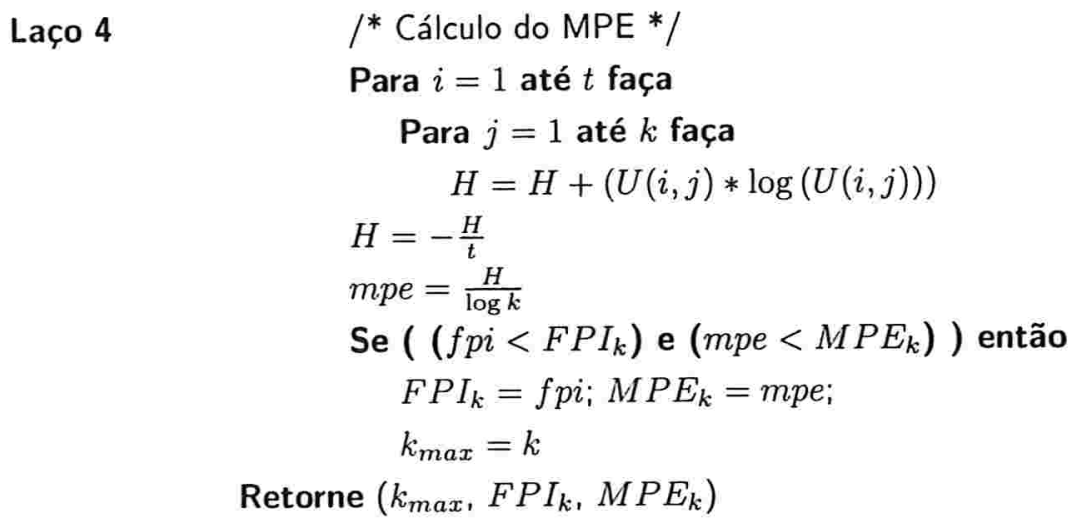

Sendo que a função CALCULA_MATRIZ_U $(k, \epsilon, z, \mathcal{X}, M)$ é calculada através do seguinte algoritmo:

\begin{tabular}{ll} 
Algoritmo & CALCULA_MATRIZ_U $(k, \epsilon, z, \mathcal{X}, M)$ \\
\hline \hline Entrada: & $k:$ quantidade de grupos por classe \\
& $\epsilon:$ condição de parada \\
& $z:$ expoente nebuloso \\
& $\mathcal{X}:$ conjunto de padrões \\
& $M:$ dimensão corrente dos padrões \\
& $t \leftarrow|\mathcal{X}| ;$ \\
& $r \leftarrow 0 ;$ \\
& $U^{(0)} \leftarrow\left[\nu_{1}^{(0)}, \nu_{2}^{(0)}, \ldots, \nu_{k}^{(0)}\right]^{t}, \nu_{i}^{(0)}=\left[\nu_{i 1}^{(0)}, \nu_{i 2}^{(0)}, \ldots, \nu_{i t}^{(0)}\right] ;$ \\
& $\operatorname{com} \sum_{i=1}^{k} \nu_{i j}^{(0)}=1, j=1,2, \ldots, t$ e $0<\sum_{j=1}^{t} \nu_{i j}^{(0)}<t, i=1, \ldots, k ;$ \\
Saída: & $U:$ matriz de pertinência $\mathrm{U}$
\end{tabular}

Laço 0

Repita

Passo $1 \quad / *$ Calcule os protótipos $V_{i}^{(r)}=\left(v_{i 1}^{(r)}, v_{i 2}^{(r)}, \ldots, v_{i M}^{(r)}\right) * /$

Para $i=1$ até $k$ faça

Para $j=1$ até $M$ faça

$$
v_{i j}^{(r)}=\frac{\sum_{e=1}^{t}\left(\nu_{i e}\right)^{z} x_{e j}}{\sum_{e=1}^{t}\left(\nu_{i e}\right)^{z}}
$$

Passo 2

/* Calcule a distância $d_{i}^{(r)}$ de cada padrão */

Para $j=1$ até $t$ faça

Passo 3:

$$
d_{i j}^{(r)}=\left\|\mathbf{x}_{j}-V_{i}^{(r)}\right\|=\left[\sum_{e=1}^{t}\left(x_{j e}-v_{i e}^{(r)}\right)^{2}\right]^{\frac{1}{2}}
$$

$$
\text { /* Computar } U^{(r+1)} \text {, como se segue: */ }
$$


Passo 3.1:

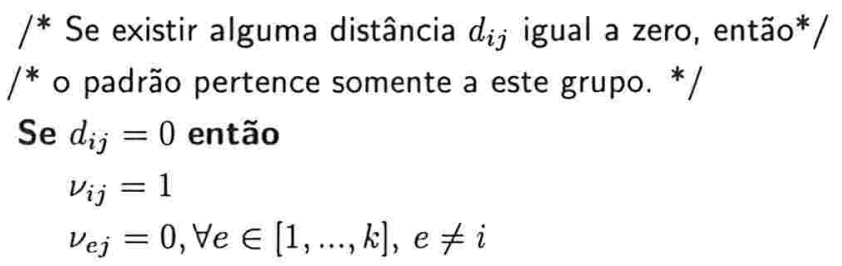

Passo 3.2:

Vá para o passo 2

/ Senão, a matriz de pertinência é a média */

/* ponderada das distâncias para todos os */

/* protótipos */

Senão

$$
\nu_{i j}=\left[\sum_{l=1}^{k}\left(\frac{d_{i j}}{d_{l j}}\right)^{\frac{2}{z-1}}\right]^{-1}
$$

Passo 4:

$$
\begin{aligned}
& r \leftarrow r+1 \\
& \text { result } \leftarrow\left\|U^{(r)}-U^{(r-1)}\right\| \\
& U^{(r)} \leftarrow U^{(r-1)}
\end{aligned}
$$

Pode-se mostrar que a complexidade do algoritmo CALCULA_MELHOR_K é de $O(c) . O\left(\mathbf{H}_{\mathbf{k}}\right)$, com $c$ o número de classes.

Em relação ao algoritmo $\mathbf{H}_{\mathbf{k}}$, a complexidade do algoritmo é $O\left(k_{\text {lim }} \cdot\{O(\right.$ laço 2$)+O$ (laço $3)+O($ laço 4) $\})$. A complexidade dos laços 3 e 4 é de $O\left(c_{3} \cdot t . k+c_{4} \cdot t . k\right)=O(t . k)$, onde $c_{3}, c_{4}$ são constantes, e a instrução 2 tem complexidade $O$ (CALCULA_MATRIZ_U). Então, a complexidade do algoritmo $\mathbf{H}_{\mathbf{k}}$ é $O\left(k_{\text {lim }} \cdot\{O(t . k)+O(\right.$ CALCULA_MATRIZ_U) $\}$.

Em relação ao algoritmo CALCULA_MATRIZ_U, a complexidade das instruções 1 e 2 é $O(t . k)$, sendo $t$ o número de padrões de entrada e $k$ o número de grupos desejados. A instrução 3 apresenta $O(k)$ para as instruções 3.1, 3.2 e 3.3, totalizando $O(k)$. A instrução 4 é executada em $O\left(c_{1} \cdot t . k+c_{2} \cdot t . k+c_{3}\right)=O(t . k)$, onde $c_{1}, c_{2}, c_{3}$ são constantes. Assim, o bloco de instruções 1 a 4 tem a complexidade $O(t . k)$. Portanto, o algoritmo CALCULA_MATRIZ_U apresenta complexidade $O(t . k . r)$, sendo $r$ o número de iterações do bloco de instruções 1 a 4 .

Com a complexidade de CALCULA_MATRIZ_U definida, temos que a complexidade de $\mathrm{H}_{\mathbf{k}}$ é $O\left(k_{\text {lim }}\right) \cdot O(t . k . r)=O\left(k^{2} . t . r\right)$. Portanto, a complexidade do algoritmo CALCULA_MELHOR_K é de $O(c) . O\left(k^{2} . t . r\right)$, onde $c$ é o número de classes, $k$ é o número de grupos por classe, $t$ é o número de amostras e $r=M A X_{-} L O O P^{2}$.

\footnotetext{
${ }^{2}$ o mesmo valor de MAX_LOOP da página 34 foi utilizado
} 


\subsubsection{Processo de obtenção de conjuntos nebulosos}

Para se utilizar a distância nebulosa baseada em tolerância como função critério, devese inicialmente, transformar os conjuntos de padrões de treinamento em conjuntos nebulosos. Esse processo é chamado de "fuzzificação".

A função de "fuzzificação" utilizada em [10] para protótipo único por classe foi definida como:

$$
\nu_{\omega}(\mathbf{x})= \begin{cases}\frac{1}{1+d\left(\mathbf{x}, p_{j}^{\omega}\right)} & \mathbf{x} \in \omega \\ 0 & \mathbf{x} \notin \omega\end{cases}
$$

para $j=1,2, \ldots, \mathbf{S}$, em que $\mathbf{x}$ é um padrão, $\nu_{\omega}(\mathbf{x})$ é a função de pertinência desse padrão ao conjunto $\omega, p_{j}^{\omega}$ representa o $j$-ésimo protótipo da classe $\omega$ e $d($.) é a distância Euclidiana, sendo $\mathbf{S}$ o número de protótipos disponíveis para cada classe. Em [10], essa função de "fuzzificação" utiliza somente um protótipo por classe, sendo o centróide da classe $\omega$ o protótipo escolhido para cada classe.

$\mathrm{Na}$ seção 4.2 .2 foi apresentada a principal motivação para a abordagem de múltiplos protótipos por classe. Assim, a definição da nova função de "fuzzificação", introduzida nesta dissertação, é:

$$
\nu_{\omega_{i}}(\mathbf{x})=\max _{j=1,2, \ldots, k}\left(\frac{1}{1+d\left(\mathbf{x}, p_{j}^{\omega_{i}}\right)}\right)
$$

em que $\mathbf{x}$ é um padrão, $\nu_{\omega_{i}}(\mathbf{x})$ é a função de pertinência desse padrão à classe $\omega_{i}, 1 \leq$ $i \leq c, p_{j}^{\omega_{i}}$ representa o $j$-ésimo protótipo da classe $\omega_{i}$, com $1 \leq j \leq k$, e $d($.) é a distância Euclidiana. A idéia por trás desta abordagem é que a divisão de cada classe em partes faz cada protótipo mais representativo de sua respectiva parte do que um protótipo único para todas as partes. A escolha do máximo na equação 4.13 foi feita com o intuito de, se um padrão está próximo de um dos protótipos de uma classe, então ela deve ser considerada mais "típica" desta classe do que um outro padrão que está mais longe. Desta forma, um padrão próximo de um dado protótipo deve ter um alto grau de pertinência.

Além do uso de múltiplos protótipos por classe, a equação de fuzzificação 4.13 apresenta uma outra diferença em relação à equação 4.12 , em que $\nu_{\omega}(\mathbf{x})$ depende da distância entre o padrão x e um protótipo $p_{j}^{\omega}$ mesmo que eles correspondam a classes distintas. Desta forma, existirá uma influência das distância dos protótipos de classes diferentes, sendo esta influência menor quanto mais distantes e compactas forem as diferentes classes, e maior quanto mais sobrepostos forem as diferentes classes. 
Desta forma, seja $\omega_{1}$ e $\omega_{2}$ duas classes distintas, e $\mathrm{x} \in \omega_{1}$ e $p_{j}^{\omega_{2}}$, um protótipo de $\omega_{2}$. No caso da equação 4.12 o valor de $\nu_{\omega_{2}}=0$, pois $\mathrm{x} \notin \omega_{2}$. No entanto, pela equação 4.13 tem-se que $\nu_{\omega_{2}} \neq 0$. Desta forma, a equação 4.13 considera que existe uma influência, ainda que pequena, dos protótipos da classe $\omega_{2}$ sobre as amostras da classe $\omega_{1}$ através do valor de $\nu_{\omega_{2}}(\mathrm{x})$.

\subsubsection{Distância Nebulosa}

A função critério proposta em [11] está baseada em uma medida de tolerância proposta em [25]. Esta distância é baseada em uma diferença local (com relação a um padrão x) entre duas classes, definida como:

$$
d_{\mathbf{x}}^{\tau}\left(\nu_{\omega_{i}}, \nu_{\omega_{j}}\right)=\inf _{\mathbf{y}, \mathbf{z} \in \mathcal{B}(\mathbf{x}, \tau)}\left|\nu_{\omega_{i}}(\mathbf{y})-\nu_{\omega_{j}}(\mathbf{z})\right|
$$

em que $\mathcal{B}(\mathrm{x}, \tau)$ denota uma bola de dimensão $N$ de raio $\tau$ e centro $\mathbf{x}$. Seu papel é fazer as regiões sobrepostas de duas classes influenciarem a resposta da função critério. O parâmetro $\tau$ é chamado de tolerância dessa distância. Assim, a distância nebulosa baseada em tolerância é definida por:

$$
d_{p}^{\tau}\left(\nu_{\omega_{i}}, \nu_{\omega_{j}}\right)=\left[\int_{F}\left[d_{\mathbf{x}}^{\tau}\left(\nu_{\omega_{i}}, \nu_{\omega_{j}}\right)\right]^{p} d \mathbf{x}\right]^{\frac{1}{p}}
$$

onde $F$ representa o espaço de características [25]. Em nossa experiência, utilizamos $p=2$.

É importante notar que a função critério acima está definida para duas classes. No entanto, problemas de reconhecimento de padrões com dados reais usualmente envolvem mais que duas classes, sendo portanto, importante definir uma função critério $g_{p}^{\tau}($.$) que$ possa avaliar a separabilidade de $c$ classes $(c>2)$. Um possível modo é obter o menor valor de separabilidade entre todos os pares de classes no espaço de características:

$$
g_{p}^{\tau}\left(\nu_{1}, \nu_{2}, \ldots, \nu_{c}\right)=\inf _{i, j \in\{1, \ldots, c\} ; i \neq j} d_{p}^{\tau}\left(\nu_{i}, \nu_{j}\right)
$$

Entretanto, pode-se mostrar que é possível obter resultados equivalentes de um modo mais eficiente com relação ao custo computacional. Isto pode ser feito por modificação 
de medida local (Equação 4.14), obtendo uma função que calcule uma medida local de separabilidade $f_{\mathbf{x}}^{\tau}($.$) entre todos os padrões de todas as classes no espaço de características:$

$$
f_{\mathbf{x}}^{\tau}\left(\nu_{1}, \nu_{2}, \ldots, \nu_{c}\right)=\inf _{\mathbf{y}, \mathbf{z} \in \mathcal{B}(\mathbf{x}, \tau) ; i, j \in\{1, \ldots, c\} ; i \neq j}\left|\nu_{i}(\mathbf{y})-\nu_{j}(\mathbf{z})\right|
$$

Então, a função critério $f_{p}^{\tau}($.$) pode ser definida como:$

$$
f_{p}^{\tau}\left(\nu_{1}, \nu_{2}, \ldots, \nu_{c}\right)=\left[\int_{F}\left[f_{\mathbf{x}}^{\tau}\left(\nu_{1}, \nu_{2}, \ldots, \nu_{c}\right)\right]^{p} d \mathbf{x}\right]^{\frac{1}{p}}
$$

\subsubsection{Algoritmo e complexidade}

Para efetuar o cálculo dessa medida de distância, propusemos o seguinte algoritmo:
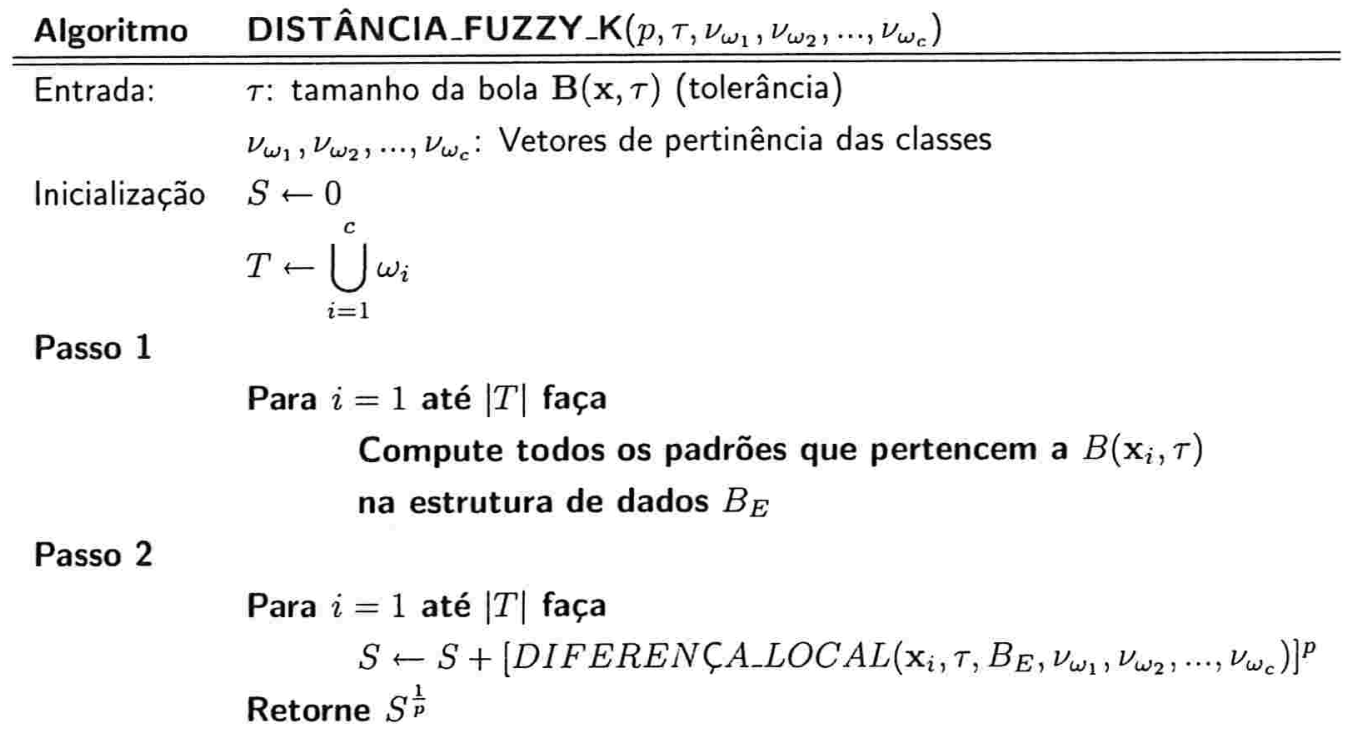

Sendo que a DIFERENÇA_LOCAL é calculada através do seguinte algoritmo: 


\begin{tabular}{ll} 
Algoritmo & DIFERENÇA_LOCAL $\left(\mathrm{x}_{i}, \tau, B_{E}, \nu_{\omega_{1}}, \nu_{\omega_{2}}, \ldots, \nu_{\omega_{c}}\right)$ \\
\hline \hline Entrada: & $\mathrm{x}_{i}:$ padrão a ser analisado \\
& $\tau:$ raio da bola $B_{E}$ \\
& $B_{E}:$ bola com centro $\mathrm{x}_{i}$ e raio $\tau$ \\
& $\nu_{\omega_{1}}, \nu_{\omega_{2}}, \ldots, \nu_{\omega_{c}}:$ Vetores de pertinência das classes \\
& $D_{\text {min }} \leftarrow$ MAIOR NÚMERO INTEIRO POSSÍVEL \\
& $b \leftarrow$ NÚMERO DE PADRÕES NA BOLA $B\left(\mathrm{x}_{i}, \tau\right)$
\end{tabular}

Laço 1

Laço 2

$$
\text { Para } i=1 \text { até } b \text { faça }
$$

Para $j=i+1$ até $b$ faça

$$
\text { Se } \begin{aligned}
D & \leftarrow \text { ÍNFIMO }\left(\mathbf{x}_{i}, \mathbf{x}_{j}, \nu_{\omega_{1}}, \nu_{\omega_{2}}, \ldots, \nu_{\omega_{c}}\right) \\
D_{\min } & \geq D \text { então }
\end{aligned}
$$$$
D_{\min } \leftarrow D
$$

Retorne $D_{\min }$

Sendo que o ÍNFIMO é calculado através do seguinte algoritmo:

\begin{tabular}{ll} 
Algoritmo & ÍNFIMO $\left(\mathrm{y}, \mathbf{z}, \nu_{\omega_{1}}, \nu_{\omega_{2}}, \ldots, \nu_{\omega_{c}}\right)$ \\
\hline \hline Entrada: & y, z: padrões a serem analisados \\
& $\nu_{\omega_{1}}, \nu_{\omega_{2}}, \ldots, \nu_{\omega_{c}}:$ Vetores de pertinência das classes \\
Inicialização & $D_{\min } \leftarrow$ MAIOR NÚMERO INTEIRO POSSÍVEL \\
Laço 1 & Para $i=1$ até $c$ faça \\
Laço 2 & Para $j=1$ até $c$ faça \\
& Se $i \neq j$ então \\
& $D \leftarrow\left|\nu_{\omega_{i}}(\mathbf{y})-\nu_{\omega_{j}}(\mathbf{z})\right|$ \\
& Se $D_{\min } \geq D$ então \\
& $D_{\min } \leftarrow D$ \\
& Retorne $D_{\min }$
\end{tabular}

Pode-se mostrar que a complexidade do algoritmo DISTÂNCIA_FUZZY_K é de $O\left(|T|^{2}\right)$ e a complexidade da instrução 2 é igual a $O(|T|)$.O(DIFERENÇA_LOCAL).

Em relação ao algoritmo DIFERENÇA_LOCAL, a complexidade do laço 1 e 2 é de $O\left(b^{2}\right) . O($ ÍNFIMO).

No algoritmo ÍNFIMO, a complexidade do laço 1 e 2 é de $O\left(c^{2}\right)$, onde $c$ é o número de classes existentes no conjunto de treinamento. Assim, supondo que $\forall x \in T$ o número de padrões nas bolas $B(\mathrm{x}, \tau)$ é $b$, então a complexidade do algoritmo DISTÂNCIA_FUZZY_K é de $O\left(|T|^{2}\right)+O(|T|) \cdot O\left(b^{2}\right) \cdot O\left(c^{2}\right)$.

Assim, no melhor caso (em termos de tempo de execução), se $\tau$ for tão pequeno que $B(\mathbf{x}, \tau)$ contenha apenas $\mathbf{x}, \forall \mathbf{x} \in T$, a complexidade do algoritmo será $O\left(|T|^{2}\right)+O(|T|)=$ 
$O\left(|T|^{2}\right)$. No pior caso, se $\tau$ for tão grande que $B(\mathbf{x}, \tau)$ contenha todos os padrões de $|T|$, a complexidade desse algoritmo será $O\left(|T|^{2}\right)+O(|T|) \cdot O\left(|T|^{2}\right)=O\left(|T|^{3}\right)$, ou seja, a complexidade é igual a $O\left(|T|^{3}\right)$.

\subsubsection{Considerações sobre o comportamento da função critério}

Nesta seção, serão discutidas as principais propriedades dessa abordagem, as quais nos motivaram a utilizá-la em seleção de características. Tais propriedades se relacionam com a distância entre os protótipos (suportes) das classes diferentes e com o quão os conjuntos são compactos (compacidade). Cada parâmetro das equações 4.14 e 4.15 será discutido isoladamente, sendo posteriormente analisados os resultados da integração desses parâmetros nessas equações. Para facilitar a ilustração dos casos, os resultados a serem mencionados em relação à compacidade são válidos para conjuntos (classes de padrões) com distribuições aproximadamente isotrópicas. Posteriormente, há uma discussão considerando casos genéricos.

1. Número de protótipos por classe: Definindo a distância mínima entre protótipos de classes diferentes como $\min _{i, j \in\{1, \ldots, c\} ; i \neq j ; a, b \in\{1, \ldots, k\} ; a \neq b} d\left(p_{a}^{\omega_{i}}, p_{b}^{\omega_{j}}\right)$ e fixando-se o raio da bola $\tau$ e a distância entre os protótipos de classes diferentes, quando aumentase o número de protótipos por classe, os valores de $\nu_{\omega_{i}}\left(\mathbf{x}_{i}\right), \forall \mathbf{x}_{i} \in \omega_{i}$ tendem a aumentar, pois a pertinência entre os padrões da classe tendem a aumentar. Sendo assim, com o aumento do número de protótipos por classe, aumenta-se a "compacidade" da classe. De forma análoga, diminuindo-se o número de protótipos por classe, diminuem-se os valores de $\nu_{\omega_{i}}\left(\mathbf{x}_{i}\right)$, para a maioria dos padrões $\mathbf{x}_{i} \in \omega_{i}$, tornando menos "compacta" a classe. Por isso, a determinação do número de protótipos por classe $(k)$ é de grande importância, apesar de não existirem critérios simples para a escolha deste $k$, conforme mencionado na subseção 4.2.2.

2. Compacidade: Fixando-se a distância entre os protótipos de classes diferentes e o raio da bola $\tau$, quando a distribuição de uma classe $\omega_{i}$ for compacta (possuir compacidade grande), para a maioria dos padrões $\mathbf{x}_{i} \in \omega_{i}$, os valores de $\nu_{\omega_{i}}\left(\mathbf{x}_{i}\right)$ serão grandes, pois o grau de pertinência de um padrão a sua classe é inversamente proporcional à distância entre esse e o protótipo dessa classe. Caso contrário, quando a compacidade da classe for grande, os valores de $\nu_{\omega_{i}}\left(\mathbf{x}_{i}\right)$ serão pequenos para a maioria dos padrões $\mathbf{x}_{i}, \mathbf{x}_{i} \in \omega_{i}$. 
3. Distância entre protótipos de classes diferentes: Seja $\omega_{i}$ e $\omega_{j}$ duas classes e $\mathbf{x}, \mathbf{y}, \mathbf{z}$ padrões com $\mathbf{y} \in \omega_{i}$ e $\mathbf{z} \in \omega_{j}, \mathbf{x} \in \omega_{i} \bigcup \omega_{j}$, fixando-se a compacidade da distribuição das classes de padrões e o raio da bola $\tau$, quando a distância entre os protótipos de classes diferentes for grande, será mais provável que um dado padrão $\mathrm{x}$ esteja próximo do protótipo de uma classe e distante da outra. Sendo $p^{\omega_{i}}$ o protótipo que se encontra mais próximo do padrão $\mathrm{x}$ e $p^{\omega_{j}}$, o protótipo que se encontra mais distante do padrão $\mathbf{x}$, o valor de $\nu_{\omega_{i}}(\mathbf{y})$ será grande, e o valor de $\nu_{\omega_{j}}(\mathbf{z})$ será pequeno. Com isso, $\left|\nu_{\omega_{i}}(\mathrm{y})-\nu_{\omega_{j}}(\mathbf{z})\right|$ será grande. Se isso ocorrer na maioria dos padrões dentro da bola $\mathcal{B}(\mathrm{x}, \tau)$, o valor de $d_{\mathrm{x}}^{\tau}$ será grande. Como isso provavelmente ocorrerá para a maioria dos padrões, o valor total da distância $d_{p}^{\tau}\left(\nu_{\omega_{i}}, \nu_{\omega_{j}}\right)$ será grande. Caso a distância entre os protótipos de classes diferentes seja pequena, seguindo o mesmo raciocínio, conclui-se que o valor de $d_{p}^{\tau}\left(\nu_{\omega_{i}}, \nu_{\omega_{j}}\right)$ será pequeno.

4. Tamanho da bola: Fixando-se a distância entre os protótipos e a compacidade, devemos considerar dois casos:

- Quando for utilizada uma bola muito pequena, para todos os padrões x, a bola $\mathcal{B}(\mathrm{x}, \tau)$ irá conter somente os padrões da classe de $\mathrm{x}$. Nesse caso, a seguinte igualdade será válida: $d_{\mathbf{x}}^{\tau}=\nu_{\omega_{l}}(\mathbf{x})$, para $\mathbf{x} \in \omega_{l}, \omega_{l}=\omega_{i}$ ou $\omega_{l}=\omega_{j}$.

Com isso,

$$
d_{p}^{\tau}\left(\nu_{\omega_{i}}, \nu_{\omega_{j}}\right)=\left[\int_{F}\left[\nu_{\omega_{l}}(\mathbf{x})\right]^{p} d \mathbf{x}\right]^{\frac{1}{p}}
$$

o que significa que o valor de $d_{p}^{\tau}\left(\nu_{\omega_{i}}, \nu_{\omega_{j}}\right)$ será exclusivamente dependente da compacidade das classes.

- Quando for utilizada uma bola muito grande, para qualquer padrão $\mathrm{x}, \mathcal{B}(\mathrm{x}, \tau)$ conterá todos os padrões de treinamento do espaço de características. Com isso, pode-se mostrar que a seguinte igualdade se torna válida:

$$
d_{p}^{\tau}\left(\nu_{\omega_{i}}, \nu_{\omega_{j}}\right)=\left[|T| \cdot\left[\inf _{\mathbf{y}, \mathbf{z} \in F}\left|\nu_{\omega_{i}}(\mathbf{y})-\nu_{\omega_{j}}(\mathbf{z})\right|\right]^{p}\right]^{\frac{1}{p}}
$$

Como resultado, a importância da compacidade e da distância entre os protótipos é reduzida, pois o valor da métrica dependerá exclusivamente da mínima diferença global entre o grau de pertinência de dois padrões de classes diferentes. Assim, não importando a distribuição dos padrões no espaço de características, se existirem dois padrões y e $\mathbf{z}$ tais que $\nu_{\omega_{i}}(\mathbf{y})=\nu_{\omega_{j}}(\mathbf{z})$, então teremos em 


$$
d_{p}^{\tau}\left(\nu_{\omega_{i}}, \nu_{\omega_{j}}\right)=0
$$

Por isso, a determinação do valor de $\tau$ é muito importante na utilização da distância de [25] como função critério. Para determinar o melhor valor de $\tau$ para um dado conjunto de padrões de treinamento, uma estratégia possível é a de tentativa e erro com vários valores de $\tau$, sendo que o valor máximo deve ser menor que o $\sup _{\mathbf{y}, \mathbf{z} \in F} d_{E}(\mathbf{y}, \mathbf{z})$.

Considerando a utilização de uma bola cujo tamanho seja ideal para avaliar um determinado conjunto de características com um certo conjunto de treinamento de duas classes, podemos construir uma lista de possibilidades, denotando por $d_{1 a}, d_{1 b}, d_{2 a}, d_{2 b}, d_{3 a}, d_{3 b}$ e seus prováveis resultados. Na figura 4.3, os protótipos representados são os baricentros das respectivas classes.

1. Se ambas as classes são compactas e ...

(a) a distância entre os protótipos é pequena $\Rightarrow d_{p}^{\tau}\left(\nu_{\omega_{i}}, \nu_{\omega_{j}}\right)=d_{1 a}$

(b) a distância entre os protótipos é grande $\Rightarrow d_{p}^{\tau}\left(\nu_{\omega_{i}}, \nu_{\omega_{j}}\right)=d_{1 b}$

2. Se ambas as classes são esparsas e ...

(a) a distância entre os protótipos é pequena $\Rightarrow d_{p}^{\tau}\left(\nu_{\omega_{i}}, \nu_{\omega_{j}}\right)=d_{2 a}$

(b) a distância entre os protótipos é grande $\Rightarrow d_{p}^{\tau}\left(\nu_{\omega_{i}}, \nu_{\omega_{j}}\right)=d_{2 b}$

3. Uma classe possui compacidade grande e a outra possui compacidade pequena e ...

(a) a distância entre os protótipos é pequena $\Rightarrow d_{p}^{\tau}\left(\nu_{\omega_{i}}, \nu_{\omega_{j}}\right)=d_{3 a}$

(b) a distância entre os protótipos é grande $\Rightarrow d_{p}^{\tau}\left(\nu_{\omega_{i}}, \nu_{\omega_{j}}\right)=d_{3 b}$

A figura 4.3 ilustra esses casos. Considerando que as duas classes possuem distribuições aproximadamente isotrópicas e que a bola $\mathcal{B}(\mathbf{x}, \tau)$ possui tamanho ideal, podemos afirmar que, intuitivamente, é mais provável que a distância $d_{1 b}$ será maior que todas as outras. Da mesma forma, podemos dizer que as distâncias $d_{3 b}$ e $d_{2 b}$ provavelmente serão maiores que a distância $d_{2 a}$. $d_{1 a}$ provavelmente será menor que $d_{3 a}$ que, por sua vez, provavelmente será menor que $d_{2 a}$.

Ao utilizarmos a distância nebulosa baseada em tolerância, pode-se dizer que a influência do número de padrões de classes diferentes que a bola $\mathcal{B}(\mathrm{x}, \tau)$ engloba tem mais importância que a distância entre os protótipos para diferentes $\mathbf{x}$. A bola $\mathcal{B}(\mathrm{x}, \tau)$ 
1.(a) $\odot \odot$

2.(a)

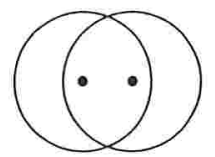

3.(a)

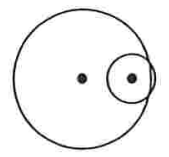

1.(b)

(-)

(2)

2.(b)
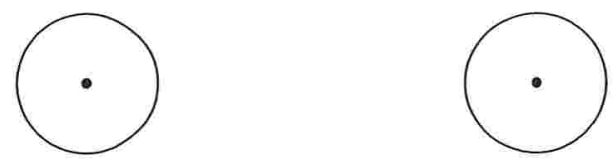

(-)

Figura 4.3: Exemplos de distribuições de duas classes em um espaço de características com dimensão 2. Cada círculo representa a compacidade de uma classe e os pontos representam protótipos. Extraído de [10] 
serve como uma medida de sobreposição das distribuições das classes no espaço de características, sendo que o valor da função critério será menor quanto mais sobrepostas estiverem as classes [10].

Fazendo uma análise sobre o comportamento das duas funções critério, a de protótipo único e a de múltiplos protótipos, na figura 4.3, podemos concluir que, intuitivamente, a função critério com múltiplos protótipos apresenta valores maiores para classes representadas em 1a, 1b, 2b e 3b. Isto decorre do aumento do número de protótipos, que melhora a pertinência dos padrões da classe, e da distância entre os padrões de uma classe aos protótipos de classes diferentes serem maiores, maximizando a equação 4.17, e portanto, maximizando o valor da função critério com múltiplos protótipos. 


\section{CAPÍTULO \\ 5 \\ Experimentos e resultados}

\subsection{Considerações preliminares}

Os experimentos deste trabalho foram realizados de forma a ilustrar a eficácia da distância nebulosa com múltiplos protótipos como função critério em problemas de seleção de características. Todos os experimentos foram executados com a função critério de protótipo único e a de múltiplos protótipos, fixando-se os parâmetros em comum, como o algoritmo de busca e seus parâmetros. Como método de seleção de características, utilizou-se somente o SFSM (Métodos de Busca Seqüencial Flutuante), com a seguinte estratégia de execução: se $M<\frac{N}{2}$ então executa busca para frente (SFFS); senão, executa busca para trás (SFBS), sendo $N$ a dimensão total do espaço de características e $M$ a dimensão a ser selecionada. Quanto aos parâmetros das funções critério, os valores de $p=2$ e de $z=2$ foram fixados nos experimentos.

A nova função critério difere em relação à função com protótipo único em dois pontos:

1. o número de protótipo por classe,

2. a distância entre os protótipos de classes diferentes, que na abordagem de protótipo único, não era considerado.

Desta forma, os dados sintéticos (ou simulados) foram gerados com o intuito de avaliar como estas duas alterações irão influenciar nas equações 4.17 e 4.18 o resultado da função 
critério. Na seção seguinte, estão descritos os experimentos com dados sintéticos. Além disso, foram realizados testes com os dados extraídos da base de dados existentes em UCI [6].

\subsection{Dados sintéticos}

O conjunto de padrões de entrada geradas artificialmente, com os padrões obedecendo uma mistura de distribuições Gaussianas, foram usados como dados sintéticos. A subseção 5.2.1 descreve o que foi feito em comum em todos os experimentos com dados sintéticos. Nas subseções subseqüentes, serão apresentados os tipos de experimentos com dados sintéticos, com a descrição desses dados e dos resultados obtidos.

\subsubsection{Descrição dos experimentos}

Todos os experimentos com dados sintéticos foram submetidos às seguintes condições:

- Todos os dados sintéticos gerados possuem distribuições Gaussianas ou mistura de distribuições Gaussianas, com dimensão do espaço de características igual a quatro $(\mathrm{N}=4)$;

- A dimensão a ser selecionada é igual a $2(M=2)$;

- A relação do conjunto de treinamento e de testes é de $\frac{2}{3}$, ou seja, $\frac{2}{3}$ como padrões de treinamento e $\frac{1}{3}$ como padrões de testes. Além disso, a cada execução do programa de seleção de características e classificação, os padrões que compõem o conjunto de treinamento e de testes foram sorteados aleatoriamente,

- o valor do tamanho da bola utilizada na distância nebulosa (parâmetro $\tau$ ) variou no intervalo entre 0.1 e 1.0, com deslocamentos de 0.1 a partir de 0.1 ;

- O programa de seleção de características e classificação executa primeiro a seleção de características e, posteriormente, a classificação, tendo como parâmetros de entrada os dados sintéticos, a dimensão a ser selecionada (M), o tamanho da bola $(\tau)$ e os parâmetros em comum descritos no início deste capítulo (vide seção 5.1);

- Este programa foi executado 100 vezes para cada valor de $\tau$; 
- Os classificadores utilizados foram os algoritmos de distância mínima ao protótipo (DMP) e KNN, com $\mathrm{K}=3$. Os valores da taxa de acerto desses classificadores expressos nas tabelas são as médias das 100 execuções realizadas para cada valor de $\tau$. Para cada valor médio da taxa de acerto, foi associado o respectivo desvio padrão;

- Para a função critério de múltiplos protótipos, utilizou-se 2 protótipos por classe.

\subsubsection{Classes compactas $\times$ distância entre classes diferentes}

Este conjunto de dados sintéticos foi gerado com a intenção de verificar qual a influência da distância entre os protótipos de classes diferentes na escolha do subconjunto de características entre duas funções critério analisadas. Este conjunto de dados sintéticos será chamado de conjunto sintético 1 .

\subsubsection{Descrição dos dados sintéticos}

O conjunto sintético 1 consiste de 1000 padrões de entrada de quatro características, e duas classes com 500 padrões por classe. Os padrões da classe $\omega_{1}$ são representados por círculos 'o' e os da classe $\omega_{2}$ por ' + ' nas figuras 5.1 .

A descrição da distribuição das duas classes nesse espaço de características é:

Características 1 e 2. Nessas características, os padrões possuem distribuições Gaussianas com médias diferentes, porém a distância entre os protótipos pequena (vide figura 5.1(a)). Note que ambas classes são compactas.

Características 3 e 4 . Nessas características, os padrões possuem distribuições Gaussianas com médias diferentes, porém a distância entre os protótipos das classes diferentes é grande (vide figura 5.1(f)). Note que ambas classes são compactas, similar à compacidade das classes representadas pelas características 1 e 2 .

As figuras 5.1(a) a 5.1(f) do conjunto das figuras 5.1 representam todas as possíveis combinações de pares de características do conjunto sintético 1.

A seguir, a descrição dos resultados obtidos com estes dados.

\subsubsection{Discussão}

Conforme esperado, a abordagem de múltiplos protótipos selecionou a par de características 3 e 4 por mais vezes, mesmo variando o tamanho da bola. As características 3 e 


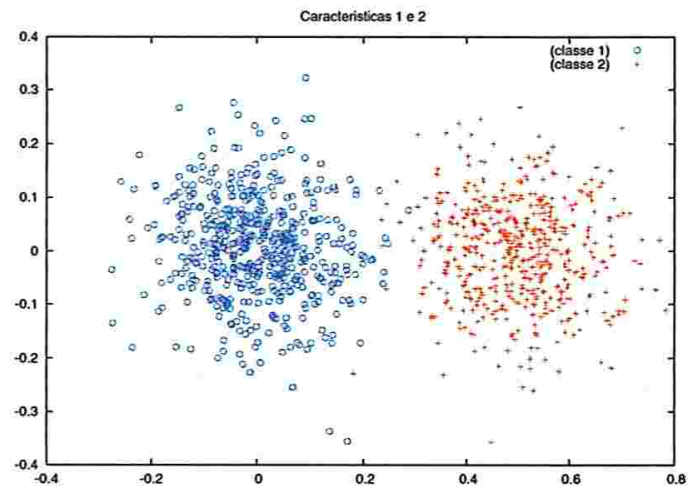

(a) Características 1 e 2

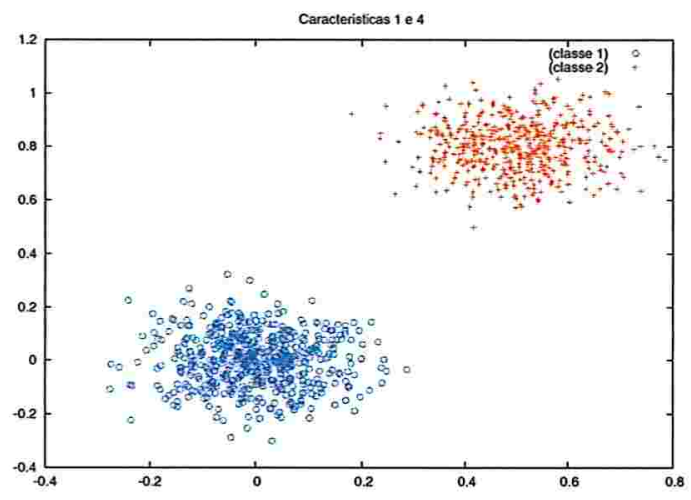

(c) Características 1 e 4

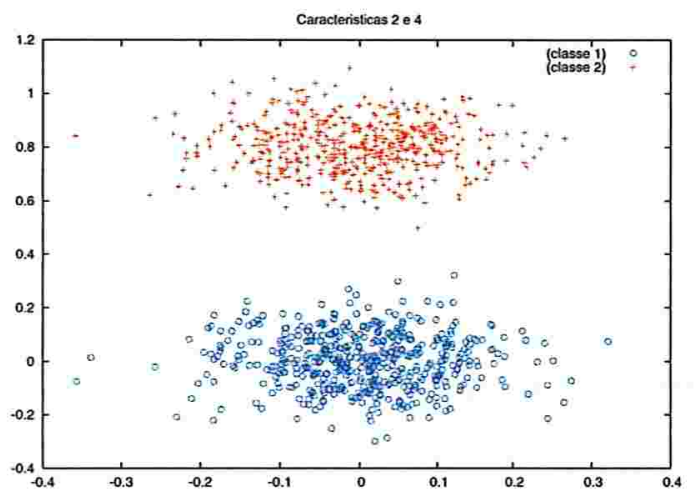

(e) Características 2 e 4

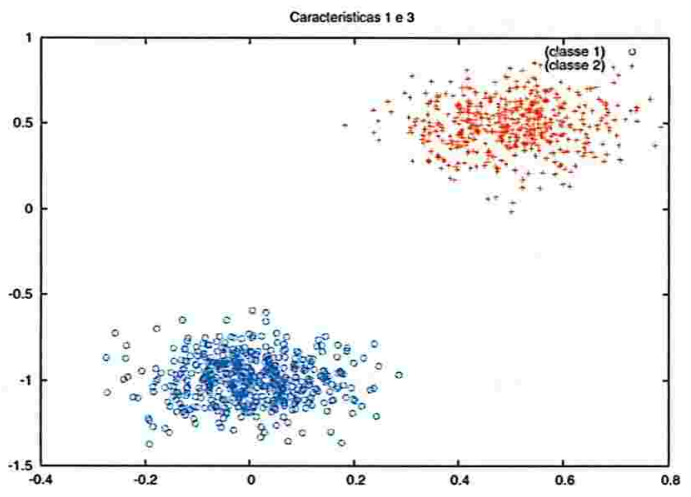

(b) Características 1 e 3

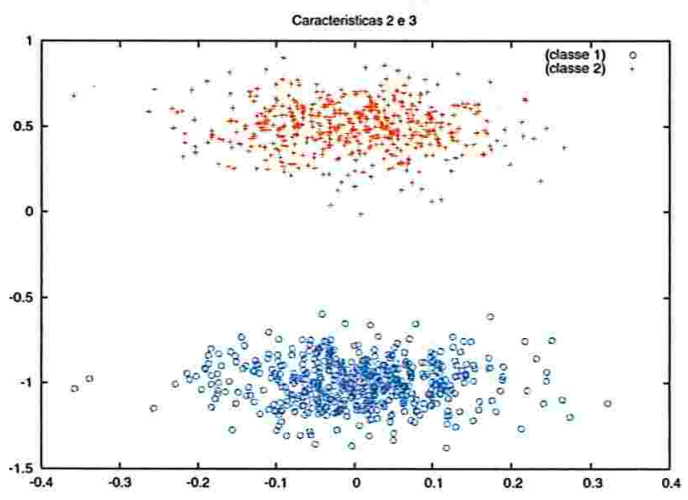

(d) Características 2 e 3

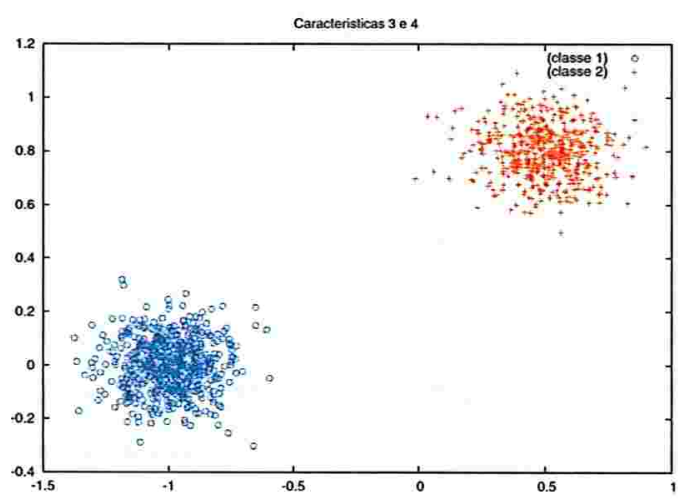

(f) Características 3 e 4

Figura 5.1: Espaços de características de dimensão 2 do conjunto sintético 1 
4 estão representadas na figura 5.1(f). A seleção deste conjunto de características ocorre porque a nova função critério (equação 4.13, página 40) leva em consideração a distância entre protótipos de classes diferentes, o que não ocorre na função critério baseada em protótipo único (equação 4.12, página 40).

A tabela 5.1 mostra os valores de tamanho da bola $(\tau)$ testados e os respectivos valores das funções critério e das características selecionadas. Note que os valores da função critério de múltiplos protótipos decresce mais rapidamente que a de protótipo único, justamente devido ao aumento do número de protótipo por classe, que aumenta os valores de pertinência dos padrões da classe, resultando em valores menores da equação 4.17.

\begin{tabular}{c|cc|cc}
\hline \hline & \multicolumn{3}{|c}{ protótipo único } & \multicolumn{2}{c}{ múltiplos protótipos } \\
\hline tamanho da bola & \multicolumn{2}{|c}{ valor da função } & características & \multicolumn{2}{c}{ valor da função características } \\
critério & $\begin{array}{c}\text { cariório } \\
\text { selecionadas }\end{array}$ \\
\hline \hline 0.1 & 27.10 & {$[2,4]$} & 11.93 & {$[3,4]$} \\
0.2 & 25.84 & {$[1,4]$} & 9.90 & {$[3,4]$} \\
0.3 & 25.59 & {$[1,4]$} & 8.61 & {$[3,4]$} \\
0.4 & 24.01 & {$[1,3]$} & 7.75 & {$[3,4]$} \\
0.5 & 23.84 & {$[1,3]$} & 7.35 & {$[3,4]$} \\
0.6 & 23.67 & {$[1,3]$} & 7.26 & {$[3,4]$} \\
0.7 & 23.25 & {$[3,4]$} & 6.56 & {$[3,4]$} \\
0.8 & 21.31 & {$[3,4]$} & 6.56 & {$[3,4]$} \\
0.9 & 15.57 & {$[3,4]$} & 4.75 & {$[3,4]$} \\
1 & 7.63 & {$[3,4]$} & 2.31 & {$[3,4]$} \\
\hline \hline
\end{tabular}

Tabela 5.1: Comparativo entre protótipo único e múltiplos protótipos em relação aos valores da função critério e das características selecionadas (conjunto sintético 1).

A tabela 5.2 mostra os valores de tamanho de bola testados e seus respectivos valores da taxa de acerto dos classificadores distância mínima ao protótipo, e KNN, com K=3. Em ambas as funções critério, a taxa de acerto para os dois classificadores foi o máximo (100\%). Isto ocorre devido às classes serem compactas e sem sobreposição, com a exceção das características 1 e 2. Este par de características, porém, não foi selecionado por nenhuma das funções critério neste experimento.

\footnotetext{
${ }^{1}$ taxa de acerto do classificador distância mínima ao protótipo para protótipo único (em \%)

${ }^{2}$ taxa de acerto do classificador $\mathrm{KNN}, \mathrm{K}=3$, para protótipo único (em \%)

${ }^{3}$ taxa de acerto do classificador distância mínima ao protótipo para múltiplos protótipos (em \%)

${ }^{4}$ taxa de acerto do classificador $\mathrm{KNN}, \mathrm{K}=3$, para múltiplos protótipos (em \%)
} 


\begin{tabular}{l|cc|cc}
\hline \hline & \multicolumn{2}{|c}{ protótipo único } & \multicolumn{2}{c}{ múltiplos protótipos } \\
\hline tamanho da bola & DMP & KNN $^{2}$ & DMP $^{3}$ & KNN $^{4}$ \\
\hline \hline 0.1 até 1.0 & 100 & 100 & 100 & 100 \\
\hline \hline
\end{tabular}

Tabela 5.2: Comparativo entre protótipo único e múltiplos protótipos em relação à taxa de acerto dos classificadores (conjunto sintético 1) (em porcentagem).

\subsubsection{Classes esparsas geradas por união de subclasses}

Este dado sintético foi gerado com a intenção de validar a nova função critério no que se refere ao número de subclasses existentes em uma classe. Este dado sintético será chamado de conjunto sintético 2.

\subsubsection{Descrição dos dados sintéticos}

O conjunto sintético 2 consiste de 1000 padrões de entrada de quatro características, e duas classes com 500 padrões por classe. Cada classe é composta de duas partes, cada uma com 250 padrões. A representação dos padrões das classes $\omega_{1}$ e $\omega_{2}$ é a mesma do experimento anterior. A descrição da distribuição das duas classes nesse espaço de características é:

Características 1 e 2. Nessas características, os padrões possuem uma mistura de distribuições Gaussianas com médias diferentes, porém a distância entre os protótipos da mesma classe e de classes diferentes pequenas (vide figura 5.2(a)). Note que ambas as classes são esparsas, porém com regiões compactas.

Características 3 e 4 . Nessas características, os padrões possuem distribuições Gaussianas com médias diferentes, porém a distância entre os protótipos da mesma classe é grande e a distância entre os centróides ${ }^{5}$ de classes diferentes é pequena (vide figura 5.2(f)). Note que ambas as classes são similares à compacidade das classes representadas pelas características 1 e 2 .

As figuras 5.2(a) a 5.2(f) do conjunto das figuras 5.2 representam todas as possíveis combinações de pares de características do conjunto sintético 2. A seguir, apresentações dos resultados obtidos com estes dados.

\footnotetext{
${ }^{5}$ baricentro dos dados representado por conjunto sintético 2
} 


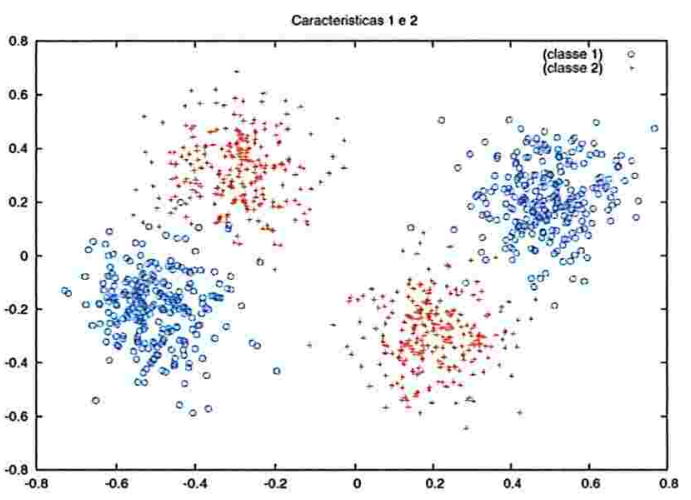

(a) Características 1 e 2

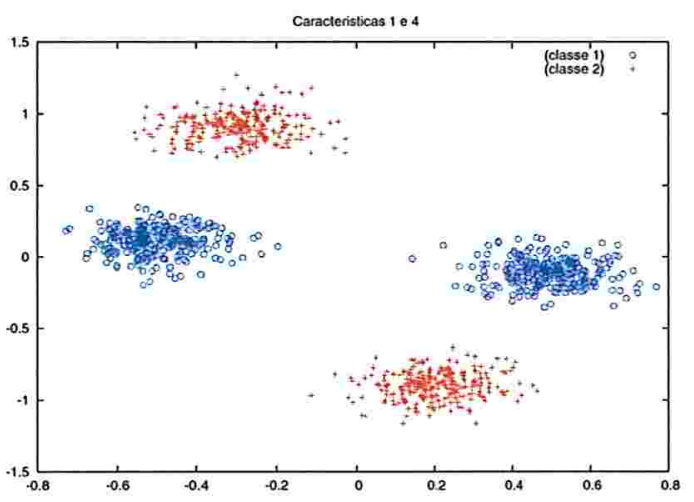

(c) Características 1 e 4

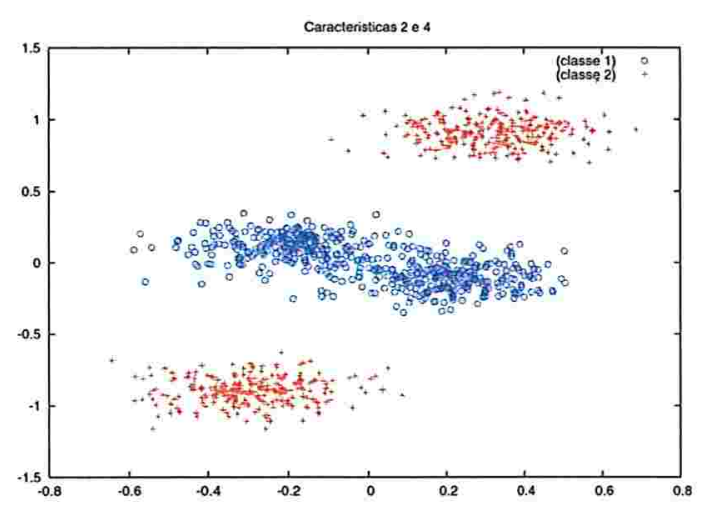

(e) Características 2 e 4

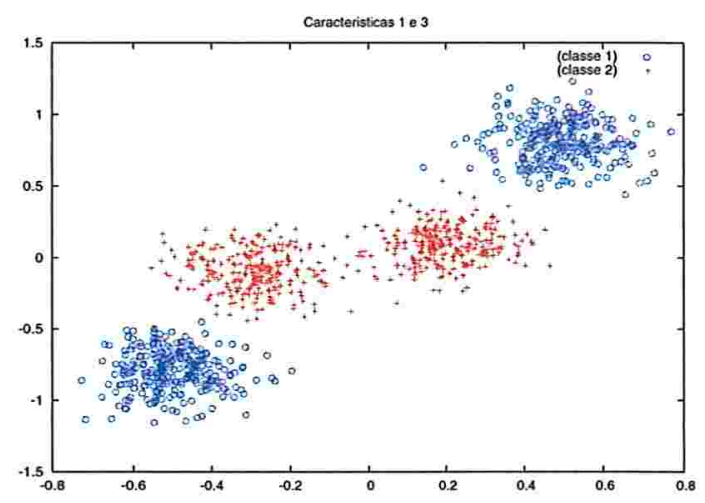

(b) Características 1 e 3

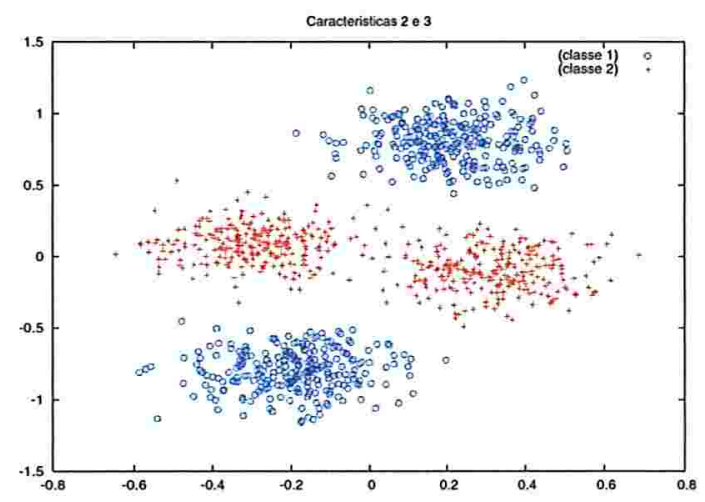

(d) Características 2 e 3

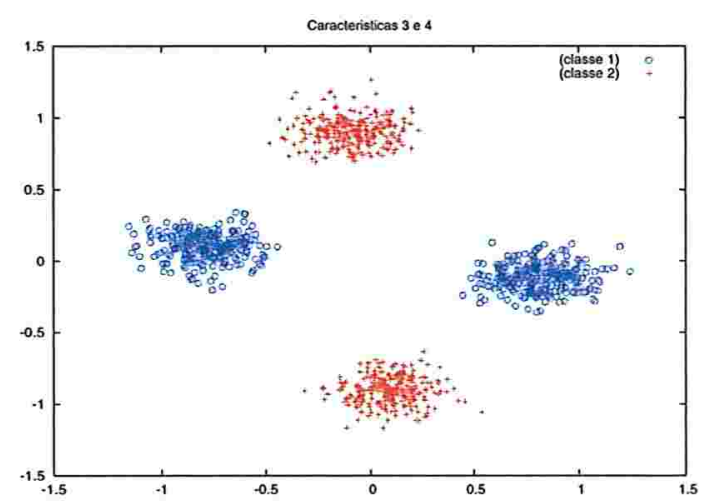

(f) Características 3 e 4

Figura 5.2: Espaços de características de dimensão 2 do conjunto sintético 2 


\subsubsection{Discussão}

Conforme esperado, a abordagem de múltiplos protótipos selecionou o par de características 3 e 4 por mais vezes, mesmo variando o tamanho da bola. As características 3e 4 estão representadas na figura 5.2(f). A seleção deste conjunto de características ocorre porque a nova função critério (equação 4.13) leva em consideração o aumento do número de protótipos, melhorando a pertinência entre os protótipos dentro da classe, e da distância entre protótipos de classes diferentes, o que resultou na escolha do conjunto de características 3 e 4 no lugar de 1 e 2 .

A tabela 5.3 mostra os valores de tamanho de bola testados e os respectivos valores da taxa de acerto e os seus desvios padrões dos classificadores distância mínima ao protótipo, e KNN, com $\mathrm{K}=3$. Em ambas as funções critério, a taxa de acerto do classificador KNN foi máxima (100\%). Isto ocorre pois as duas partes de cada classe são regiões compactas, conforme podemos notar nas figuras 5.2. No caso do classificador distância mínima ao protótipo, a diferença de valor na taxa de acerto nos intervalos de 0.7 a 0.9 e 0.1 a 0.6 para múltiplos protótipos possivelmente foi ocasionado pelo sorteio dos padrões de treinamento e de testes, ocasionando, assim, esta diferença na taxa de acerto. De forma semelhante, podemos concluir que no intervalo entre 0.5 a 0.7 do protótipo único e no intervalo de 0.1 a 0.6 de múltiplos protótipos ocorre uma variação na escolha dos padrões que compõem os conjuntos de treinamento e de testes.

\begin{tabular}{c|cc|cc}
\hline \hline & \multicolumn{2}{|c}{ protótipo único $^{2}$ múltiplos protótipos $^{-}$} & DNNN $^{9}$ \\
\hline tamanho da bola & DMP $^{7}$ & $17.98 \pm 0.29$ & 100 \\
\hline \hline 0.1 & $47.74 \pm 0.17$ & 100 & $47.98 \pm 0.29$ & 100 \\
0.2 & $47.74 \pm 0.17$ & 100 & $47.98 \pm 0.29$ & 100 \\
0.3 & $47.74 \pm 0.17$ & 100 & $47.98 \pm 0.29$ & 100 \\
0.4 & $47.74 \pm 0.17$ & 100 & $47.98 \pm 0.29$ & 100 \\
0.5 & $48.61 \pm 0.31$ & 100 & $47.98 \pm 0.29$ & 100 \\
0.6 & $48.61 \pm 0.31$ & 100 & $48.47 \pm 0.36$ & 100 \\
0.7 & $48.61 \pm 0.31$ & 100 & $48.50 \pm 0.27$ & 100 \\
0.8 & $47.74 \pm 0.17$ & 100 & $48.06 \pm 0.29$ & 100 \\
0.9 & $47.74 \pm 0.17$ & 100 & $49.23 \pm 0.44$ & 100 \\
1 & $47.74 \pm 0.17$ & 100 & \multicolumn{4}{c}{} \\
\hline \hline
\end{tabular}

Tabela 5.3: Comparativo entre protótipo único e múltiplos protótipos em relação à taxa de acerto dos classificadores (conjunto sintético 2) (em porcentagem). 
A tabela 5.4 mostra os valores de tamanho da bola testados e os respectivos valores das funções critério e das características selecionadas. Note que a velocidade em que os valores da função critério de múltiplos protótipos decresce entre os seus intervalos do tamanho da bola é maior que a velocidade em que decresce entre os mesmos intervalos da função critério de protótipo único.

\begin{tabular}{|c|c|c|c|c|}
\hline \multirow[b]{2}{*}{ tamanho da bola } & \multicolumn{2}{|c|}{ protótipo único } & \multicolumn{2}{|c|}{ múltiplos protótipos } \\
\hline & $\begin{array}{l}\text { valor da funçã } \\
\text { critério }\end{array}$ & $\begin{array}{l}\text { características } \\
\text { selecionadas }\end{array}$ & $\begin{array}{l}\text { valor da função } \\
\text { critério }\end{array}$ & $\begin{array}{l}\text { características } \\
\text { selecionadas }\end{array}$ \\
\hline 0.1 & 21.83 & {$[2,4]$} & 7.90 & {$[3,4]$} \\
\hline 0.2 & 20.68 & {$[2,4]$} & 5.56 & {$[3,4]$} \\
\hline 0.3 & 19.88 & {$[2,4]$} & 4.33 & {$[3,4]$} \\
\hline 0.4 & 17.87 & {$[2,3]$} & 3.79 & {$[3,4]$} \\
\hline 0.5 & 13.88 & {$[3,4]$} & 3.06 & {$[3,4]$} \\
\hline 0.6 & 8.12 & {$[3,4]$} & 1.77 & {$[3,4]$} \\
\hline 0.7 & 2.40 & {$[3,4]$} & 0.53 & {$[3,4]$} \\
\hline 0.8 & 1.10 & {$[2,4]$} & 0.11 & {$[3,4]$} \\
\hline 0.9 & 0.90 & {$[2,4]$} & $2.75 \mathrm{e}-05$ & {$[3,4]$} \\
\hline 1 & 0.82 & {$[2,4]$} & $8.74 \mathrm{e}-06$ & {$[1,4]$} \\
\hline
\end{tabular}

Tabela 5.4: Comparativo entre protótipo único e múltiplos protótipos em relação aos valores da função critério e das características selecionadas (conjunto sintético 2).

\subsection{Dados reais}

Nesta seção, está descrito o experimento realizado com a base de dados pública Ionosphere, obtida do repositório de dados público da $U C I^{10}$ [6]. Este repositório de dados apresenta uma quantidade considerável de bases de dados que estão agrupados da seguinte forma:

- um título que identifica a base de dados;

- uma breve descrição sobre esta base;

- a documentação existente;

\footnotetext{
${ }^{6}$ taxa de acerto do classificador distância mínima ao protótipo para protótipo único (em \%)

${ }^{7}$ taxa de acerto do classificador $\mathrm{KNN}, \mathrm{K}=3$, para protótipo único (em \%)

${ }^{8}$ taxa de acerto do classificador distância mínima ao protótipo para múltiplos protótipos (em \%)

${ }^{9}$ taxa de acerto do classificador $\mathrm{KNN}, \mathrm{K}=3$, para múltiplos protótipos (em \%)

${ }^{10} \mathrm{URL}=\mathrm{http}: / /$ www.ics.uci.edu/ ${ }^{\mathrm{m} l e a r n / M L R e p o s i t o r y . h t m l ~}$
} 
- o número de padrões, bem como o número de características que representa cada padrão;

- informação referente à existência ou não de valores indefinidos ou indeterminados para as características;

- os arquivos contendo os dados e informações, normalmente representados da seguinte forma:

- nome.names contendo as informações sobre os dados presentes nesta base de dados;

- nome.data, indicando que o conjunto de treinamento e de testes está representado em um único arquivo, ou

- nome.tra e nome.tes, indicando respectivamente, o arquivo com a base de treinamento e o arquivo com a base de testes.

\subsubsection{Base de dados Ionosphere}

\subsubsection{Informações da base de dados}

Esta base de dados apresenta as seguintes informações:

- O conjunto de treinamento e de testes está presente em um único arquivo, ionosphere.data;

- Ele apresenta dados de radar coletados por um sistema. Os radares bons são aqueles que mostram evidências de algum tipo de estrutura na ionosfera; os ruins, não;

- a existência de apenas duas classes, "bom" e "ruim", rotulados como 'G' e 'B';

- o número de padrões de entrada igual a 351 , sendo cada padrão representado por 34 características, acrescido de um atributo que identifica a classe;

- existem 225 padrões da classe 'G' e 126 padrões da classe 'B';

- Não existem valores indeterminados para as características que fazem parte dos padrões de entrada. 
Segundo um levantamento feito por David Aha(aha@ics.uci.edu) [6] nesta base de dados, o valor da taxa de acerto do classificador KNN é de 92,1\%. Esta informação está no arquivo ionosphere.names. Em nosso levantamento, conseguimos uma valor melhor para o mesmo classificador, conforme será mostrado a seguir.

\subsubsection{Descrição do experimento}

Para a realização deste experimento, a base de dados original foi modificada para que os rótulos ' $\mathrm{B}$ ' e ' $\mathrm{G}$ ' fossem substituídos pelos valores 1 e 2 , respectivamente. Isto foi necessário para o funcionamento adequado do nosso programa, que não aceita valores nãonuméricos. Além disso, os dados desta base foram normalizados, ou seja, transformados para apresentar média 0 e variância 1 .

Para a execução da seleção de características, os seguintes parâmetros foram definidos:

- os valores do tamanho da bola utilizados nas distâncias nebulosas (parâmetro $\tau$ ) variam no intervalo de 0.1 a 1.0 , em intervalos de 0.05 ;

- para cada valor da dimensão a ser selecionada $M$, todos os valores do intervalo acima foram submetidos e os conjuntos de características calculados;

- para a função critério de múltiplos protótipos, a cada valor de $\tau$, variou-se os valores do número de protótipos a ser calculados para cada classe. Para os experimentos realizados, o mesmo número de protótipos foi utilizado para todas as classes.

$\mathrm{Na}$ etapa de classificação, com o subconjunto de características selecionado pela etapa anterior, foram utilizados dois classificadores: distância mínima ao protótipo (DMP) e o $\mathrm{KNN}$, com $\mathrm{K}=3$. Para cada execução do classificador, o conjunto de padrões de entrada é dividido em dois conjuntos: o conjunto de treinamento e o de testes. Esta divisão é feita obedecendo a uma proporcionalidade de $\frac{2}{3}$, ou seja, $\frac{2}{3}$ farão parte do conjunto de treinamento e $\frac{1}{3}$ como padrões de testes. Porém, o critério de escolha de quais padrões pertencem ao conjunto de treinamento ou de testes é feito por sorteio. Visando obter uma melhor precisão nos resultados da classificação, este processo de classificação é executado 500 vezes, e calcula-se a média e o desvio padrão de todas as taxas de acerto calculadas nessas 500 execuções. Esta média e seu desvio padrão é o valor que será considerado.

Para determinar o melhor valor de $M$, foram realizados testes considerando as variações no tamanho da bola $(\tau)$ para cada valor de $M$. Estes testes tiveram como objetivo determinar o valor de $\tau$ que propiciasse os melhores resultados de seleção de características 
para um dado valor de $M$. Para a abordagem de múltiplos protótipos, além da variação do tamanho da bola, variou-se o número de protótipos associados a cada classe. Isto foi feito variando este número para cada valor de $\tau$ fixado. Os números de protótipos por classe variaram de 2 a 13 para este experimento.

\subsubsection{Discussão}

Como resultado destes experimentos, o melhor valor encontrado para $M$ foi 7 . A tabela 5.5 mostra as melhores taxas de acerto com os respectivos desvios padrões dos classificadores de distância mínima ao protótipo e $\mathrm{KNN}$, com $\mathrm{K}=3$, para as duas funções critério analisadas. Para a função critério de múltiplos protótipos existe uma subdivisão destas taxas de acerto para o número de protótipos por classe. Podemos notar em ambas as funções critério as grandes variações das taxas de acerto dos classificadores $K N N, K=3$, e da distância mínima ao protótipo.

\begin{tabular}{lc|ccc}
\hline \hline \multicolumn{3}{c}{ protótipo único } & \multicolumn{3}{c}{ múltiplos protótipos } \\
\hline DMP ${ }^{11}$ & KNN $^{12}$ & $\begin{array}{c}\text { número de pro- } \\
\text { tótipos }\end{array}$ & & DNP ${ }^{13}$ \\
\hline \hline $\mathbf{6 9 . 3 0} \pm \mathbf{1 . 4 1}$ & $\mathbf{9 3 . 4 3 \pm 0 . 3 9}$ & 2 & $72.56 \pm 1.56$ & $91.01 \pm 0.47$ \\
& 3 & $74.02 \pm 1.45$ & $90.14 \pm 0.51$ \\
& 4 & $\mathbf{7 3 . 9 1} \pm \mathbf{1 . 4 5}$ & $\mathbf{9 3 . 7 0} \pm \mathbf{0 . 4 0}$ \\
& 5 & $71.34 \pm 1.52$ & $92.83 \pm 0.43$ \\
& 6 & $70.51 \pm 1.42$ & $92.07 \pm 0.44$ \\
& 7 & $63.81 \pm 1.48$ & $92.30 \pm 0.44$ \\
& 8 & $73.69 \pm 1.38$ & $91.40 \pm 0.46$ \\
& 9 & $73.08 \pm 1.38$ & $91.40 \pm 0.48$ \\
& 10 & $74.89 \pm 1.38$ & $91.95 \pm 0.46$ \\
& 11 & $75.01 \pm 1.41$ & $92.03 \pm 0.45$ \\
& 12 & $74.40 \pm 1.40$ & $91.60 \pm 0.47$ \\
\hline \hline
\end{tabular}

Tabela 5.5: Melhores taxas de acerto do classificador $\mathrm{KNN}(\mathrm{K}=3)$ para $M=7$ para as funções critério de protótipo único e de múltiplos protótipos.

Com o objetivo de obter o melhor valor de $\mathrm{K}$ do classificador $\mathrm{KNN}$, foram realizados testes variando o seu valor entre 1 e 5 . Estes testes de classificação foram feitos somente

\footnotetext{
${ }^{11}$ taxa de acerto do classificador distância mínima ao protótipo para protótipo único (em \%)

${ }^{12}$ taxa de acerto do classificador $\mathrm{KNN}, \mathrm{K}=3$, para protótipo único (em \%)

${ }^{13}$ taxa de acerto do classificador distância mínima ao protótipo para múltiplos protótipos (em \%)

${ }^{14}$ taxa de acerto do classificador $\mathrm{KNN}, \mathrm{K}=3$, para múltiplos protótipos (em \%)
} 


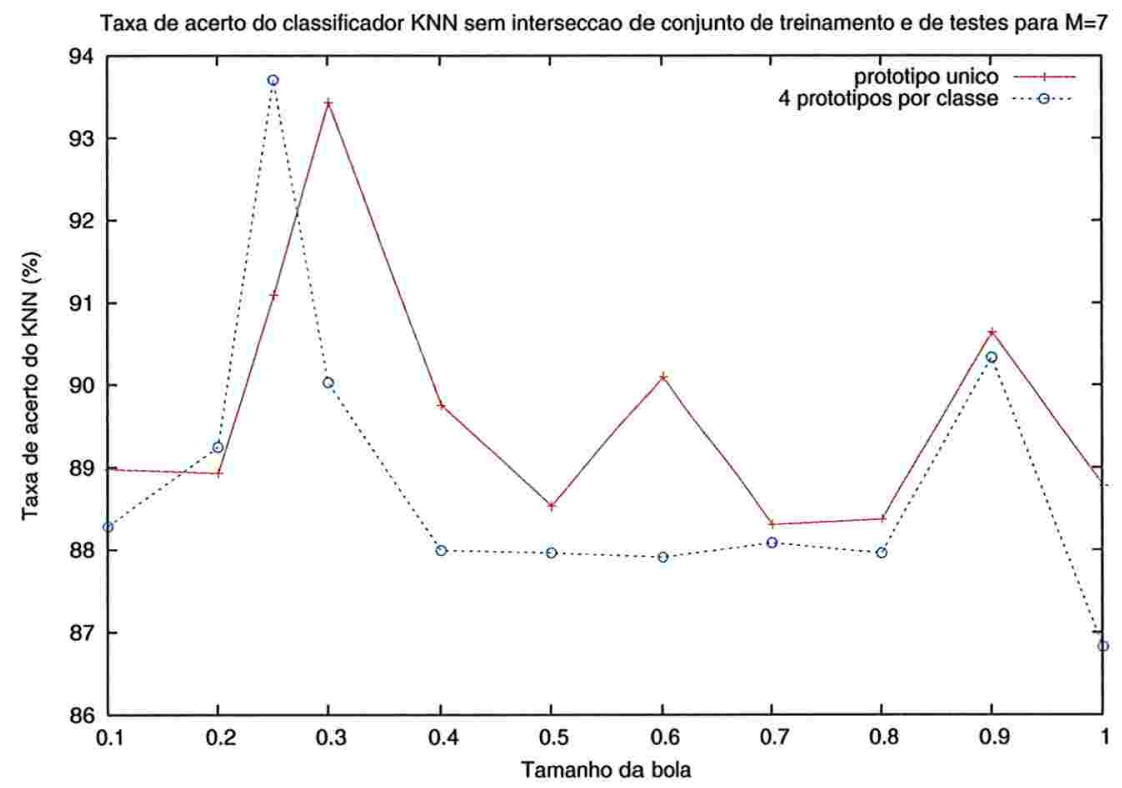

Figura 5.3: Resultados obtidos pelas melhores taxas de acerto do classificador $\mathrm{KNN}(\mathrm{K}=3)$ no intervalo de tamanho da bola selecionado (para $M=7$ ).

com a dimensão $M=7$, onde se conseguiu a melhor taxa de acerto do $\mathrm{KNN}, \mathrm{K}=3$, para ambas as funções critério. Um fato interessante ocorrido é que, apesar da variação do $\mathrm{K}$ em KNN, os valores nas taxas de acerto mantiveram iguais por todos os intervalos de tamanho de bola. Isto provavelmente ocorreu porque o classificador KNN implementado atribui um peso maior ao padrão mais próximo. Para simples fim ilustrativo, a figura 5.3 mostra a taxa de acerto para o classificador $\mathrm{KNN}, \mathrm{K}=3$, para os intervalos de tamanho da bola $(\tau)$. Podemos observar que a taxa de acerto deste classificador é maior para a função critério de múltiplos protótipos (4 protótipos) somente no intervalo de tamanho de bola (parâmetro $\tau$ ) entre 0.2 e 0.3 . No restante do intervalo de $\tau$, a função critério de protótipo único apresenta melhores valores de taxa de acerto para este classificador.

Também para simples fim ilustrativo, os valores obtidos pelas melhores taxas de acerto do classificador KNN variando o valor $M$ estão ilustrados na figura 5.4. Note que a partir do valor de $M=7$, a nova função critério obteve uma taxa de acerto maior que a função critério de protótipo único. Isto confirma que o aumento do número de protótipos por classe ajuda melhorar o subconjunto das características selecionadas. Note também que, para $M=34$, as duas funções critério convergem, pois a dimensão total da base de dados Ionosphere é 34 . 


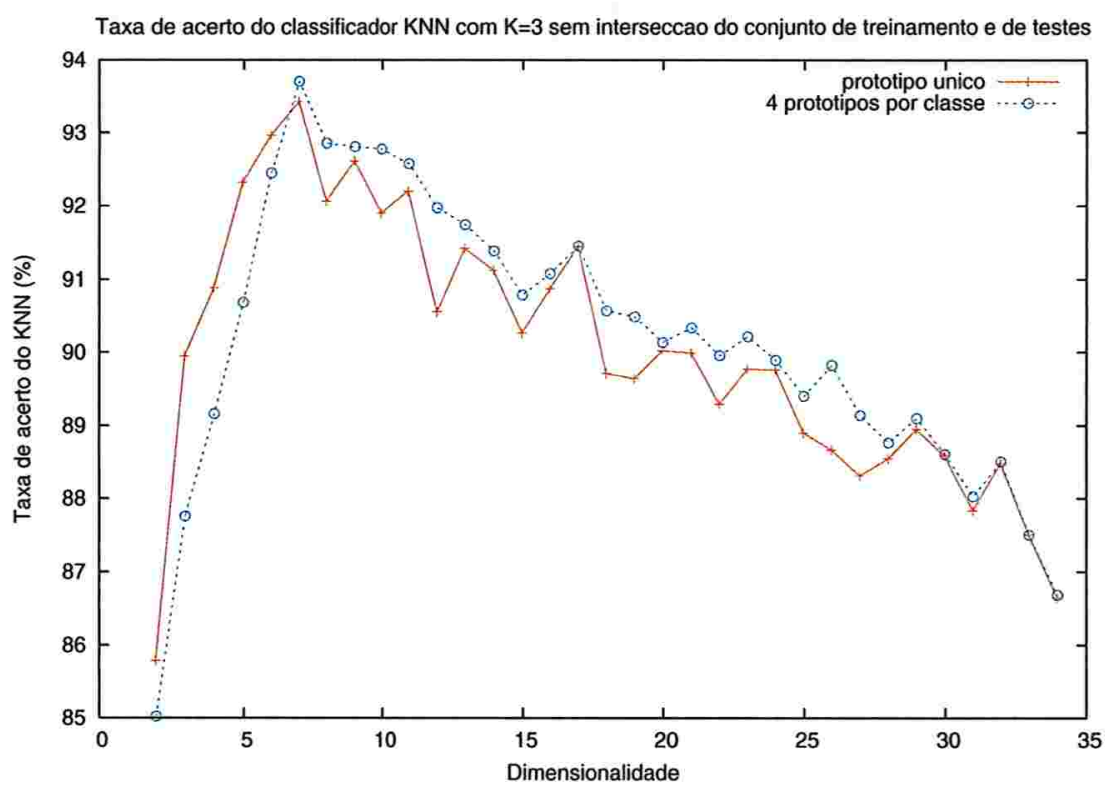

Figura 5.4: Resultados obtidos pelas melhores taxas de acerto do classificador $\mathrm{KNN}(\mathrm{K}=3)$ no conjunto de características selecionado.

Analisando o tamanho da bola $\tau$, as melhores taxas de acerto para as dimensões analisadas foram entre os intervalos 0.2 a 0.4 e 0.9 a 1.0 para função critério de protótipo único e os intervalos 0.1 a 0.3 e 0.6 a 0.9 para a função critério de múltiplos protótipos. Os valores de $k$ do algoritmo fuzzy $k$-means variaram de 2 a 13 protótipos por classe para esta base. O intervalo entre 2 e 6 protótipos por classe foi aquele que mais ocorreu em todos as dimensões analisadas, tendo sido o intervalo que apresentou as melhores taxas de acerto do classificador KNN.

Em relação ao tempo de execução, a nova função critério é mais lenta que a de protótipo único. Isto era esperado devido à necessidade de calcular os protótipos através do algoritmo fuzzy $k$-means. Além de calcular os protótipos, a nova função critério precisa determinar o valor de pertinência para todos os padrões de todas as classes, o que não era necessário na função critério anterior. Apesar disso, a diferença de execução não foi significativa para este experimento. No melhor caso, a nova função critério levou 12 segundos, e no pior caso, 23 minutos. A função critério com protótipo único foi de 2 segundos no melhor caso e de 11 minutos no pior caso para este experimento. 


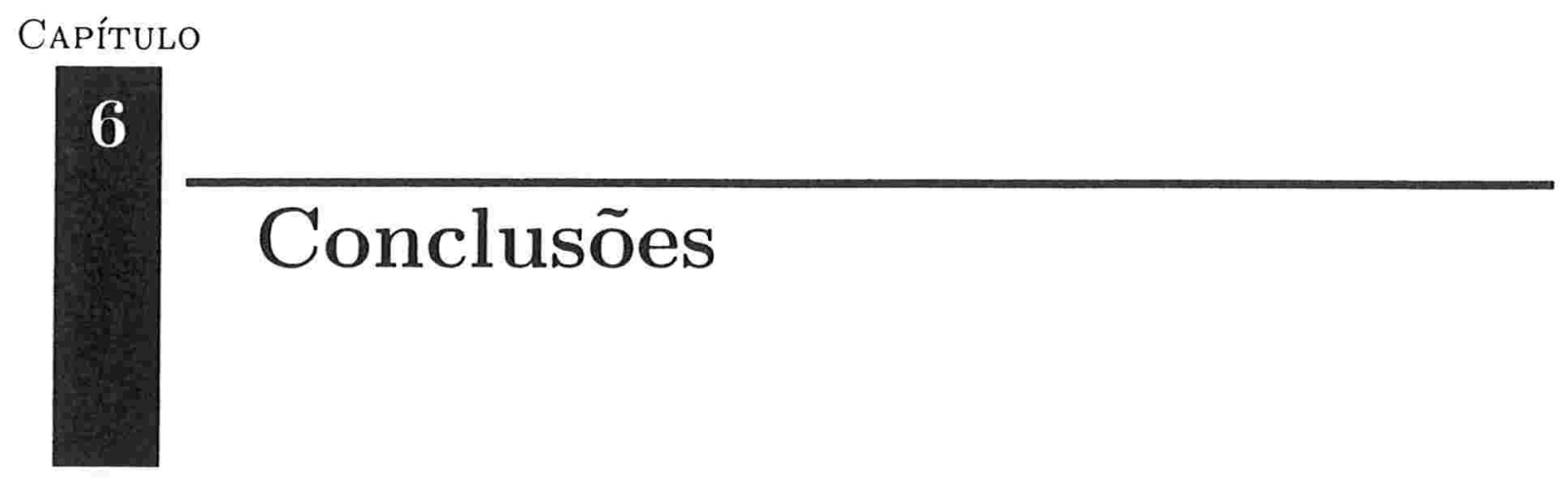

Neste trabalho, foram descritos os experimentos e os resultados iniciais obtidos utilizandose a seleção de características com função critério baseada em distância nebulosa com múltiplos protótipos, tendo como referência o trabalho realizado por Teófilo E. Campos em [10]. A implementação desta nova função critério foi a principal contribuição deste mestrado. Os resultados com dados sintéticos indicam que esta nova função critério pode-se mostrar melhor em alguns casos, principalmente em classes esparsas com regiões compactas, assim como em classes com maior distância entre protótipos de classes distintas.

Para validar o algoritmo CALCULA_MELHOR_K(.) proposto na subseção 4.2.2.4, foram implementados os algoritmos envolvidos para validação de eficiência de agrupamento no programa de seleção de características. Para a validação deste algoritmo, o programa de seleção de características foi executado duas vezes: a primeira, com o número de protótipos igual a 1 ; e a segunda, com o valor do número de protótipos $\left(k_{\max }\right)$ obtido do maior valor de taxa de acerto do classificador KNN em todos os tamanhos de bola (parâmetro $\tau$ ) analisados em uma determinada dimensão $M$. Nas execuções com dados sintéticos, este procedimento de execução em dois passos mostrou-se eficaz, obtendo-se o valor máximo na taxa de acerto do classificador. Para a base de dados Ionosphere, este procedimento somente mostrou sua eficácia para a dimensão $M$ cuja taxa de acerto do classificador KNN era máxima, que em nosso experimento era $M=7$.

Um problema que ficou em aberto neste trabalho foi o processo de obtenção da me- 
lhor quantidade de protótipos por classe $(k)$ do fuzzy $k$-means em dados reais. Embora o procedimento de execução em dois passos tenha apresentado resultado razoável, este procedimento não se mostrou eficaz para algumas dimensões $M>7$.

No desenvolvimento desta dissertação, alguns estudos e procedimentos foram feitos que ajudaram na melhoria da seleção de características proposta inicialmente em [10]. Porém, restaram algumas tarefas a serem desenvolvidas futuramente. Dentre elas, podemos citar:

- atribuição de número de protótipos por classe diferentes para cada classe da base de dados analisada. Nos testes com a base de dados Ionosphere, foi constatado que os números de protótipos por classe obtidos através do algoritmo CALCULA_MELHOR_K(.) eram diferentes;

- o problema para estimar corretamente o valor do expoente nebuloso $(z)$ utilizado no algoritmo fuzzy $k$-means, tendo como referência o trabalho feito pelos autores [24];

- Estudar os métodos de validação de eficiência da quantidade de protótipos por classe no fuzzy k-means, tendo como referência o trabalho feito pelos autores [20] (a relação dos índice FPI (fuzziness performance index) e MPE (Modified Partition Entropy); 


\section{Referências Bibliográficas}

[1] K. Alsabti, S. Ranka, and V. Singh. An efficient k-means clustering algorithm. Technical report, Syracuse University and University of Florida and Information Technology Lab (ITL) of Hitachi America, Ltd., http://www.cs.ndsu.nodak.edu/ serazi/ presentations/efficientKmeans.pdf, 2001.

[2] J. Ashimine, T. E. Campos, R. M. César Jr, and I. Bloch. Person recognition through eigeneyes selection using a new criterion function. In Abstract Proceedings of the $15^{\text {th }}$ Brazilian Symposium on Computer Graphics and Image Processing, October 2002.

[3] E. Backer. Computer-Assisted Reasoning in Cluster Analysis. Prentice Hall, 1995.

[4] J. Bernardo and A. Smith. Bayesian Theory. John Wiley and Sons, 1994.

[5] J. C. Bezdek. Pattern Recognition with Fuzzy Objective Function Algorithms. Plenum Press, New York, USA, 1981.

[6] C.L. Blake and C.J. Merz. UCI repository of machine learning databases, 1998. For information contact ml-repository@ics.uci.edu.

[7] I. Bloch. On fuzzy distances and their use in image processing under imprecision. Pattern Recognition, 11(32):1873-1895, 1999. 
[8] B. Boydell and A.B. McBratney. Identifying potential within-field management zones from cotton yield estimates. 114:331-341, July 1999. Artigo disponivel em http://springerlink.metapress.com/media/H8KMTJWVTRX7LTMVRMEG/ Contributi\%ons/G/5/3/W/G53W5028G03788W2.pdf.

[9] O. Boz. Feature subset selection by using sorted feature relevance, 2004. Artigo disponível em http://citeseer.ist.psu.edu/boz02feature.html.

[10] T. E. Campos. Tecnicas de seleção de características com aplicações em reconhecimento de faces. Master's thesis, Instituto de Matemática e Estatística da Universidade de São Paulo, R. do Matão, 1010 - Dep. da Ciência da Computação, May 2001. Dissertação de Mestrado sob orientação do Prof. Dr. Roberto M. Cesar Jr.

[11] T. E. Campos, I. Bloch, and R. M. César-Jr. Feature selection based on fuzzy distances between clusters: First results on simulated data. In Lecture Notes in Computer Science, ICAPR'2001 - International Conference on Advances in Pattern Recognition, Rio de Janeiro, Brazil, March 2001. Springer-Verlag Press.

[12] T. E. Campos, R. S. Feris, and R. M. César Jr. Improved face x non-face discrimination using fourier descriptors through feature selection. In Wizard V. Oz and Mihalis Yannakakis, editors, $13^{\text {th }}$ Brazilian Symposium on Computer Graphics and Image Processing, Gramado, Brazil, October 2000. IEEE Computer Society Press.

[13] K. R. Castleman. Digital Image Processing. Printice-Hall, Englewood Cliffs, N.J., USA, 1996.

[14] T. H. Cormen, C. E. Leiserson, and R. L. Rivest. Introduction to Algorithms. The MIT Press, McGraw-Hill Company, 1990.

[15] A. J. O. Cruz. Notas de aulas - "clustering algorithms: Fuzzy c-means". Technical report, Universidade Federal do Rio de Janeiro, Instituto de Matemática, Departamento de Ciência da Computação, July 2002. Artigo disponível em http: //equipe.nce.ufrj.br/adriano/fuzzy/transparencias/clusteralgorithm\%s.pdf.

[16] L. Devroye, L. Gyorfi, and G. Lugosi. A Probabilistic Theory of Pattern Recognition. Springer-Verlag, Berlin, 1996.

[17] D. Dubois, H. Prade, and R. R. Yager. Fuzzy Information Engineering. Willey Computer Publishing, USA, 1997. 
[18] R. O. Duda and P. E. Hart. Pattern Classification and Scene Analysis. WileyInterscience, USA, first edition, 1973.

[19] Australian Centre for Precision Agriculture. Fuzzy k means. Technical report, Australian Centre for Precision Agriculture - University of Sydney, http://www.usyd.edu. au/su/agric/acpa/fkme/FuzME_Theory.pdf, 2003.

[20] C. W. Fraisse, N. R. Kitchen, and K. A. Sudduth. Delineation and analysis of sitespecific management zones. Technical report, USDA - Agricultural Reasearch Service - University of Missouri, http://www.fse.missouri.edu/mpac/pubs/erim2k_jjf.pdf, 2003.

[21] A. K. Jain and B. Chandrasekaran. Dimensionality and sample size considerations in pattern recognition practice. Handbook of Statistics, 2:835-855, 1982.

[22] A. K. Jain, R. P. W. Duin, and J. Mao. Statistical pattern recognition: A review. IEEE Trans. on Pattern Analysis and Machine Intelligence, 22(1):4-37, 2000.

[23] A. K. Jain and D. Zongker. Feature selection: Evaluation, application, and small sample performance. IEEE Trans. on Pattern Analysis and Machine Intelligence, 19(2):152-158, February 1997.

[24] F. Klawonn and F. Höppner. A modified fuzzy $\mathrm{k}$ means for predictive classification. M.R. Berthold, H.-J. Lenz, E. Bradley, R. Kruse, C. Borgelt(eds.) Advances in Intelligent Data Analysis, pages 254-264, 2003.

[25] R. Lowen and W. Peeters. On various classes of semi-pseudometrics used in pattern recognition. In Seventh IFSA World Congress, volume I, pages 232-237, Prague, June 1997.

[26] J. Mao, K. Mohiuddin, and A. K. Jain. Parsimonious network desgin and feature selection through node pruning. In Proceedings of $12^{\text {th }}$ ICPR, pages 622-624, Jerusalem, 1994.

[27] B. Minasny and A. McBratney. Fuzme: Fuzzy k-means with extragrades program. Technical report, University of Sydney, Australia, http://www.usyd.edu.au/su/agric/ acpa/fkme/FkME.html, July 2002.

[28] P. M. Narendra and K. Fukunaga. A branch and bound algorithm for feature subset selection. IEEE Transactions on Computers, C-26(9):917-922, September 1997. 
[29] P. Pudil, P. Novovicová, and J. Kittler. Floating search methods in feature selection. Pattern Recognition Letters, 15:1119-1125, 1994.

[30] S. J. Raydys and A. K. Jain. Small sample size effects in statistical pattern recognition: Recommendations for practitioners. IEEE Trans. Pattern Analysis and Machine Intelligence, 13(3):252-264, 1991.

[31] S. J. Raydys and V. Pikelis. On dimensionality, sample size, classification error, and complexity of classification algorithms in pattern recognition. IEEE Trans. Pattern Analysis and Machine Intelligence, 2:243-251, 1980.

[32] M. Roubens. Fuzzy clustering algorithms and their cluster validity. European Journal of Operational Research, (10):294-301, 1982.

[33] R.S. Sexton, R.E. Dorsey, and J.D. Jonson. Optimization of neural networks: A comparative analysis of the genetic algorithm and simulated annealing. European Journal of Operational Research, 114:589-601, 1999. Artigo disponível em http:// organ.postech.ac.kr/research/methodology/method.htm.

[34] W. Siedlecki and J. Sklansky. On automatic feature selection. International Journal of Pattern Recognition and Artificial Intelligence, 2(2):197-220, 1988.

[35] W. Siedlecki and J. Sklansky. A note on genetic algorithms for large-scale feature selection. Pattern Recognition Letters, 10:335-347, November 1989.

[36] P. Somol, P. Pudil, J. Novovicová, and P. Paclík. Adaptive floating search methods in feature selection. Pattern Recognition Letters, 20:1157-1163, 1999.

[37] S. Theodoridis and K. Koutroumbas. Pattern Recognition. Academic Press, USA, first edition, 1999.

[38] S. Watanabe. Pattern Recognition: Human and Mechanical. Wiley, New York, 1985.

[39] L. Zadeh. Fuzzy sets. Information and Control, 8:338-353, 1965. 